\title{
El desarrollo de la herpetología en Colombia
}

\author{
Federico Medem
}

Rev. Acad. Colomb. Cienc. Ex. Fis. Nat. 1968, 13 (50): 149-200.

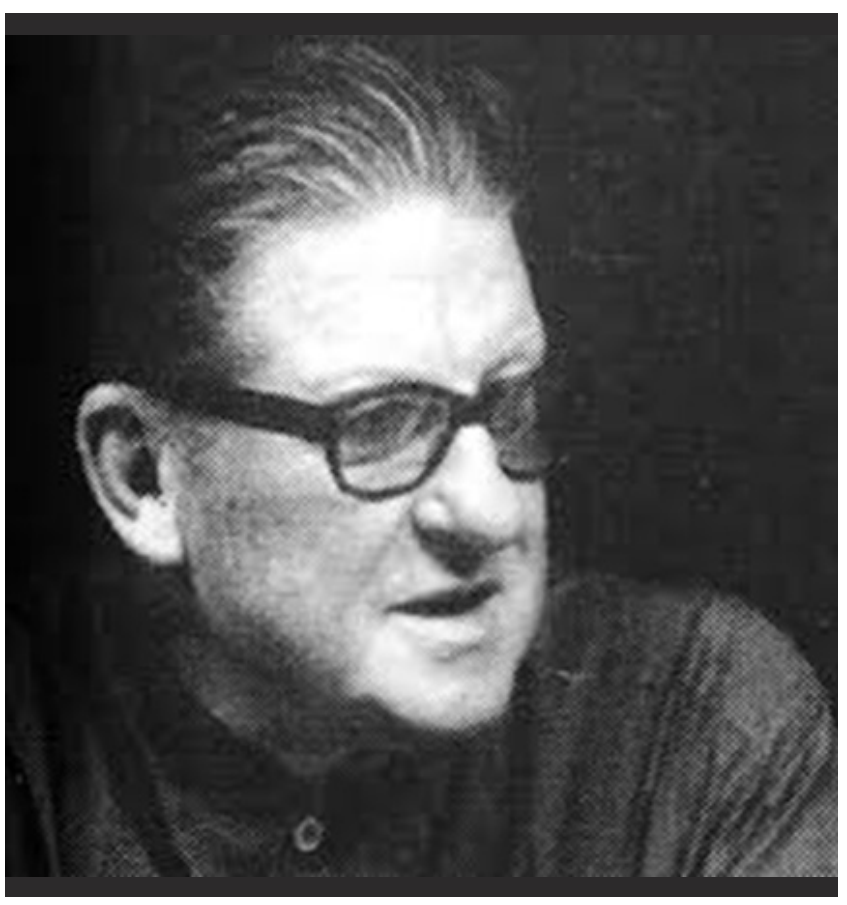

\section{Federico Medem (1912-1984)}

Fue un herpetólogo colombiano de origen letón, quien dedicó una buena parte de su trabajo en Colombia al estudio de los Crocodylia (caimanes y cocodrilos) y las tortugas. Estudió zoología y antropología física en los años 40 en la Universidad Humboldt de Berlín y llegó a ser instructor en el Instituto de Zoología de la Universidad de Berna, Suiza. A partir de 1950, año de su llegada a Colombia, y 1960, trabajó en la Universidad de los Andes, el Instituto Roberto Franco en Villavicencio y la Universidad Nacional de Colombia. Dentro de sus más destacadas publicaciones están los dos tomos sobre los Crocodylia de Colombia y de Suramérica, editados por Colciencias en 1981. Aunque la taxonomía propuesta por Medem en estos documentos ha sufrido algunos cambios, en general, ella se mantiene hoy en día. El doctor Medem también se caracterizó por mantener una actitud conservacionista, principalmente con respecto a los grupos de su mayor interés.
En este artículo, el doctor Federico Medem hace una síntesis de los grandes grupos supragénéricos (Superórden, Orden y Familia) de los géneros y de las especies que hasta ese entonces, los conformaban. Hay que reconocer que éste fue un gran esfuerzo si se tiene en cuenta que se incluyeron todas las especies de reptiles. Es interesante el hecho de haber realizado un repaso paleogeográfico de las cordilleras colombianas con el fin de comprender mejor la complejidad y distribución de nuestra herpetofauna. Destacable también es su revisión histórica con respecto a los momentos en que se registran, por primera vez, datos sobre la herpetofauna colombiana comenzando con exploradores del siglo XVIII, como fueron los misioneros que estuvieron en el Orinoco. Se nombra aquí al padre Joseph Gumilla quien, en 1741, narró sus observaciones de reptiles de la zona. Luego se pasa a mencionar a los autores colombianos y extranjeros que publicaron obras, ya sean libros o artículos, en los siglos XIX y XX sobre la herpetofauna de Colombia. Estos son algunos de los nombres a resaltar: Alexander von Humboldt (1799-1801), Carl Lehman (1892, 1893, 1898), Emmett Reid Dunn (1943-1944), el Hermano Nicéforo María (1920-1958) entre los extranjeros; y los colombianos Evaristo García (1892, 1896), Posada Arango (1889, 1909), y los hermanos Osorno Mesa (1938, 1946), entre otros. La última parte, la más larga, está dedicada a presentar una lista de los grupos de anfibios y reptiles. Se presenta, igualmente, un diagnóstico para las clases (Amphibia y Reptilia) y, dentro de éstas, para los órdenes, por ejemplo, Apoda en anfibios y Sauria en reptiles, e igualmente, para algunas familias. Para los reptiles, se hace la lista de todas las especies, pero para los anfibios solo se presenta la de los géneros, lo que muestra su clara preferencia y, tal vez, su conocimiento asimétrico de los grupos.

Julio Mario Hoyos H, Ph.D.

Profesor Titular

Pontificia Universidad Javeriana

Sandra Baena, Ph.D.

Miembro Correspondiente 


\title{
EL DESARROLLO DE LA HERPETOLOGIA EN COLOMBIA
}

\author{
POI FEDERICO MEDEM ${ }^{1}$
}

\section{INTRODUCCION}

Colombia ocupa una posición clave y central en relación con los estudios fundamentales sobre los problemas taxonómicos, ecológicos y de distribución geográfica de la Herpeto-Fauna (anfibios y reptiles) suramericana.

La situación geográfica la convierte en un "puente" entre la América Central y Suramérica ecuatorial, es decir, el área denominada pan-amazónica, la cual incluye las hoyas del Amazonas y Orinoco.

Debido parcialmente a su gran extensión (1.138.338 $\mathrm{Kms}^{2}$ ) y al relieve de su suelo, Colombia tiene, además, un gran número de zonas ambientales (Habitat o biotopo), que van desde las áridas hasta la selva tropical pluvial, y de las sabanas tropicales y subtropicales a las cimas más altas de las mantañas.

La fauna colombiana es muy rica y compleja en concordancia con la variada geografía del país. Además de las formas endémicas, o sea aquellas que se encuentran solamente en el país o en ciertas regiones limítrofes, según su habitat preferido, existen otros elementos faunísticos que migraron en épocas geológicas pasadas desde el norte 0 el sur del Continente y se establecieron en el actual territorio de Colombia, $y$, en consecuencia, se consideran pertenecientes a la fauna autóctona.

La distribución de los animales no está restringida por fronteras políticas, sino depende en gran parte de la situación geográfica y las condiciones climáticas tanto de épocas geológicas pasadas como recientes.

Para la mejor comprensión de la complejidad de la herpeto-fauna colombiana, es necesario hacer primero un repaso sucinto paleogeográfico del Terciario y Cuaternario.

El Terciario abarca desde el Paleoceno hasta el Plioceno, con una duración aproximada de 74 millones de años; el Cuaternario incluye el período Pleistoceno o Glacial y el Holoceno o Postglacial o Reciente; duró más de un millón de años.

\section{TABLA 1}

Durante el Terciario tuvieron lugar dos fenómenos geológicos que influyeron decisivamente las migraciones y, consecuentemente, en la distribución geográfica de los animales del Continente americano:

1. Desde el Cretáceo (Mesozoico) inferior, pero con pronunciamiento desde el Paleoceno, empezó una temporada de cambios tectónicos ocasionada en gran parte por el volcanismo.

Los plegamientos ocasionaron la elevación de varias regiones extensas y la formación de las tres Cordilleras principales, la Central, Occidental y Oriental. Esta última constituye barrera infranqueable para las migraciones de anfibios y reptiles en cualquier dirección. Las elevaciones cordilleranas fueron interrumpidas repetidas veces por zonas de hundimiento, que cubrió el mar durante el Terciario. La elevación final, es decir, la formación de las montañas altas y permanentes de la Cordillera Oriental, ocurrió geológicamente muy tarde entre el Plioceno y el Pleistoceno Superior, aproximadamente de tres a un millón de años.

2. Como resultado de los mencionados plegamientos se presentaron a principios del Terciario Sinclinorios o zonas de hundimiento, entre ellos el Sinclinorio de Bolívar, el cual se extendió desde el golfo de Guayaquil (Ecuador) hasta el golfo de Urabá y se bifurcó hacia el norte en la rama de Turía (Panamá) y hacia el oriente en la de Cartagena. Esta zona permaneció invadida por el mar desde el Eoceno Medio hasta el Mioceno Superior, es decir, unos 27 millones de años aproximadamente, aunque no en su totalidad, pues las regiones de considerable elevación permanecieron secas.

Actualmente, los valles de los ríos San Juan y Atrato constituyen los últimos remanentes del Sinclinorio de Bolívar (Bürgl, 1961) ; (Hershkovitz, 1966). Además, el mar formó una bahía extensa entre el actual litoral del Pacífico y el Valle del Cauca durante el Oligoceno Superior; sin embargo, una zona elevada y relativamente angosta se extendió aproximadamente a lo largo del presente litoral desde el Mioceno hasta el Oligoceno; los remanentes de esta franja elevada son la Isla Gorgona-Gorgonilla, Cabo Corrientes y Cabo Marzo, que originalmente pertenecieron a la Sierra del Baudó.

Desde el Oligoceno hasta el Plioceno, es decir, durante unos 25 millones de años, se mantuvo con mayor pronunciamiento una cadena de islas entre el norte de la América Central y Suramérica. Sin embargo, no existió comunicación terrestre continua y permanente ninguna, hasta la elevación definitiva del Istmo de Panamá, lo cual se llevó a

1 Profesor Titular de la Universidad Nacional de Colombia, en Bogotá, D. E.; Jefe de la Sección de Biología Tropical (Instituto "Roberto Franco"), del Instituto de Ciencias Naturales en Villavicencio (Meta). 


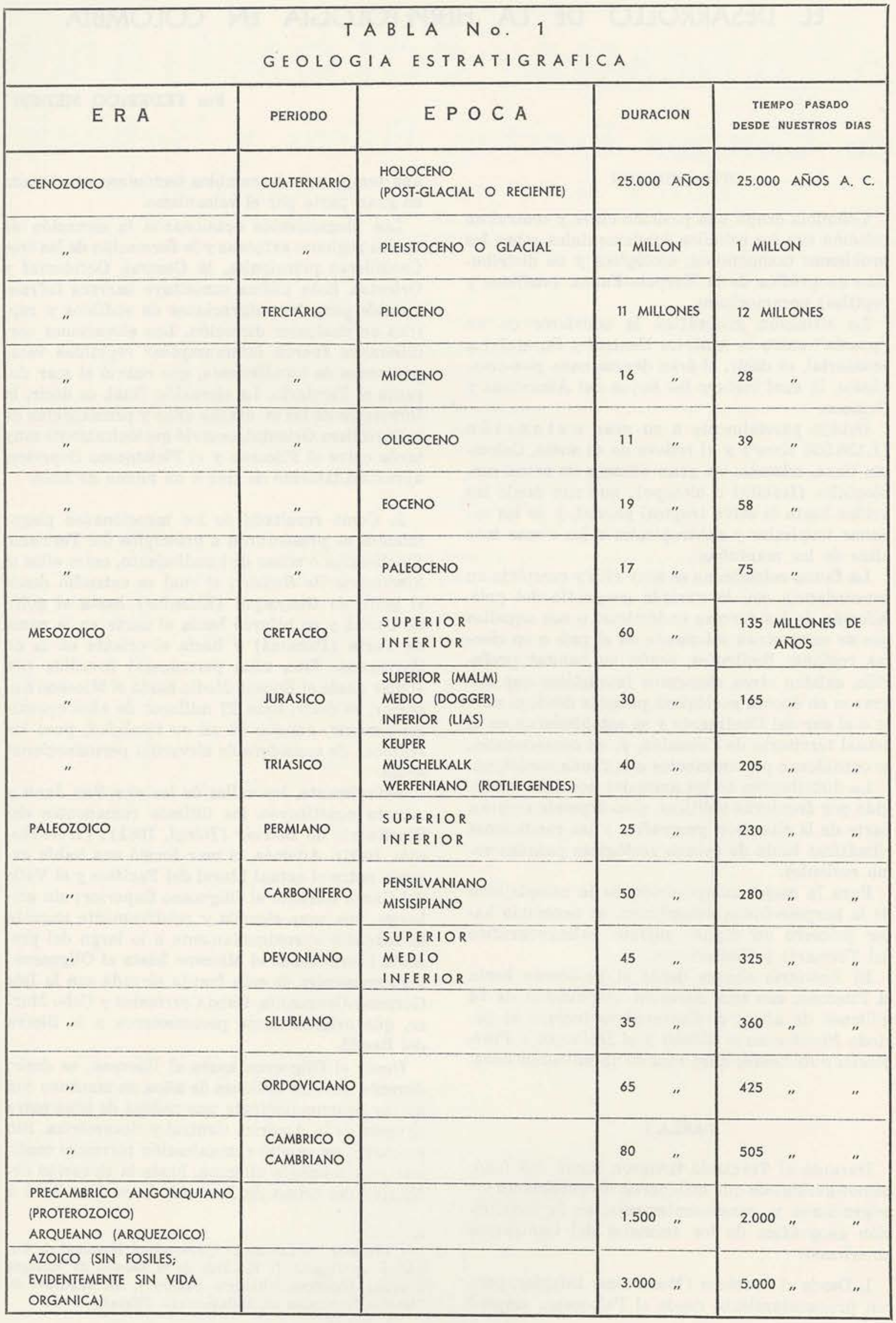


efecto durante el Plioceno Superior y el Pleistoceno Inferior, es decir, hace un millón y medio de años aproximadamente. La duración exacta es todavía desconocida (Nygren, 1950).

Ello significa que en total existieron unas cinco conexiones intercontinentales en el lapso comprendido entre el Cretáceo y el Mioceno Superior, alternándose con períodos de hundimientos.

La última separación entre el norte y el sur del Continente americano la produjo el Sinclinorio de Bolívar, no obstante que esta separación aparentemente nunca ha sido total, sino más bien parcial $\mathrm{y}$, consecuentemente, ha existido siempre la posibilidad de migraciones de anfibios y reptiles en una y otra dirección.

Se puede afirmar que, en general, el intercambio de elementos faunísticos entre el norte y el sur, y viceversa, se acentuó desde el Pleistoceno, pero, existieron también ciertamente otros intercambios sucesivos a partir del Cretáceo Superior; no obstante son aún escasos los hallazgos de fósiles.

En relación con las migraciones hay que apuntar que tanto los ejemplares adultos y juveniles como también los huevos de reptiles, presentan gran tolerancia al agua salobre y aun salada en razón del escamado y de las cáscaras resistentes, respectivamente.

Los anfibios, en cambio, muestran tal tolerancia en grado considerablemente inferior, ya que todos ellos carecen de escamas y, sobre todo, porque la mayoría de los estados larvales (renacuajos) y huevos requieren para el desarrollo del medio ambiente de agua dulce.

Por esta razón, tanto las migraciones activas, por estrechos o venciendo corrientes marítimas, como las pasivas, es decir, los ejemplares adultos, juveniles y también los huevos "viajan" en islas flotantes formadas por aglomeraciones de vegetación lacustre, árboles y palizadas arrastradas por las corrientes, son mucho más comunes entre los reptiles que entre los anfibios. Esto ha sido confirmado por observaciones personales en las Islas del Rosario, Isla Fuerte y GorgonaGorgonilla.

No obstante considerarse tradicionalmente el Holoceno como el Post-Glacial, se efectuaron repetidas glaciaciones regionalmente limitadas, especialmente en las Sierras Nevadas de Santa Marta y Cocuy.

\section{TABLA 2}

De acuerdo con los resultados de los estudios palinológicos, es decir, el análisis de las fluctuaciones del polen de los árboles, arbustos y plantas herbáceas de la flora holocena, por van der Hammen $(1961,1962)$, es evidente que estas glaciaciones causaron repetidas fluctuaciones alternantes de húmedo-frío a húmedo-templado y de seco frío, seco-templado y seco-caliente. Demuestran, además, que en las cordilleras ecuatoriales los fenómenos glaciales e interglaciales tuvieron también las características de temporadas pluviales e interpluviales, aún entre los años 11.000 A. C. y 1.900 D. C. (Reichel-Dolmatoff, 1965, figura 4).

De otra parte sabemos que las condiciones climáticas han cambiado notablemente aun en tiempos históricos; así, por ejemplo, los cronistas españoles del siglo XVI relataron que el Darién, actualmente una región cubierta por selva tropical pluvial típica, en aquel tiempo su vegetación fue de sabanas abiertas extensas, y estaba densamente poblado por tribus indígenas de agricultores. Estos cambios climáticos trajeron, como consecuencia, cambios decisivos en los medios ambientales y produjeron, indudablemente, impactos protuberantes en la historia de la vida de la mayoría de los anfibios y reptiles, tanto tropicales como subtropicales y, quizás, también de tierra fría (Duellman, 1966); (Krogzemis, 1967).

Las fluctuaciones del clima han constituído y todavía ahora constituyen una barrera más efectiva para impedir las migraciones que la misma separación total o parcial de la conexión intercontinental.

Existen en Colombia reptiles y anfibios que, evidentemente, correspondieron a la fauna norteamericana, en el sentido de la zona que abarca el sur de los Estados Unidos y México, donde estuvo ubicado el centro de su evolución y radiación hacia el sur; otros provinieron de la fauna de Suramérica ecuatorial y su radiación se efectuó hacia el norte. Si esta teoría resultare correcta, se debe encontrar hacia el norte de Colombia más elementos faunísticos de origen nórdico y centroamericano y, por el contrario, los elementos procedentes del área ecuatorial abundarán más hacia el sur de la Cordillera Oriental.

Esta constituye barrera decisiva con respecto al intercambio de reptiles y anfibios recientes por migración, entre el norte y el sur de Colombia, y divide el país en dos áreas extensas y bien definidas.

Tal es el caso de la distribución de los Testu dinata y Crocodylia y, aparentemente, también para la mayoría de los géneros de los Sauria y Serpentes. Hay que advertir, sin embargo, que debido al gran número de especies y por falta de estudios detallados, se conocen muchos menos datos exactos sobre la distribución geográfica de lagartos y serpientes que acerca de las tortugas y crocodilídeos.

En general, puede decirse, $v . g r .$, que si la misma especie se encuentra a ambos lados de la Cordillera Oriental, es porque tal especie había ya logrado invadir una $u$ otra zona respectivamente antes de la elevación de la Cordillera.

\section{DATOS HISTORICOS}

En las obras de los cronistas de Indias (Oviedo, etc.), no hemos encontrado referencia alguna 


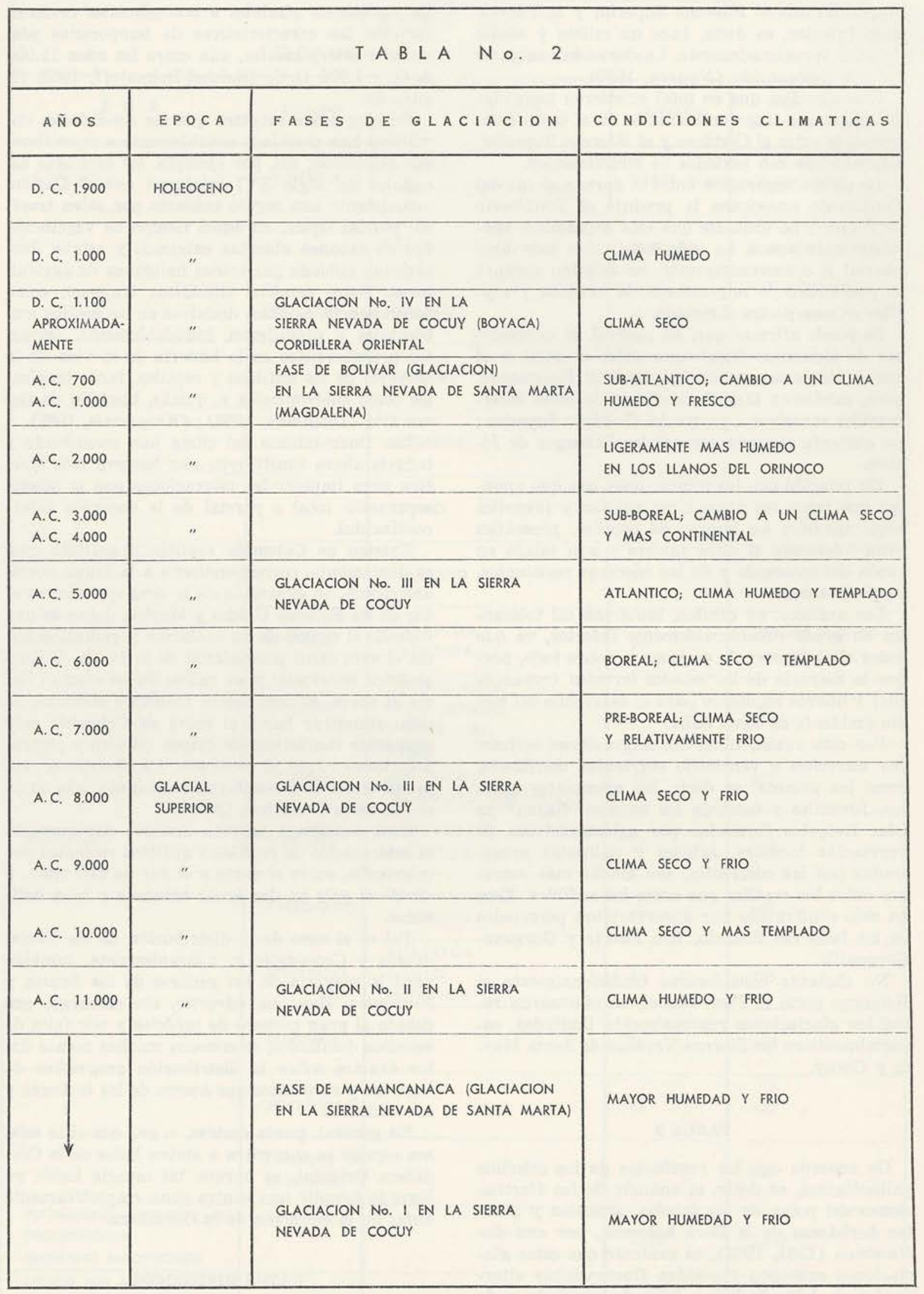

T A B L A 2 LOS CAMBios Climaticos DESDE lOS AÑos A. C. 11.000 HASTA D. C. 1.900 APROXIMADAMENTE: PARCIALMENTE ADAPTADO SEGUN REICHEL-DOLMATOFF, 1965, FIG. 4. 
respecto a la herpeto-fauna colombiana, aunque es de esperarse que existieron, pero se perdieron para la posteridad.

En cambio, disponemos de descripciones e informes elaborados por los misioneros; entre ellos sobresale, indudablemente, la obra del Padre Joseph Gumilla, 1741, intitulada "El Orinoco Ilustrado". El mérito principal del autor consiste en la acumulación de una cantidad enorme de datos sobre la etnología, folclore, historia, geografía, botánica y zoología de la hoya del Orinoco, observados y anotados por él mismo durante sus largos viajes, con cierto espíritu crítico y, a veces, con buen sentido de humor. Muchos de estos datos se refieren a los reptiles, ya sean útiles o peligrosos para los nativos e informan sobre las costumbres y modo de vivir de ellos, punto de vista ciertamente nada común en el siglo XVIII.

A modo de ejemplo, veamos un trozo breve pero significativo acerca de la ecología de las tortugas, de las serpientes, caimanes y lagartos, con varias referencias a las creencias y supersticiones populares.

Tomo I, pp. 298-308 de la edición de 1944.

"Cosecha admirable de tortugas"... El autor se refiere a la multitud innumerable de individuos de dos especies de tortugas, a la cosecha de huevos y a la fabricación del aceite en el Orinoco.

El Terecay (Podocnemis unifilis), que apenas tiene una arroba de peso, pone en el mes de febrero en las playas; los nidos contienen hasta 24 huevos. La Tortuga grande (Podocnemis expansa) "que pesa dos arrobas, sin falta, como lo he experimentado yo con la romana", sale también en febrero a principios de noche... "temerosas del sol, que las suele su calor dejar muertas en las playas"... a poner sus nidadas de 72 a 74 huevos. Las tortuguitas recién nacidas no salen de día, ya que el calor del sol las mata, e, igualmente, las aves de rapiña las persiguen y devoran con mayor facilidad, sino de noche. El Padre Gumilla se sorprendió... "que nunca yerran el camino, sino que vía recta se van al agua"... Hizo una serie de experimentos... "esto me causó gran armonía, que repetidas veces puse las tortuguillas a gran distancia del río, llevándolas cubiertas, y haciéndolas dar muchas vueltas, y revueltas en el suelo, para que perdiesen el tino; pero luego se veían libres tomaban el rumbo derechamente al agua..." Los indios Otomacos y otros cosechan grandes cantidades de tortugas, tortuguillas y huevos, pero "también concurren multitud de Tigres (Panthera onca) a voltear, y comer tortugas, que realmente vuelven fastidioso el paseo, y regocijo de los indios..."

Tomo II, pp. $142-158$.

"De las culebras venenosas de aquellos países, y sus remedios prácticos". "El primer horrible serpentón... es el buío al que llaman los indios jirará aviofa... su largo suele llegar a ocho varas... por hallarse con gran frecuencia... en las lagunas y ríos, donde de ordinario vive..."

Se trata del Güío negro o Anaconda (Eunectes murinus gigas) el cual representa el ofidio más grande del mundo (véase: lista de serpientes).

Evidentemente, la creencia popular que aún perdura en los campos acerca de que el güío negro atonta la presa mediante su vaho penetrante, es bastante antigua y el Padre Gumilla se refiere a ella como sigue: "....con todo, el que sabe el alcance largo del pestilente vaho de su boca, pone en fuga su mayor seguridad... un vaho tan ponzoñoso, y eficaz, que detiene, atonta y vuelve inmóvil al animal que infirió...". Además, el autor cree que el buío no tiene dientes... "y así gasta largo tiempo, y aun días enteros, en engullir una presa...", lo que es, en realidad, erróneo, pero hace otra observación biológicamente muy importante: “... se encuentran frecuentemente tendidos al sol dichos buíos, con las astas de un venado hechas bigoteras; y es, que después de engullir el venado, se le atranca la cornamenta, hasta que digerido lo que tragó, sacude de su boca las astas...". Indudablemente, este hecho ha dado origen a otra creencia popular todavía existente, v. gr., la de una culebra enorme "con corona" o "con cachos".

Un buío ha sido observado atacando a un caimán (Crocodylus intermedius) y ya ha engullido la tercera parte "... que sería vara y media..." cuando lo mataron mediante grandes esfuerzos con flechas y lanzas y sacaron la piel... "la cual después de seca tuvo siete varas y tres cuartas de largo, y tres tercias de ancho..."

La observación es, por cierto correcta, ya que el güío negro se alimenta con frecuencia de babillas (Caiman sclerops) y caimanes, estos últimos todavía abundantes en tiempos pasados.

"Otras culebras cazadoras". "...en lo corpulento llegan a igualar a los buíos, pero en lo largo los exceden en muchas varas; éstas tienen librado su alimento en su velocidad...".

Estos ofidios son difíciles para clasificar: serpientes de un tamaño tan largo no existen; muy posiblemente se trata de una combinación de informes de los nativos que se refieren tanto al Güío perdicero (Constrictor constrictor constrictor), el cual crece hasta cuatro metros, como a varias Cazadoras (Chironius carinatus; Spilotes pullatus; Pseustes poicilonotus, etc.), que crecen hasta unos tres metros, andan con gran velocidad y son muy agresivas pero no venenosas.

\section{La Cascabel (Crotalus durissus terrificus)...}

“...tienen los sonoros en la extremidad de la cola, sirven a los curiosos, y a los médicos: a aquéllos para saber, después de muerta, cuántos años tenía la culebra, porque cada año les nace un nuevo cascabel... ; a éstos, sirven de triaca y reme- 
dio para varios dolores...". La creencia popular acerca del cascabel anual todavía persiste, pero no corresponde a la realidad (véase: lista de serpientes).

La Culebra Macaurel es altamente venenosa y ataca a saltos... Posiblemente se trata de $\mathrm{Bo}$ throps atrox, denominada "macaurel" o "macabrel" en el Arauca, pero "cuatronarices" en el Meta; en cambio, llaman "macaureles" a varias especies de ofidios inofensivos (Boa canina; Boa hortulana hortulana, etc.).

La Culebra Sibucán. "...y por ser su color de tierra, ni la ve, ni la distingue... ; pero cuando ella está enroscada dentro de sí misma, se hace más incógnita, porque a cualquiera le parece que es una bosta de buey ya seca..." "Tiene tres varas de longitud, es altamente venenosa y ataca a saltos a caminantes como a jinetes; se encuentra en la tierra cálida y templada donde abunda; vive en la sombra de los bosques dentro de la maleza... Tanto el tamaño como las costumbres indican que, quizás se trata de la "Rieca" o "Verrugosa" (Lachesis muta muta), un ofidio muy venenoso, grueso y de escamas sobresalientes, parecidas a la superficie de un "sibucán" o "tipití", que usan los indios para exprimir el jugo venenoso de la yuca brava antes de fabricar el manioco ; crece hasta cuatro metros y representa una de las serpientes ponzoñosas más grandes del mundo.

Las culebras corales (género Micrurus). “...llamadas así, porque prevalece el color encarnado, veteado de negro, pardo, amarillo y blanco..., aunque según la variedad de ellas varían más 0 menos sus colores...; pero aunque varían de color, no varían de humor: tal, que entre cuantas culebras hay hasta hoy conocidas por allá, ninguna llega a la violencia del veneno de las corales...".

La creencia popular de que el colmillo del caimán constituye el contraveneno más efectivo, tiene su origen en Africa y, muy posiblemente, en la costa occidental, de donde se transportó la mayoría de los esclavos.

El Padre Gumilla anotó (pp. 196-197): “... contra las yerbas venenosas que los negros esclavos suelen usar unos contra otros; y no pocas veces contra sus amos...". "...el descubrimiento de la virtud de tal colmillo, es moderno, y fue así: deseoso un negro esclavo, en las haciendas de Caracas, de matar a otro, le dio ocultamente de cuantos venenos y yerbas venenosas tenía noticia..."; y viendo que se cansaba en balde, porfiando en vano, porque su enemigo estaba bueno... hasta que un día dijo el negro malévolo al otro: "camarada, y si algún mal cristiano nos quisiese dar veneno, ¿qué remedio sabes?" El otro sacó el brazo, levantó la manga, y mostrándole un colmillo de caimán atado a la carne, le dijo ingenuamente: "amigo, teniendo este colmillo, no hay veneno que valga". Corrió la voz, y con la experiencia el aprecio...
De los caimanes o cocodrilos ( $p p$. 187-198).

Los "caimanes" (Crocodylus intermedius) abundan principalmente "...en los raudales, remolinos y peñascos, donde suelen naufragar las embarcaciones, y junto a las poblaciones donde van las gentes a lavarse..." Se alimentan de peces, pero evidentemente pasan por largas temporadas sin alimentarse... "porque desentrañando algunos después de muertos, rara, y casi ninguna vez les hallé en el estómago comida alguna: los que todos sí tienen en el fondo del ventrículo, es un gran canasto de piedras menudas muy lisas y lustrosas, amolándose con la a git a ción unas a otras...", "dicen aquellos indios que cuando va creciendo el caimán, va recibiendo dificultad en dejarse aplomar al fondo del río, sobre cuyas arenas duerme cubierto del todo el peso de las aguas, que sobre él corren...", “...recurre a la playa, y traga tantas piedras, cuantas necesita para su lastre y contrapeso, por lo cual en los caimanes grandes se halla, como dije, su vientre recargado con una canasta de piedras...". En tres tiempos están bravos. "Solo casualmente aprenden a cebarse en carne humana; y así en los ríos donde no hay poblaciones y hay poco concurso de embarcaciones, solo en tres circunstancias de tiempo son de temerse los caimanes". "La primera, cuando por septiembre y octubre, andan celosos en continuo seguimiento de sus hembras. La segunda, cuando puestos los huevos en hoyas, que para ellos excavan en las playas... andan la hembra y el macho remudando la guardia no muy lejos de la nidada..., la tercera, cuando salidos ya del cascarón los caimancillos, van todos arrimaditos a las barrancas, nadando por la misma orilla del agua; entonces andan sus padres a la vista, y en este y en los otros tiempos dichos, gastan infaliblemente de su sañudo humor... y embisten con furia, disparando al mismo tiempo una ventosidad, o intolerable almizcle, tal, que aturde el sentido..." Ponen... "a lo menos 40 huevos tremendos, gruesos y largos... todo cuanto contienen adentro es clara, y en su centro una mancha parda, que dicen ellos (=los Otomacos) ser la parte que ha de ser la cabeza del caimán..." "Así lo creo, porque abriendo muchos de aquellos huevos ya empollados, he reconocido que el cuerpo y la cola del caimancillo, de más de un jeme de largo (= el término de 'jeme' significa una medida longitudinal, la distancia desde la extremidad del dedo pulgar hasta el dedo índice), ... da vuelta enroscada por el circuito interior del huevo, y la cabeza queda en el medio, o en el centro, la cual sacan luego que se rompe la cáscara, y muerden con furia el palo con que se rompió el huevo, clavando reciamente los dientes afilados en el palo...".

La mayoría de estas observaciones contiene gran valor científico, por razón de suministrar datos acerca de las costumbres y el modo de vivir de los caimanes en su ambiente natural y todavía 
no alterado por actividades humanas. Hoy en día no se pudiera llevar a cabo tales estudios, ya que los caimanes están virtualmente exterminados, y los pocos que se refugiaron en regiones remotas, son tan ariscos que ya no se comportan más de manera natural. Los datos son, por lo general, correctos, v. gr., los referentes a la posición del caimancillo dentro del huevo y el modo de defenderse a mordiscos tan pronto como sale del huevo.

La carne del caimán es muy apreciada por los indígenas, “. . . especialmente en el invierno, y creciente del río, cuando es poco útil otra pesca..." Constituye otra observación muy correcta, ya que es bien sabido que la pesca en las aguas turbias de los ríos y caños crecientes es en realidad inútil. Así, los indios de aquellos tiempos siempre tenían carne en abundancia durante todo el año, lo que hoy en día no es el caso por las razones arriba mencionadas.

Los métodos usados por los Otomacos para la caza del caimán están descritos meticulosamente. La grasa o manteca del caimán constituye un alimento básico y, al mismo tiempo, un purgante indispensable para los nativos; limpia totalmente el estómago "sin dejar en él tierra alguna...", en relación con la costumbre de la geofagia, común en estas tierras, a la cual se refiere también Alexander von Humboldt detalladamente. El Padre Gumilla ya realizó los efectos dañinos "...el pan de los indios Otomacos es, a lo menos, la mitad de tierra gredosa, que naturalmente había de dañar a los que le comen...".

Además, el autor se refiere a la abundancia "de muchos caimanes de la misma forma y figura; pero no son bravos (aunque cuando los torean mucho, los he visto enojados), éstos solo se mantienen de pescado, y ellos son comida apetecible y de buen gusto; y cuando hay babilla (así se llaman) abandonan los indios cualquier otro pescado..." Se trata de la "Babilla" o "Cachirre". (Caiman sclerops; Paleosuchus palpebrosus), todavía bastante común en los Llanos Orientales.

Páginas 233 - 235. Anota la cantidad innumerable de iguanas (Iguana iguana iguana) y que en media hora los indios recogen cien de ellas "... son unos feísimos lagartos, de color entre verde y amarillo, que se mantienen de hojas de árboles; y también viven en el río, como en tierra...".

Finalmente, el Padre Gumilla suministra datos correctos sobre la ecología... "una especie de tortugas terrestres, que se llaman icoteas, y también morrocoyes... No se acercan al agua, y su concha está matizada de amarillo, encarnado, blanco y pardo... cuando el sol las fatiga, si hay alguna cueva, se amontonan en ella muchas, y los que se van en busca, suelen de una sola cueva sacar ocho, y a veces diez cargas de ellas... causa admiración el ver, que multipliquen tanto, siendo un animal tan impróvido, que no se esconde los huevos, como las demás especies de tortugas... ; como van caminando, suelta acá un huevo, otro acullá, sin cuidarse más de ellos...".
En realidad, los "morrocoyes" (Geochelone denticulata) presentan durante el verano o temporada seca un período de estivación, es decir, permanecen en estado inmóvil debajo de los árboles caídos, rastrojo denso o encuevados hasta que caen los primeros aguaceros del invierno. El "morrocoy" procedente de las hoyas del Orinoco y Amazonas, en contraste con la otra especie ( $\mathrm{Geo}$ chelone carbonaria) que vive al norte de la Cordillera Oriental, no excava, al parecer, huecos para anidar, sino deja los huevos "regados" en el suelo; este fenómeno lo he observado en La Macarena y en otras regiones.

En resumen, muchos de los datos del Padre Gumilla, causan admiración por cuanto denotan marcada inclinación hacia los problemas de la naturaleza, lo cual resulta excepcional habida consideración del espíritu predominante en la época.

Los informes sobre otros grupos de animales, tales como insectos, peces, aves y mamíferos, merecen estudios por parte de especialistas, en razón de que muchos datos serán muy difíciles o, quizás, del todo imposibles de verificar mediante observaciones en nuestro tiempo debido a la escasez o exterminación de ciertas especies de animales por la actividad destructiva del género humano.

El Padre don Antonio Julián, 1787, El Discurso XIX, pp. 121-126, de la edición de 1854, se refiere brevemente a una especie de tortuga marina: "De la concha fina de tortuga y madre de perla de Santa Marta", pág. 123. "De la pulpa... sacan manteca y aceite... pero lo que más se aprecia de estas tortugas de mar es la concha que en América llaman Carey...".

Se trata del "Carey" (Eretmochelys imbricata imbricata), el cual abundaba antiguamente entre Santa Marta y Riohacha, pero actualmente está virtualmente exterminado en las regiones situadas al oriente de Santa Marta, debido a la persecución continua.

Finalmente, el Padre José de Calasanz Vela, 1890 , suministra muchos datos biológicos anotados durante el largo viaje que se efectuó desde Puerto Bolívar, cerca de San Martín, en el Alto Ariari (Meta), San Fernando de Atabapo, el Orinoco, los ríos Vichada, Muco y Meta, hasta Puerto de la Cruz, situado a unos 400 metros abajo de las bocas de los ríos Guatiquía y Humea (Meta), y que duró desde el 4 de marzo hasta el 14 de noviembre de 1889.

Abundaban los "caimanes" (Crocodylus intermedius) y las "babillas" (Caiman sclerops), las tortugas "terecay" (Podocnemis unifilis) y "sabanera" (Podocnemis vogli), también llamado "galápago", en el río Ariari, todos muy perseguidos por su carne y los huevos por los indios Mitúas. En el Guaviare, desde el río Iteviare por abajo, la "tortuga" o "chapanera" (Podocnemis expansa) era poco abundante, en cambio, el "terecay" sí abundaba; las "sabaneras" se encontraron con frecuencia en las lagunas y caños, afluentes del Guaviare, mientras el "morrocoy" (Geochelone 
denticulata) y la "hicotea" (nombre usado para la "matamata", Chelus fimbriatus, en los Llanos Orientales) eran más bien escasos. Al fin del viaje anotó con asombro, que en el río Muco (Vichada) la culebra "macaurel" (Boa hortulana hortulana) era $\tan$ frecuente que se encontraron a veces de cuatro a cinco ejemplares en un solo árbol.

La obra del Padre Vela, virtualmente desconocida, contiene numerosas descripciones sobre la Geografía de estas vastas regiones, correctamente elaboradas, junto con múltiples datos etnográficos sobre muchas tribus indígenas ya extinguidas.

\section{ESTUDIOS SOBRE LA HERPETOLOGIA}

Los estudios sistematizados propiamente dichos sobre la fauna colombiana empezaron en época relativamente reciente, es decir, a fines del siglo XIX, con la sola excepción de las abundantes, exactas y críticas investigaciones hechas por Alexander von Humboldt entre 1799 y 1801. En mayo de 1801, observó numerosos ejemplares recién nacidos del "caimán" (Crocodylus acutus) en Mompox y estudió su anatomía; estos estudios fueron publicados en 1805, e intitulados: Mémoire sur l'os Hyoide et de Larynx des Oiseaux, des Singes et du Crocodile, pp. 1-12, figs.

Durante repetidas expediciones científicas se coleccionaron reptiles y anfibios, luego descritos en su mayoría por herpetólogos europeos.

J. Goudot coleccionó reptiles en el valle del Magdalena y otras regiones; participó en las expediciones dirigidas por J. B. Boussingault y F. D. Roulin en las regiones de Cúcuta, Pamplona, Santa Rosa, Tunja, Bogotá, de 1822 a 1823; luego en 1824, en los Llanos de San Martín y hasta la desembocadura del río Meta. Después viajó con el peruano Rivero a las regiones de Bogotá y Vélez, y en 1825, hacia Mariquita, el paso de Herveo hacia Supía y a las provincias de Antioquia, Popayán y el Tolima.

Las descripciones de nuevas especies de reptiles y anfibios fueron hechas por Duméril \& Bibron, 1836-1854, los cuales también estudiaron el material coleccionado por Bernard Léwy en la región de Honda y Girardot.

El geólogo Carl Degenhardt, 1839, hizo estudios en las provincias de Popayán y Antioquia (Santa Rosa de Osos y Medellín), y sus colecciones de reptiles fueron descritas por Berthold (1846 a; $1846 \mathrm{~b} ; 1859)$. Peters, 1862 , describió varias nuevas especies de Sauria (lagartos) procedentes de la Sabana de Bogotá.

Evaristo García presentó el primer informe sobre los ofidios venenosos del Cauca el 20 de julio de 1892, y en 1896 publicó su obra clásica intitulada: "Los ofidios venenosos del Cauca, métodos empíricos y racionales empleados contra los accidentes producidos por la mordedura de esos reptiles"; pp. i - xii; 1-102, pls. 1-15 en colores. Cali.
Describió una nueva especie de serpiente: "Rabo de Chucha" del Chocó. Total 30 ctms. Habitat en las montañas del Dagua. "La designaremos con el nombre de Lachesis punctatus".

La descripción de García permaneció en el olvido hasta cuando Nicéforo María, 1929, comprobó que el nombre científico de punctatus tiene derecho de prioridad sobre el de leptura Amaral, 1923. Actualmente se denomina como Bothrops punctatus (García), 1896.

W. F. Rosenberg, M. G. Palmer y H.G.F. Spurrell coleccionaron una cantidad considerable de nuevos anfibios y reptiles en las regiones de Buenaventura y Cali, Noanamá, río San Juan, y Peña Lisa, río Condoto, afluente del San Juan (Chocó), respectivamente, los cuales describió Boulenger (1896, 1908, 1913, etc.) en sus obras clásicas.

Posada Arango $(1889,1909)$ publicó varios trabajos sobre anfibios y, principalmente, sobre ofidios.

Causó gran confusión por aplicar nombres científicos nuevos, erróneos por cierto, y cambiar la nomenclatura de muchas especies ya clasificadas y descritas correctamente en años anteriores.

El cónsul Friedrich Carl Lehmann, oriundo de Popayán, se dedicó a estudios sobre la fauna y flora del Alto Cauca y de Nariño e hizo expediciones a tan aisladas regiones, aún en nuestro tiempo, como son las del litoral del Pacífico entre los ríos Mira y Patía, en el cual último río murió ahogado. Coleccionó, de 1890 en adelante, muchas especies nuevas de anfibios y reptiles, las cuales fueron publicadas por Oskar Boettger (1892, 1893, 1898) ; entre ellas se cuenta una rana (Hyla lehmanni); Boettger, igualmente, publicó sobre el material herpetológico coleccionado por Georg Hübner, 1895, en el río Inírida, y Fritz Regel, 1897, en el valle del Magdalena.

Robert Mertens (1925 a, 1925 b, 1926) describió un género nuevo de Amphisbaenidae y una nueva especie de Iguanidae coleccionadas por Hübner en el Inírida.

Los resultados de las colecciones hechas por la Princesa Teresa de Baviera, 1898, en el valle del Magdalena, entre Barranquilla y el río Lebrija, han sido publicados por Siebenrock (1902, 1909).

Otto Bürger, 1900, relató en una obra popular su expedición efectuada durante los años 1896 1897, la cual empezó en Barranquilla, siguiendo por el valle del Magdalena, Purnio (Ant.), una mina de oro en la región de La Dorada, Honda, Bogotá, Villavicencio, y terminó en Orocué, río Meta. Fassl (1910), coleccionó en el cañón del Tolima y la Sabana de Bogotá, principalmente reptiles.

Ambas colecciones fueron estudiadas por Werner $(1899,1916,1923,1927)$. Fuhrmann y Mayor coleccionaron de julio 20 a noviembre 2 de 1910 , entre Barranquilla, Puerto Berrío, ríos Nus y Porce, Medellín, Angelópolis, Titiribí, Filadelfia, Manizales, Mariquita, Honda, Alto del Trigo, Vi- 
lleta, Facatativá, Bogotá, Zipaquirá, Laguna de Ubaque, Páramo Cruz Verde; regresaron por vía de Tocaima, Viotá, Girardot, Ambalema, La Dorada y Magangué a Barranquilla. Los resultados fueron publicados por Fuhrmann (1914) y Peracca (1914).

Barbour (1905, 1921) hizo los primeros estudios sobre los reptiles y anfibios de las islas Gorgona-Gorgonilla y Providencia.

Desde los años 1920 en adelante, nuestros conocimientos sobre la herpetología colombiana han aumentado en forma acelerada, principalmente gracias a la labor de tres destacados científicos:

El Hermano Nicéforo María se ha dedicado principalmente a estudios sobre ofidios, pero también sobre varios grupos de anfibios entre 1929 y 1958; elaboró el primer "censo" en 1942, intitulado "Los ofidios de Colombia" y publicado en la "Revista Colombiana de Ciencias Exactas, Físicas y Naturales", Vol. 5, No 17, pp. 84-101, pls. 1-12.

Se registraron 180 especies y subespecies, 26 de ellas halladas por primera vez en el país.

Emmett Reid Dunn publicó durante su estadía en Colombia, de junio de 1943 a fines de julio de 1944, varios artículos extensos en Caldasia sobre anfibios y reptiles, incluyendo en ellos todos los grupos registrados que se conocían del país; además, hizo otras numerosas contribuciones entre 1928 y 1957. Merecen citarse entre ellas un estudio sobre los lagartos endémicos en la isla de Malpelo.

Afranio do Amaral, Director del Instituto Butantan en São Paulo, Brasil, hizo contribuciones básicas a la ofiología colombiana entre 1923 y 1954, a base de material enviado por los Hermanos Apolinar y Nicéforo María. Además el Hermano Daniel, Director del Colegio San José de Medellín $(1939,1949,1955)$, ha publicado resúmenes sobre ofidios, suministrando varios datos ecológicos nuevos.

Hernando y Ernesto Osorno Mesa $(1938,1946)$, estudiaron detalladamente los problemas sobre la reproducción, alimentación y comportamiento de las especies de Iguanidae procedentes de la Sabana de Bogotá (Leiocephalus ornatus trachycephalus y Phenacosaurus heterodermus y richteri). Federico Medem, de 1950 en adelante, se ha dedicado a estudios sobre la ecología, distribución geográfica y taxonomía de los Crocodylia y Testudinata. Valdivieso y Tamsitt (1963 a, 1963 b), hicieron nuevas investigaciones sobre la fauna herpetológica de la tierra firme y de las islas San Andrés y Providencia.

La base de todos los estudios científicos está formada por la vocación profesional. Evaristo García (1896, pp. 37-38), ya ha expresado el punto de vista del investigador genuino, con las siguientes palabras: "El vulgo, inclinado siempre a lo maravilloso, acepta como verdades incontrovertibles las impresiones de los sentidos, por absurdos que parezcan los hechos mal observados.
Basta la coincidencia de los fenómenos, para admitir entre ellos relaciones de causas invariables. El hombre pensador comienza por dudar de los hechos e investiga la verdad... por medio de estudio, la observación y la experimentación; el vulgo comienza por creer las relaciones fantásticas de un modo tan obstinado, que en ocasiones es mejor no discutir con él... El buen sentido aconseja estudiar los medios naturales de que se valen, antes de caer en las supercherías de los juglares..."

Evidentemente, García, como otros profesionales, tenía que luchar contra un sinnúmero de supersticiones de índole tradicional-emocional que obstaculizan el progreso científico en todos los países del mundo.

Antes de la compilación presentada, tenemos que referirnos a unos términos relacionados con la reproducción que han causado cierta confusión:

1. Organismos ovíparos. Las hembras ponen huevos de los cuales nacen nuevos individuos; los huevos pasan por un período de incubación durante el cual se desarrolla el nuevo organismo.

2. Organismos ovoviviparos. Los huevos contienen mucha yema, que suministra alimento durante el desarrollo embrional dentro de los oviductos de la hembra, donde se efectúa un "período de incubación interna"; los nuevos organismos "nacen vivos".

En realidad, no hay una distinción exacta entre la oviparidad y ovoviviparidad, por razón de que muchos organismos ovíparos ponen huevos dentro de los cuales los embriones ya están en estado de desarrollo muy avanzado y próximos a nacer.

3. Organismos vivíparos. Los diminutos huevos contienen yema escasa y los embriones se alimentan de materia orgánica del cuerpo maternal, suministrada por la corriente de la sangre a través de las paredes del útero hasta su nacimiento.

Hablando solamente de la Herpeto-Fauna, viviparidad genuina ocurre únicamente en las Caeciliidae (anfibios) y unos pocos grupos de reptiles.

Lo que sigue es una compilación de anfibios y reptiles, fósiles y recientes, con el fin de demostrar la riqueza de la herpeto-fauna colombiana, como atrás quedó señalada.

Con ello se busca hacer ostensible el progreso logrado durante los últimos veinte años en el conocimiento de la herpetología del país.

\section{Clase AMPHIBIA}

Comprenden vertebrados que carecen de escamas externas; poseen glándulas que humedecen la piel; respiración por la piel, branquias y pulmones; u ovíparos o vivíparos; la postura de los huevos se efectúa, por lo general, en el agua; con 
o sin dientes y extremidades; los estados larvales ("renacuajos") de varios grupos se distinguen notablemente de los adultos; acuáticos, terrestres, subterráneos y arborícolas.

Se distinguen tres Ordenes de Anfibios como sigue:

1. Apoda. Tatacoas

2. Caudata. Salamandras

3. Anura. Ranas y Sapos.

\section{Apoda. - Familia Caeciliidae.}

Anfibios de cuerpo vermiforme; sin extremidades; piel lisa con pliegues transversales; con dientes pequeños; subterráneos y acuáticos.

Los géneros Caecilia, Siphonops y Rhinatrema son ovíparos, mientras los Gymnophis y Typhlonectes son vivíparos.

Género Caecilia (Linnaeus), 1758.

Especies:

1. C. bassleri Dunn, 1942. Pto. Asís (Putumayo), 500 metros altura.

2. C. caribea Dunn, 1942. Terra typica: Pensilvania (Caldas), Valle del Cauca, 1920 m. alt., Barranquilla.

3. C. degenerata Dunn, 1942. Terra typica; Garagoa (Boyacá), región de Miraflores, $1639 \mathrm{~m}$. alt., vertiente oriental de la Cordillera Oriental hacia el Casanare. Choachí, Tomaque (Cund.).

4. C. dunni Hershkovitz, 1938. Quebrada "Las Animas" (Chocó), afluente del río Quito, Valle del Atrato. Andagoya, río San Juan; Peña Lisa, río Condoto, afluente del Alto San Juan (Chocó).

5. C. guentheri Peters, 1879. Peña Lisa; Urrao (Ant.), valle del Atrato.

6. C. nigricans Boulenger, 1902. Sinónimo: $C$. palmeri Boulenger, 1913, Nóvita (Chocó), río Tamaná, afluente del San Juan. Isla Gorgona (Cauca) ; "Río Quesada" (= Ciénaga de Quesada, vecindad de Murindó (Ant.), Bajo Atrato; Andagoya; Peña Lisa.

7. C. ochrocephala Cope, 1866. Turbo (Ant.), golfo de Urabá.

8. C. pachynema Günther, 1859. Medellín; Villavicencio; Medina (Cund.), $576 \mathrm{~m}$. alt., vertiente oriental de la Cordillera Oriental hacia el Casanare.

9. C. polyzona Fischer, 1879. Terra typica; Cáceres (Ant.), río Cauca, $150 \mathrm{~m}$. alt.

10. C. subnigricans Dunn, 1942. Terra typica: Río Magdalena.

11. C. tentaculata Linnaeus, 1758. Puerto Asís; Garagoa; Sabanalarga (Atl.); Río Frío (Magd.).
12. C. thomsoni Boulenger, 1902. Terra typica: Villeta (Cund.), 1.842 m. alt. La Mesa (Cund.); Ibagué; Muzo (Boyacá).

\section{Género Gymnophis Peters, 1874.} Especies:

1. G. nicefori Barbour, 1924. Terra typica: Honda (Tolima), marzo 1924, Nicéforo María. Girardot; Cáceres.

2. G. pricei Dunn, 1944. Terra typica: El Centro (Sant.), $150 \mathrm{~m}$. alt., diciembre 24, 1943, E. R. Dunn, dentro de un tronco podrido. Solamente conocida de la localidad típica.

\section{Género Rhinatrema Duméril \& Bibron, 1841.} Especies:

1. R. columbianum Rendahl \& Vestergren, 1938. Terra typica: El Tambo (Cauca), 1.000 alt. Kjell von Sneidern.

2. R. parkeri Dunn, 1942. Terra typica: Medellín (Ant.), $1.538 \mathrm{~m}$. alt. Solamente conocida de la localidad típica.

Género Siphonops Wagler, 1828. Monotípico.

Especies:

1. S. annulatus (Mikan), 1820. Medina (Cund.); Guaicaramo (Boyacá), depresión entre El Engaño, al N. de Medina, y Barranca de Upía, al E. del río Meta; Sierra de La Macarena, sur, Alto Guayabero (Meta); Leticia.

Género Typhlonectes Peters, 1879.

Especie:

1. T. compressicauda natans (Fischer), 1879. Terra typica: Río Cauca, Muy probablemente Cáceres (Ant.), Medellín; Puerto Berrío; Honda; Barranquilla; Soplaviento (Bol.); Canal del Dique; Cúcuta (N. de Sant.) ; Ciénaga de Quesada ("Río Quesada" en el texto).

Nota: de fines de marzo a principios de abril de 1963, las "Ciegas" se encontraron con frecuencia en el Alto Uré (Córdoba), afluente del Alto San Jorge, pero entre enero y principios de marzo nunca se ha observado un solo ejemplar. Entre las $6: 30$ y 8:00 p. m., unos tres a cinco se alimentaron de intestinos de pescado cerca de la orilla; se confunden fácilmente con el pez "Anguilla" (Synbranchus marmoratus Bloch, 1795); miden de $516 \mathrm{~mm}$. a $570 \mathrm{~mm}$. de longitud total; son principalmente acuáticos, pero también se mueven ágilmente en tierra húmeda; de día permanecen en el fondo de las aguas o encuevadas dentro de las palizadas. Respecto a la reproducción, Heinroth (1915, citado por Dunn, 1942, p. 536), mantenía una hembra de $480 \mathrm{~mm}$. de largo en cautividad desde julio 14, 1914; enero 16, 1915, nacieron cuatro crías que no tenían branquias y midieron de $190 \mathrm{~mm}$. a $200 \mathrm{~mm}$. 


\section{Paleontología.}

No se han encontrado apodos fósiles hasta la fecha; sin embargo, es muy probable que evolucionaron de los Microsaurios, un grupo de anfibios que floreció durante el Carboniano y Permiano (Goin \& Goin, 1962).

Se conocen de Colombia cinco géneros con 18 especies de Cecilias, varias de ellas son endémicas.

\section{Caudata. - Familia Plethodontidae.}

Cuerpo dividido en cabeza, tronco y cola; cuatro extremidades; sin branquias o pulmones; respiración por la piel; terrestres y arborícolas; se encuentran o en el suelo húmedo debajo de piedras y troncos o en las Bromeliáceas, plantas epifíticas que crecen en los árboles; se desconocen datos exactos sobre la reproducción de la mayoría de las especies. Nicéforo María (1958), comprobó por primera vez que Bolitoglossa adspersa es ovípara.

Género Bolitoglossa Duméril \& Bibron, 1854. Sinónimo: Magnadigita Taylor, 1944.

Especies:

1. B. adspersa (Peters), 1863. Terra typica: Bogotá.

Sinónimo: Geotriton andicola Posada Arango, 1909, Cordillera Central (Ant.), sin localidad exacta.

2. B. altamazonica (Cope), 1874. Acacías (Meta) ; Muzo (Boyacá).

3. B. biseriata Tanner, 1962. Isla Gorgona; norte, colonia penal; Bajo Calima (Valle).

4. B. capitana Brame \& Wake, 1963. Terra Typica: Hacienda "La Victoria", entre Albán y Sasaima (Cund.), $1.780 \mathrm{~m}$. alt., Nicéforo María.

5. B. hypacra (Brame \& Wake), 1962. Terra typica: Páramo Frontino (Ant.), 3.610 m. alt., M. A. Carriker, Jr.

6. B. nicefori Brame \& Wake, 1963. Terra typica: unos $14 \mathrm{kms}$. al N. de San Gil (Sant.), 1.500 m. alt., Nicéforo María.

7. B. pandi Brame \& Wake, 1963. Terra typica: Pandi (Cund.), 1.300 m. alt., septiembre 19, 1913, Wilhelm Fritsche.

8. B. phalarosoma Wake \& Brame, 1962. Terra typica: Medellín (Ant.), $1.538 \mathrm{~m}$. alt.

9. B. savagei Brame \& Wake, 1963. Terra typica: Cerro de San Lorenzo, Sierra Nevada de Santa Marta, $1.400-2.100$ m. alt.

10. B. vallecula Brame \& Wake, 1963. Terra typica: Yarumal (Ant.), $2.300 \mathrm{~m}$. alt., enero 1962, Nicéforo María. La Ceja (Ant.), 2.217 m.; San
Pedro (Ant.), $2.700 \mathrm{~m}$; $6 \mathrm{kms}$. de Retiro en dirección a Rionegro (Ant.), 2.300 m.; Santa Rosa de Osos (Ant.), $2.640 \mathrm{~m}$.

Género Oedipina Keferstein, 1868.

Especies:

1. O. complex (Dunn), 1924. Isla Gorgona, norte, colonia penal.

2. O. parvipes (Peters), 1879. Terra typica: Cáceres (Ant.), río Cauca. Peña Lisa (Chocó), Condoto.

Recientemente, Brame \& Wake (1963), hicieron una revisión taxonómica de las salamandras suramericanas, y describieron siete nuevas especies de Colombia.

\section{Paleontología.}

Salamandras fósiles que pertenecen a la familia Plethodontidae se conocen del Paleoceno (Goin \& Goin, 1962).

En Colombia existen dos géneros con 12 especies de salamandras conocidas hasta la fecha.

\section{Anura o Salientia.}

Cabeza y cuello fusionados; virtualmente no hay cuello en los adultos sino la cabeza está en contacto estrecho con el tronco; sin cola en el estado adulto y postlarval; larvas (renacuajos) con cola; acuáticos, terrestres, arborícolas y cavernícolas; ovíparos, ovovivíparos y vivíparos los representantes de varios géneros cargan los huevos dentro de una o varias bolsas o pliegues, situadas en la parte dorsal (Pipa; Gastrotheca); otros cargan los renacuajos en las partes dorsal o lateral (Dendrobates; Hyloxalus; Phyllobates).

Hunter \& Valdivieso (1962), estudiaron la Ovogénesis de Hyla labialis Peters, 1863, la rana más común en la Sabana de Bogotá.

Heredia Caño está preparando experimentos sobre la reproducción del "Sapo Mamboré", Bufo blombergi Myers \& Funkhouser, 1951, descrito de Nachao (Nariño), $550 \mathrm{~m}$. alt., Cordillera Occidental; es endémico en Colombia y representa el sapo más grande conocido del mundo.

Lo hemos encontrado, 1960, en la región de Anchicayá (Valle), entre Cali y Buenaventura, es decir, de una localidad nueva señalada por el Prof. F. Carlos Lehmann; sin embargo, los límites de su distribución geográfica son todavía desconocidos.

Se desconoce el número total exacto de los Anuros existentes en el país. Goin \& Cochran han descrito recientemente tres géneros nuevos y cinco nuevas especies de Colombia, y están preparando una monografía. Debido a lo arriba mencionado, nos limitamos a citar la lista de los Anuros colombianos, tentativamente elaborada por Goin (1965). 


\section{TABLA 3}

Por esta razón nos limitamos en citar la lista preliminar elaborada por Goin (1965) como sigue:

\begin{tabular}{|c|c|c|c|c|}
\hline Familia & G én e ro & & & $\begin{array}{l}\text { ero tentativo } \\
\text { las especies }\end{array}$ \\
\hline Pipidae & Pipa ... . . . . . & . . & * & 2 \\
\hline Ranidae & 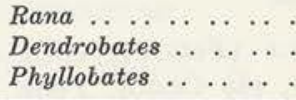 & $\begin{array}{l}\cdots \\
\ldots \\
\ldots\end{array}$ & $\begin{array}{l}\cdots \\
\cdots \\
\cdots\end{array}$ & $\begin{array}{r}1 \\
11 \\
14\end{array}$ \\
\hline Mierohylidae & 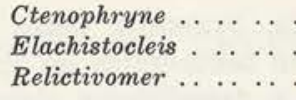 & $\begin{array}{l}\ldots \\
\ldots \\
\ldots\end{array}$ & $\begin{array}{l}\cdots \\
\cdots \\
\cdots\end{array}$ & $\begin{array}{l}1 \\
1 \\
1\end{array}$ \\
\hline Pseudidae & Pseudis . . . . . . & .. & . & 1 \\
\hline Bufonidae & Bufo $\ldots \ldots \ldots \ldots \ldots$ & .. & $\cdots$ & 10 \\
\hline Atelopidae & Atelopus ......... & .. & .. & 8 \\
\hline Hylidae & 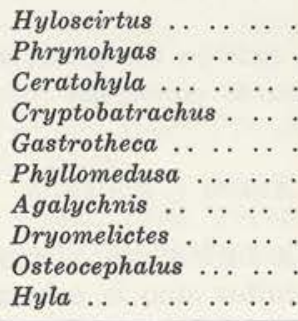 & 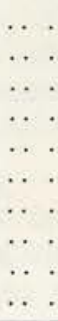 & $\begin{array}{l}\cdots \\
\cdots \\
\cdots \\
\cdots \\
\cdots \\
\cdots \\
\cdots \\
\cdots \\
\cdots\end{array}$ & $\begin{array}{r}1 \\
2 \\
2 \\
3 \\
8 \\
7 \\
2 \\
3 \\
3 \\
50\end{array}$ \\
\hline Leptodactylidae & 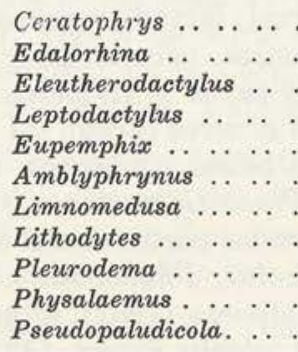 & $\begin{array}{l}\ldots \\
\ldots \\
\ldots \\
\ldots \\
\ldots \\
\ldots \\
\ldots \\
\ldots \\
\ldots \\
\ldots \\
\ldots \\
\ldots \\
\ldots\end{array}$ & $\begin{array}{l}\cdots \\
\cdots \\
\cdots \\
\cdots \\
\cdots \\
\cdots \\
\cdots \\
\cdots \\
\cdots\end{array}$ & $\begin{array}{r}2 \\
1 \\
45 \\
13 \\
2 \\
1 \\
1 \\
1 \\
2 \\
1 \\
1\end{array}$ \\
\hline \multirow[t]{2}{*}{ Centrolenidae } & 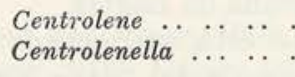 & $\begin{array}{l}\cdots \\
\cdots\end{array}$ & & $\begin{array}{l}1 \\
6\end{array}$ \\
\hline & & & & 208 \\
\hline
\end{tabular}

El mismo autor estima que se encuentren más de unos 225 anuros, entre especies y subespecies, en Colombia.

\section{Paleontología.}

Savage (1951) describió Leptodactylidae de La Venta (Huila), entre Cerro Gordo y Las Mesitas, del Mioceno Superior.

Estes y Wassersug (1963), encontraron un $\mathrm{Bu}$ fo marinus casi completo también del Mioceno.

Durante los últimos veinte años se han encontrado cantidades considerables de anuros fósiles, esperialmente en varios sitios argentinos. La rana propiamente dicha más antigua conocida hasta la fecha, es Notobatrachus degiustoi Reig, 1957, del Jurásico de Patagonia.

Además, se conocen Leptodactylidae del Cretáceo; Ranidae y Bufonidae del Eoceno; Pipidae del Cretáceo; Hylidae del Oligoceno, y Leptodactylidae y Ceratophrynidae del Mioceno de Patagonia (Goin \& Goin, 1962).

El número total de los anfibios colombianos comprende, tentativamente presentado:

1. Apoda: 5 géneros con 18 especies y subespecies.

2. Caudata: 2 géneros con 12 especies y subespecies.

3. Anura: 35 - 36 géneros con 225 especies y subespecies.

Eso quiere decir que un total de 43 géneros con 255 especies y subespecies de anfibios ha sido registrado hasta la fecha del país.

\section{Clase REPTILIA}

Comprenden vertebrados de piel seca, córnea $y$, por lo general, provista de escamas, placas y escudos; cuatro extremidades en la mayoría de los géneros, pero en varios grupos reducidos o ausentes; con o sin dientes; órgano copulador (hemipenes) doble en los Sauria y Serpentes; ovíparos, ovovivíparos y vivíparos; herbívoros, omnívoros y carnívoros; terrestres, subterráneos, arborícolas y acuáticos. Se distinguen cuatro Ordenes, los cuales se denominan como sigue:

1. Testudinata. Tortugas en general.

2. Crocodylia. Caimán, Babillas, Yacaré, Tulisio.

3. Superorden Squamata.

A. Orden Sauria. Lagartos en general.

B. Orden Serpentes. Serpientes, ofidios, culebras.

Debido a la gran cantidad de lagartos y serpientes, no es posible incluír todas las localidades colombianas para no alargar la presente contribución, sino nos referimos a las localidades típicas y a otras en el caso de una amplia distribución dentro del país; no incluímos las localidades típicas situadas en otros países, sino en casos excepcionales, $v$. gr. de una clasificación errónea.

\section{Orden Testudinata.}

Cuerpo dentro de un caparazón (Carapax y Plastron), formado por una capa gruesa ósea, la cual está cubierta por láminas córneas delgadas ; cabeza, cola y las cuatro extremidades retráctiles; sin dientes; maxilar y mandíbulas con cubiertas córneas; ovíparos; terrestres, de agua dulce, y marinas. 
Suborden Cryptodira.

Tortugas de cuello oculto, en las cuales la cabeza se esconde por completo en la concha por medio de una flexión vertical del cuello.

\section{Familia Chelydridae.}

Género Chelydra Schweigger, 1812.

Especie:

1. C. serpentina acutirostris Peters, 1862. "Bache, Guachí, Guáchara”. La longitud de la cola es mayor que la del caparazón en los juveniles, casi igual en los adultos; acuática. Alto Sinú; Litoral del Pacífico; Valle del Cauca hasta alrededor de Armenia.

\section{Familia Kinosternidae.}

Género Kinosternon Spix, 1824.

Especies:

1. K. albogulare Duméril \& Bocourt, 1870. "Swanka, Shangua". Constituye un elemento faunístico centroamericano (Nicaragua y Costa Rica) ; se encuentra solamente en San Andrés, isla, pero no en Providencia, isla, y Santa Catalina, isla.

2. K. dunni K. P. Schmidt, 1947. Terra typica: Puerto Pizarro (Chocó), desembocadura de río Baudó, costa del Pacífico. "Cabeza de trozo"; muy rara y endémica en Colombia; confinada a las hoyas del San Juan y Baudó, probablemente en el Alto Atrato (Medem, 1961 a).

3. K. postinguinale Cope, 1887. "Tapaculo". Lebrija, San Gil; La Mesa (Cund.); Garzón (Huila), $700 \mathrm{~m}$. alt.; Mesa de Cucuana (Tolima), $800 \mathrm{~m}$. alt. Evidentemente representa una especie que vive en áreas de cierta elevación de la vertiente de la Cordillera Oriental hacia el valle del Magdalena; se desconocen los límites de su distribución; no se encuentra en la costa del Caribe y en el Sinú.

4. K. scorpioides scorpioides (Linnaeus), 1766. "Tapaculo", morichelero. Desde los Llanos Orientales del Arauca hasta Florencia (Caquetá) y el Amazonas.

5. K. scorpioides panamense K. P. Schmidt, 1946. "Tapaculo". Hoyas del Magdalena y Sinú; Catatumbo (N. de Sant.).

6. K. spurrelli Boulenger, 1913. "Tapaculo, Morrocoy". Terra typica: Peña Lisa (Chocó), río Condoto, afluente del Alto San Juan. Litoral del Pacífico; Valle del Cauca hasta Sevilla; río Sinú; río Uré (Córdoba), afluente del San Jorge; escasamente en la región de Tolú (Sucre).
Familia Emydidae.

Género Geoemyda Gray, 1834.

Especies:

1. G. annulata (Gray), 1860. "Montañé". Terrestre. Litoral del Pacífico; Valle del Atrato; Alto Uré; río Manso, afluente del Alto Sinú.

2. G. punctularia diademata Mertens, 1954. "Inguensa". En Colombia se encuentra solamente en el Catatumbo.

3. G. punctularia melanosterna (Gray), 1861. Terra typica emendata (Medem, 1962 c, p. 315) : Punta Charambirá (Chocó), delta del río San Juan, Colombia. "Chibiguí, Palmera, Bijaoguera”. Costa del Pacífico; valles del Atrato y Sinú; valle del Magdalena hasta La Girona (Sant.), al E. de Lebrija.

4. G. punctularia nasuta (Boulenger), 1902. "Tortuga blanca, Chibiguí". Litoral del Pacífico; en todos los ríos que se desembocan en el Pacífico; río Quito, afluente del Alto Atrato (Chocó), muy escasa en el río Truandó, afluente del Bajo Atrato.

Género Pseudemys Gray, 1856.

Especies:

1. P. scripta callirostris (Gray), 1855. Terra typica restricta: Río Magdalena, Colombia (L. Müller, 1940).

"Icotea". Hoyas del Magdalena y Sinú; escasamente al E. de Santa Marta hacia la Guajira; posiblemente su distribución geográfica ha sido más extensa durante el último Pluvial, ya que se ha encontrado en el Cerro Chichiriviche, Estado de Falcón, Venezuela (Shreve, 1947).

2. P. scripta ornata (Gray), 1831. "Pecho de Carey”. Acandí (Chocó), río Truandó; Turbo, golfo de Urabá; 1965, se encontraron dos ejemplares en la orilla del mar en Tolú, encima de taruya flotante (Eichornia spec.), una planta de agua dulce que abunda en las ciénagas, posiblemente procedente del Valle del Atrato; uno de ellos murió pronto, el otro vivió varios meses en el criadero de la C. V. M., en Cartagena. Constituye un caso típico de la "migración pasiva", tomando en cuenta la resistencia contra el agua salada y la distancia considerable. Lo mismo se ha observado con cierta frecuencia en las Islas del Rosario (Bolívar), donde se encontraron las "Icoteas", $P$. scripta callirostris, en la Isla Grande, evidentemente procedentes del Canal del Dique.

\section{Familia Testudinidae.}

Género Geochelone Fitzinger, 1836. Especies:

1. G. carbonaria (Spix), 1824. "Morrocoy". En las regiones al Norte de la Cordillera Oriental; 
Suborden Cryptodira.

Tortugas de cuello oculto, en las cuales la cabeza se esconde por completo en la concha por medio de una flexión vertical del cuello.

\section{Familia Chelydridae.}

Género Chelydra Schweigger, 1812.

Especie:

1. C. serpentina acutirostris Peters, 1862. "Bache, Guachí, Guáchara”. La longitud de la cola es mayor que la del caparazón en los juveniles, casi igual en los adultos; acuática. Alto Sinú; Litoral del Pacífico; Valle del Cauca hasta alrededor de Armenia.

\section{Familia Kinosternidae.}

Género Kinosternon Spix, 1824.

Especies:

1. K. albogulare Duméril \& Bocourt, 1870. "Swanka, Shangua". Constituye un elemento faunístico centroamericano (Nicaragua y Costa Rica) ; se encuentra solamente en San Andrés, isla, pero no en Providencia, isla, y Santa Catalina, isla.

2. K. dunni K. P. Schmidt, 1947. Terra typica: Puerto Pizarro (Chocó), desembocadura de río Baudó, costa del Pacífico. "Cabeza de trozo"; muy rara y endémica en Colombia; confinada a las hoyas del San Juan y Baudó, probablemente en el Alto Atrato (Medem, 1961 a).

3. K. postinguinale Cope, 1887. "Tapaculo". Lebrija, San Gil; La Mesa (Cund.); Garzón (Huila), $700 \mathrm{~m}$. alt.; Mesa de Cucuana (Tolima), $800 \mathrm{~m}$. alt. Evidentemente representa una especie que vive en áreas de cierta elevación de la vertiente de la Cordillera Oriental hacia el valle del Magdalena; se desconocen los límites de su distribución; no se encuentra en la costa del Caribe y en el Sinú.

4. K. scorpioides scorpioides (Linnaeus), 1766. "Tapaculo", morichelero. Desde los Llanos Orientales del Arauca hasta Florencia (Caquetá) y el Amazonas.

5. K. scorpioides panamense K. P. Schmidt, 1946. "Tapaculo". Hoyas del Magdalena y Sinú; Catatumbo (N. de Sant.).

6. K. spurrelli Boulenger, 1913. "Tapaculo, Morrocoy". Terra typica: Peña Lisa (Chocó), río Condoto, afluente del Alto San Juan. Litoral del Pacífico; Valle del Cauca hasta Sevilla; río Sinú; río Uré (Córdoba), afluente del San Jorge; escasamente en la región de Tolú (Sucre).
Familia Emydidae.

Género Geoemyda Gray, 1834.

Especies:

1. G. annulata (Gray), 1860. "Montañé". Terrestre. Litoral del Pacífico; Valle del Atrato; Alto Uré; río Manso, afluente del Alto Sinú.

2. G. punctularia diademata Mertens, 1954. "Inguensa". En Colombia se encuentra solamente en el Catatumbo.

3. G. punctularia melanosterna (Gray), 1861. Terra typica emendata (Medem, 1962 c, p. 315) : Punta Charambirá (Chocó), delta del río San Juan, Colombia. "Chibiguí, Palmera, Bijaoguera”. Costa del Pacífico; valles del Atrato y Sinú; valle del Magdalena hasta La Girona (Sant.), al E. de Lebrija.

4. G. punctularia nasuta (Boulenger), 1902. "Tortuga blanca, Chibiguí". Litoral del Pacífico; en todos los ríos que se desembocan en el Pacífico; río Quito, afluente del Alto Atrato (Chocó), muy escasa en el río Truandó, afluente del Bajo Atrato.

Género Pseudemys Gray, 1856.

Especies:

1. P. scripta callirostris (Gray), 1855. Terra typica restricta: Río Magdalena, Colombia (L. Müller, 1940).

"Icotea". Hoyas del Magdalena y Sinú; escasamente al E. de Santa Marta hacia la Guajira; posiblemente su distribución geográfica ha sido más extensa durante el último Pluvial, ya que se ha encontrado en el Cerro Chichiriviche, Estado de Falcón, Venezuela (Shreve, 1947).

2. P. scripta ornata (Gray), 1831. "Pecho de Carey”. Acandí (Chocó), río Truandó; Turbo, golfo de Urabá; 1965, se encontraron dos ejemplares en la orilla del mar en Tolú, encima de taruya flotante (Eichornia spec.), una planta de agua dulce que abunda en las ciénagas, posiblemente procedente del Valle del Atrato; uno de ellos murió pronto, el otro vivió varios meses en el criadero de la C. V. M., en Cartagena. Constituye un caso típico de la "migración pasiva", tomando en cuenta la resistencia contra el agua salada y la distancia considerable. Lo mismo se ha observado con cierta frecuencia en las Islas del Rosario (Bolívar), donde se encontraron las "Icoteas", $P$. scripta callirostris, en la Isla Grande, evidentemente procedentes del Canal del Dique.

\section{Familia Testudinidae.}

Género Geochelone Fitzinger, 1836. Especies:

1. G. carbonaria (Spix), 1824. "Morrocoy". En las regiones al Norte de la Cordillera Oriental; 
valle del Atrato; Providencia, isla; no se encuentra en el litoral del Pacífico.

2. G. denticulata (L.), 1766. "Morrocoy". En las regiones al oriente y sur de la Cordillera Oriental, desde los Llanos Orientales hasta la Amazonia.

Superfamilia Chelonioidea.

Familia Cheloniidae. Tortugas marinas.

Género Caretta Rafinesque, 1814.

Especies:

1. C. caretta caretta (L.), 1758. "Caguamo, Gogó". En el Mar Caribe.

2. C. caretta gigas Deraniyagala, 1939. "Caguama”. En el Océano Pacífico.

Género Chelonia Latreille, 1801.

Especies:

1. C. mydas mydas (L.), 1758. "Tortuga verde, Tortuga blanca". En el Mar Caribe. No anida en Colombia, sino en Costa Rica; ejemplares marcados en la Playa "Tortuguero" han sido encontrados en Cartagena y Riohacha; debido a la persecución continua y no controlada por leyes de protección, está bastante escasa.

2. C. mydas japonica (Thunberg), 1787. En el Océano Pacífico.

Género Eretmochelys Fitzinger, 1843.

Especies:

1. E. imbricata imbricata (L.), 1766. "Carey". En el Mar Caribe; ya muy escaso al oriente de Santa Marta, más frecuente en el golfo de Urabá.

2. E. imbricata bissa (Rüppel), 1835. En el Océano Pacífico.

Género Lepidochelys Fitzinger, 1843.

Especie:

1. L. olivacea kempi (Garman), 1880. Un nombre vulgar no existe en Colombia; un solo ejemplar ha sido encontrado al E de Cartagena (Nicéforo M., 1953) ; L. olivacea kempi es una tortuga marina pronunciadamente migratoria; el centro de su distribución es el golfo de México.

\section{Familia Dermochelidae.}

Género Dermochelys Blainville, 1816. Monotípico. Especie:

1. D. coriacea (L.), 1766. "Tortuga Canal, Barriguda". Representa la tortuga más grande del mundo; su caparazón alcanza la longitud de unos dos metros aproximadamente y el peso comprende hasta una y media toneladas. Anida en la pla- ya de Acandí (Chocó), golfo de Urabá, y al oriente de Santa Marta, entre los ríos Don Diego y Buritacá.

\section{Suborden Pleurodira.}

Tortugas de cuello escondido; esconden la cabeza bajo el borde anterior del caparazón, doblando el cuello hacia un lado.

\section{Género Podocnemis Wagler, 1830.}

Especies:

1. P. dumeriliana (Schweigger), 1812. "Cabezona, Cabezudo". Ríos Guainía (Alto Río Negro) ; Isana y Bajo Inírida (Comisaría Guainía); Vichada; Bajo Caquetá y Putumayo.

2. P. expansa (Schweigger), 1812. "Tortuga, Chapanera". Representa la tortuga de agua dulce más grande del mundo; las dimensiones del carapax y plastron sobrepasan $800 \mathrm{~mm}$. y $600 \mathrm{~mm}$. respectivamente. Hoyas del Orinoco y Amazonas; no existe en los ríos Guayabero-Guaviare, Vaupés y Apaporis, sino se encuentra escasamente en sus desembocaduras, debido a raudales y saltos, los cuales inhiben el acceso.

3. P. lewyana Duméril, 1852. Terra typica: Santafé de Bogotá (sic). Evidentemente procedente del río Magdalena, coleccionada por Bernard Léwy, y luego enviada desde Bogotá al museo de París. Confinada a las hoyas del Magdalena y Sinú (Medem, 1964).

4. P. sextuberculata Cornalia, 1849. "Cupiso, Ayassá". Ríos Amazonas, Bajo Putumayo y Caquetá.

5. P. unifilis Troschel, 1848. "Terecay, Taricayá, Charapa". Hoyas del Orinoco y Amazonas; no existe en los cursos medio y alto del Vaupés y Apaporis debido a los raudales; trasladada por los indígenas al medio Inírida, donde originalmente no existió por la misma causa (Medem, 1964).

6. $P$. vogli L. Müller, 1935. "Galápaga, Sabanera". En los Llanos Orientales del Arauca, Casanare, Meta y Vichada hasta la orilla oriental del Guaviare; muy escasa en el Alto Guayabero.

\section{Familia Chelidae.}

Tortugas de cuello de serpiente; esconden la cabeza o, mejor dicho, solamente la nariz en la piel suelta de la parte anterior del caparazón, dejando el cuello al descubierto.

Género Chelus Duméril, 1806. Monotípico. Especie:

1. C. fimbriatus (Schneider), 1783. "Matamatá, Icotea, Caripatúa”. Hoyas del Orinoco y Amazo- 
nas; antiguamente se encontró a unos $25 \mathrm{kms}$. al S. de Villavicencio y Acacías (Meta).

Género Phrynops Wagler, 1830. Especie:

1. P. geoffroanus tuberosus (Peters), 1870. "Charapa, Matamatá". En los afluentes de los ríos Inírida, Vaupés, Apaporis y Caquetá; río Muco, afluente del Vichada. Se desconoce su presencia en los ríos Guaviare y Putumayo.

Subgénero Batrachemys Stejneger, 1909. Especies:

1. Phrynops (Batrachemys) dahli Zangerl \& Medem, 1958. Terra typica: Sincelejo (Sucre), junio 1956, George Dahl. Confinada a la región entre Sincelejo, San Onofre y Chinú (Córdoba); muy escasa; representa la única especie de la familia Chelidae encontrada en las regiones situadas al N. de la Cordillera Oriental. (Medem, 1966).

2. P. (Batrachemys) nasuta (Schweigger), 1812. "Matamatá". Puerto Nariño (Am.); Lago "El Dorado", Alto Vaupés; región de San José del Guaviare (Vaupés).

Subgénero Mesoclemmys Gray, 1873. Monotípico. Especie:

1. Phrynops (Mesoclemmys) gibba (Schweigger), 1812. "Hedionda". Región entre Villavicencio y Puerto López (Meta) ; Sabana de San Juan de Arama (Meta) ; alrededor de Florencia (Caquetá), Alto Orteguaza.

Género Platemys Wagler, 1830.

Especie:

1. P. platycephala (Schneider), 1792. "Matamatá”. Ríos Amazonas, Apaporis, Caquetá, Alto Orteguaza; río Guamués, afluente del Alto Putumayo, frente a Puerto Asís.

Paleontología.

En Colombia se encontraron tortugas fósiles en los siguientes sitios (Royo y Gómez, 1946; Stirton, 1953; Bürgl, 1961):

1. La Venta, Villavieja (Huila), formación Honda del Mioceno Superior, el sitio más rico en fósiles de vertebrados en el país conocido hasta la fecha.

A) Caparazones casi intactos de Podocnemis expansa.

B) Un caparazón virtualmente entero de Chelus fimbriatus y fragmentos de otros caparazones de la misma especie.
Nota: Ambas no existen hoy en día al norte de la Cordillera Oriental; evidentemente, su distribución se extendió a estas áreas antes de la elevación final de la mencionada Cordillera durante el Plioceno Superior y el Pleistoceno, hace 3 a un millón de años (Medem, 1966).

C) Fragmentos de Emydidae y Testudinidae indeterminados.

2. Tama (Sant.), río Oponcito, a $5 \mathrm{kms}$. al SE. de El Centro, valle del Magdalena; formación Mugrosa del Eoceno Superior.

Fragmentos (caparazones) de tortugas indeterminadas.

3. Chaparral (Tolima); formación Tuné del Oligoceno Inferior. Placas y fragmentos de tortugas grandes indeterminadas.

4. Coyaima (Tolima); formación Honda del Oligoceno Superior. Partes del carapax y plastron de tortugas indeterminadas.

5. Carmen de Apicalá (Tolima); formación Honda del Mioceno Superior. Fragmentos del carapax y plastron de Pelomedusidae indeterminadas.

Fósiles de Testudinidae se conocen desde el $\mathrm{Pa}$ leoceno; Dermochelidae del Eoceno y Chelydridae del Oligoceno (Goin \& Goin, 1962).

En Colombia existen 14 géneros con 36 especies y subespecies de Testudinata, entre ellos 2 terrestres, 25 de agua dulce y de 7 a 8 marinos, lo que comprende una cantidad mayor de tortugas que en los demás países de Centro y Sur América.

\section{Orden Crocodylia.}

Cuerpo dividido en cabeza, tronco y cola; cuatro extremidades; tegumento de placas óseas gruesas cubiertas por láminas córneas delgadas ; maxilares y mandibulares provistos de dientes situados en alvéolos; ovíparos; los juveniles hasta unos 800 milímetros, se alimentan principalmente de insectos acuáticos, moluscos y cangrejos; los ejemplares de tamaño mayor de invertebrados y vertebrados (peces, anfibios, reptiles, aves y mamíferos); son principalmente acuáticos pero muy ágiles en tierra y aptos para caminar a distancias considerables.

\section{Familia Alligatoridae.}

Género Caiman Spix, 1825. Especies:

1. C. sclerops apaporiensis Medem, 1955. Terra typica: Alto Apaporis (Vaupés), entre el raudal Jirijírimo, Soratama y Puerto Yaviya, febrero 18, 1952, F. Medem. Solamente conocido de la localidad típica; $A$. sclerops apaporiensis no se encuentra en los cursos medio y bajo del mismo río. 
2. C. sclerops chiapasius (Bocourt), 1876. "Babilla, Tulisio”. Costa del Pacífico; Isla Gorgona; valle del Atrato; Acandí; Turbo. Originalmente descrito del sur de México y siempre confundido con $C$. sclerops fuscus; constituye, sin embargo, una subespecie válida debido a varias características constantes que la distinguen de la otra subespecie.

3. C. sclerops fuscus (Cope), 1868. Terra typi$c a$ : Río Magdalena, Nueva Granada. "Babilla". Hoyas del Magdalena y Sinú; Catatumbo. Se desconocen los límites de su distribución hacia el occidente, posiblemente existe entre el Sinú y el río Mulatos una zona de intercambio con chiapasius.

Además, existen unas cuatro o cinco populaciones locales o aún, quizá, subespecies genuinas, bien distintas morfológicamente, procedentes de los Llanos Orientales, Guayabero-Guaviare; Alto Vaupés; Caquetá; Putumayo y Amazonas. Una revisión del género Caiman está en preparación, principalmente en relación con estas populaciones locales ("Demes"), con el fin de definir su estado taxonómico.

Género Melanosuchus Gray, 1862. Monotípico. Especie:

1. M. niger (Spix), 1825. “Caimán, Yacaré assú, Jacaré açú". Ríos Amazonas, Putumayo y Caquetá hasta Araracuara; su distribución geográfica y ecología en Colombia han sido estudiadas recientemente (Medem, 1963).

\section{Género Paleosuchus Gray, 1862.} Especies:

1. P. palpebrosus (Cuvier), 1807. "Cachirre, Yacaré coroa”. Principalmente en los caños y ríos de aguas correntosas de la selva del Amazonas y Orinoco; Sierra de La Macarena; no está escaso en los Llanos del Meta y del Vichada.

2. P. trigonatus (Schneider), 1801. "Yacaré coroa, Cachirre". Se encuentra en el mismo habitat como $P$. palpebrosus; La Macarena, norte, río Sansa, afluente del Güejar; río Ocoa (Meta), a unos $10 \mathrm{kms}$. de Villavicencio hacia Puerto López; hacienda "La Libertad" (Meta), a 12 kms. en la misma dirección; Hoya del Amazonas.

Se desconoce la presencia de ambas especies en el Arauca y Casanare. En varios ríos ambos $P a$ leosuchus son simpátricos; en cambio, en otros se encuentra o palpebrosus o trigonatus; se desconocen datos exactos sobre la reproducción de ambos.

\section{Familia Crocodylidae.}

Cocodrilos propiamente dichos.

Es poco conocido que en Colombia existen dos especies de verdaderos cocodrilos. Esto ha causado y todavía causa mucha confusión en la literatura popular por razón de que el término "Caiman" significa el nombre genérico en latín para las "Babillas".

\section{Género Crocodylus Laurenti, 1768.}

Especies:

1. C. acutus Cuvier, 1807. "Caimán". A lo largo del litoral Caribe desde la Guajira hasta el golfo de Urabá; Islas del Rosario (Bol.); Islas de San Bernardo (Sucre) e Islas Fuerte y Tortuguilla (Córdoba); valles del Atrato, Magdalena y Sinú; Catatumbo; costa del Pacífico; pero ausente en las islas Gorgona-Gorgonilla.

2. C. intermedius Graves, 1819. "Caimán". Confinado a la hoya del Orinoco; el límite de su distribución hacia el occidente forma el río Duda (Meta), afluente del Alto Guayabero (Medem, 1958 b).

Ambas especies alcanzan una longitud de unos 23 pies (7.75 metros) ; Alexander von Humboldt y A. Bonpland, 1799, midieron un ejemplar procedente del río Apure, Llanos de Venezuela, que tenía una longitud total de 22 pies con 4 pulgadas.

Debido a la caza comercial no controlada por leyes efectivas de protección de recursos naturales, ambas especies están virtualmente exterminadas y pronto a desaparecer como elementos faunísticos típicos de Colombia.

Existen cuatro géneros con ocho especies y subespecies en el país; además, unas cuatro a cinco populaciones locales ("Demes") distintas. Esto significa una cantidad mayor de crocodilídeos que en todos los demás países sur y centroamericanos. Solamente dos especies suramericanas no se encuentran en Colombia:

$1^{\text {a }}$ Caiman yacare (Daudin), 1802, presente desde el río Paraná (Paraguay) hasta el río Guaporé (Brasil-Bolivia). (Medem, 1960 a).

$2^{\text {a }}$ Caiman latirostris (Daudin), 1802, presente desde el río San Francisco (Brasil); Uruguay; el norte de Argentina y el oriente de Paraguay. En cambio, las dos especies procedentes de la América Central, Caiman sclerops chiapasius y Crocodylus acutus, eran ampliamente distribuídos en el territorio colombiano.

\section{Paleontología.}

Se conocen crocodilídeos fósiles (Archosauria) desde el Triásico Superior; respecto a las familias todavía existentes, los Crocodylidae ya estaban presentes en el Cretáceo Superior y los Gavialidae probablemente desde el Eoceno (Goin \& Goin, 1962).

Varios sitios en Colombia constituyen los más ricos en Crocodilídeos fósiles del Terciario, conocidos hasta la fecha, en la América del Sur. 
Las excavaciones principales han sido llevadas a caho por Royo y Gómez y Henao Londoño de 1941 a 1944; Stirton, Savage, Henao Londoño y Fields en 1949, y Henao Londoño y Savage de 1950 a 1951.

La primera referencia acerca de un hallazgo de un Crocodilídeo fósil ha sido publicada por el Hno. Nicéforo María, 1936 (Anónimo). El cráneo, procedente de El Rodeo (N. de Sant.) y actualmente perdido, pertenece muy probablemente a un ejemplar adulto de Caiman neivensis (Mook), 1941. Langston (1965) hizo una revisión muy completa de los Crocodylia del Terciario suramericano, principalmente a base de los ejemplares excavados en Colombia. Esta obra constituye una contribución básica al conocimiento sobre la taxonomía, paleo-ecología y distribución geográfica de los Eusuchia del Eoceno al Mioceno. Contiene, además, las descripciones de una familia, dos géneros y seis especies nuevas, encontradas en su mayoría en los mismos sitios como los Testudinata.

La Venta (Huila), Mioceno Superior, formación Honda.

1. Sebecosuchia. Familia Sebecidae.

A) Sebecus huilensis, spec. nov.

2. Eusuchia. Familia Gavialidae.

A) Rhamphostomopsis spec.

Nota: En la actualidad, existe un solo representante de los Gavialidae, Gavialis gangeticus (Gmelin), 1799, confinado a la India y Birmania.

Familia Crocodylidae.

Género Charactosuchus, gen. nov.

1. Charactosuchus fieldsi, spec. nov.

Nettosuchidae, fam. nov.

1. Nettosuchus atopus, gen. et spec. nov.

Nota: Se presentó el caso de que esta familia ya ha sido designada por Price (1964), como Mourasuchus y, consecuentemente, hubo la necesidad del cambio del nombre por razones de prioridad (Langston, 1966). Actualmente la designación taxonómica es la siguiente:

Género Mourasuchus Price, 1964.

Especies:

1. M. amazonensis Price, 1964. ¿Plioceno? Río Juruá, Estado do Acre (Brasil).

2. M. atopus (Langston), 1965. Mioceno Superior, La Venta (Huila), Colombia.
La Venta (Huila).

Familia Alligatoridae.

1. Caiman neivensis (Mook), 1941.

2. Caiman spec. (¿lutescens?)(Rovereto), 1912. Alligatoridae, gen. et spec. indet.

Carmen de Apicalá (Tolima), Mioceno Superior, formación Honda.

Eusuchia. Familia Alligatoridae.

1. Eocaiman (¿cavernensis?) Simpson, 1933.

2. Caiman neivensis (Mook), 1941.

Coyaima (Tolima), Oligoceno Superior, formación Honda.

Sebecosuchia. Familia Sececidae.

1. Sebecus spec.

Eusuchia. Familia Gavialidae.

1. Gavialis colombianus, spec. nov.

Crocodylidae, gen. et spec. indet.

Alligatoridae, gen. et spec. indet.

Chaparral (Tolima), Oligoceno Inferior, formación Honda.

Eusuchia. Familia Gavialidae.

Gavialidae, gen. et spec. indet.

Familia Alligatoridae.

1. Balanerodus, gen. nov.

Balanerodus longimus, spec. nov.

2. Alligatoridae, incertae sedis.

Tama (Sant.), río Oponcito, Eoceno Superior, formación Mugrosa.

Sebecosuchia. Familia Sebecidae.

1. Sebecus spec.

Eusuchia.

Crocodylidae, incertae sedis.

Crocodylidae, gen. et spec. indet.

Ortega (Tolima), a $2 \mathrm{kms}$. al sur de la carretera hacia Guamo; Mesozoico ¿Cretáceo Superior? Mesosuchia.

Familia indet.

1. gen. et spec. indet.

2. gen. et spec. indet.

En relación con la evolución de los representantes recientes del género Caiman, Eocaiman cavernensis Simpson, 1933, del Eoceno de Patagonia (Argentina), constituye aparentemente una forma ancestral; es, sobre todo, suficientemente antiguo para que todos los grupos más modernos pudiesen derivarse de este género, v. gr., los géneros Caiman y Melanosuchus; en cambio, el ori- 
gen filogenético de Paleosuchus es desconocido; posiblemente se trata de un grupo muy antiguo pero ya especializado pronto durante el período de su evolución.

Fósiles de Crocodylus acutus e intermedius ambos, aún de formas ancestrales estrechamente relacionadas, son desconocidos del Terciario centro y suramericano; probablemente se trata de una evolución muy reciente o de inmigrantes procedentes de otros continentes; habrían tenido que invadir un habitat con diferentes nichos ecológicos ya ocupados por el género Caiman y otros actualmente extintos y, además, competir con ellos, teniendo en cuenta que los representantes de varios géneros extintos eran por lo menos tan grandes como los cocodrilos recientes.

El hecho que el género Crocodylus no ha invadido el subcontinente suramericaro entero, sino solamente llegó hasta el Orinoco, sustenta la probabilidad de su inmigración durante épocas comparativamente recientes (Langston, 1965).

\section{Superorden SQUAMATA}

Orden Sauria. Lagartos propiamente dichos.

Vertebrados con escamas o placas córneas, derivaciones de la epidermis; cuerpo alargado; normalmente con cuatro extremidades, reducidas 0 ausentes en varios grupos ; órgano copulador (hemipenes) doble y protráctil; mandíbulas soldadas anteriormente; en su mayoría ovíparos, otros ovovivíparos y vivíparos; omnívoros, herbívoros, pero en su mayoría carnívoros; se alimentan principalmente de insectos; terrestres, subterráneos, arborícolas y acuáticos.

\section{Familia Oekkonidae. \\ "Gecos, Salamanquejas, Tuquecos".}

Lagartos pequeños, en su mayoría trepadores; los dedos de ambos pares de extremidades están dilatados por su parte inferior o ventral y contienen láminas transversales o "almohadillas" que consisten básicamente en unas placas, cada una de las cuales lleva una gran cantidad de células microscópicas en forma de gancho, susceptibles de engancharse en la más pequeña irregularidad de cualquier superficie, $v . g r$., aún de vidrio. El funcionamiento de tales almohadillas ha creado muchas confusiones, pero ni la succión ni una substancia pegajosa intervienen en su funcionamiento para adherirse, sino las mencionadas cadenas de ganchos microscópicos (Schmidt \& Inger, 1959, p. 67). Las "salamanquejas" están consideradas como altamente venenosas, una de las numerosas supersticiones populares que aparentemente tienen su origen en el ambiente mediterráneo; en realidad son inofensivas $\mathrm{y}$, sobre todo, prestan un gran servicio en las casas por alimentarse de mosquitos y otros insectos dañinos.
Por esta razón se debe protegerlas efectivamente. Los gecos de sur y centroamérica todos ponen huevos de cáscara dura y resistente debajo de troncos y piedras; son muy resistentes contra el agua salada y eso explica la presencia de muchas especies en islas situadas a considerable distancia de la tierra firme, donde evidentemente llegaron por migración pasiva, v. gr., encima de las cáscaras de árboles flotantes, cocos u otra materia arrastrada por la corriente, como también en embarcaciones.

\section{Género Aristelliger Cope, 1861. \\ Especie:}

1. A. georgeensis (Bocourt), 1873. "Screeching lizard", "screaming lizard". Islas San Andrés y Providencia. Originalmente descrito de Belize, George Island, y presente en varias de las Islas Antillas; posiblemente sinónimo con Aristelliger praesignis (Hallowell), 1856. Todas las especies conocidas son insulares.

Género Gonatodes Fitzinger, 1843.

Gecos de hábitos diurnos y de un marcado dimorfismo sexual; los machos tienen, por lo general, la cabeza de color de herrumbre, la parte dorsal del cuerpo y cola negruzca y la punta de la cola blanca; en cambio, las hembras y juveniles son de color gris claro, salpicado de numerosas manchas oscuras.

Especies:

1. G. albogularis albogularis (Duméril \& Bibron), 1836. Cúcuta; San Gil; Honda; Mariquita ; Viotá (Cund.).

2. G. albogularis fuscus (Hallowell), 1885. Costas del Atlántico y Pacífico; Isla Gorgona; Quibdó; Florencia (Caquetá); Espinal; Gualanday; Medellín; Barrancabermeja. En Honda y San Gil ambas subespecies son simpátricas.

3. G. caudiscutatus (Günther), 1859. Litoral del Pacífico.

4. G. concinnatus (O'Shaughnessy), 1881. Villavicencio (Meta). Los huevos blancos de cáscara dura miden de $7.5 \mathrm{~mm}: 7.00 \mathrm{~mm}$. a $8.5 \mathrm{~mm}$.: 8.0 milímetros y pesan entre $70 \mathrm{mg}$. y $270 \mathrm{mg}$., según el estado de desarrollo embrional; estos datos han sido tomados de 10 a 12 de abril de 1967, en Villavicencio, Sección de Biología Tropical, y comprenden las dimensiones y el peso de 30 huevos.

5. G. vittatus (Lichtenstein \& von Martens), 1856. Río Don Diego (Magd.) ; Riohacha (Guajira). Aparentemente su habitat consiste en zonas semiáridas y áridas. Los machos poseen una línea amarillenta vertebral que corre desde la cabeza hasta la cola, mientras las hembras son de color gris, salpicado con vermiculaciones y manchas pardo-oscuras. Los huevos blancuzcos de cás- 
cara dura se encuentran debajo de la cáscara de cocos en el suelo, en la corteza de las palmas y en varios lugares en el techo de paja de los ranchos; miden de $5.5 \mathrm{~mm}$.: $5.0 \mathrm{~mm}$. a $6.5 \mathrm{~mm}$.: $7.0 \mathrm{milí}-$ metros (Roze, 1964).

Género Hemidactylus Oken, 1817. Especies:

1. H. brooki haitianus Meerwarth, 1901. Litoral del Caribe; Honda; de hábitos nocturnos.

2. H. leightoni Boulenger, 1911. Terra typica: Honda (Tolima), río Magdalena. Solamente conocido del tipo, depositado en el British Museum (Natural History) en Londres; nunca se ha encontrado otro ejemplar.

Nota: La especie presente en Leticia (Am.), Puerto Leguízamo (Putumayo) y Villavicencio no está debidamente clasificada; probablemente se trata de Hemidactylus mabouia (Moreau de Jonnés), 1818, la cual ha llegado en los barcos desde las islas Antillas a las hoyas del Orinoco y Amazonas, un caso muy típico de migración pasiva, común en los Gecos.

Género Lepidoblepharis Peracca, 1897.

Sinónimos: Pseudogonatodes Ruthven, 1915. Latrogecko Ruthven, 1916.

Especies:

1. L. intermedius Boulenger, 1911. Terra typica: Andagoya (Chocó), Alto San Juan, confluencia con el río Condoto. Isla Gorgona.

2. L. peraccae Boulenger, 1908. Terra typica: Los Mangos (Valle), entre Buenaventura y El Pilón.

3. L. muthveni Parker, 1926. Isla Gorgona (Cauca), norte, represa, $45 \mathrm{~m}$. alt., febrero 10, 1961, F. Medem, entre hojarasca en el suelo, junto con L. intermedius, en el monte.

Es el primer registro de esta especie, conocida del Ecuador, para Colombia (Uzzell, 1963, in. litt.) ; (ICN Nos. 653, 657, 658).

4. L. sanctae-martae sanctae-martae (Ruthven), 1916. Terra typica: Fundación (Magd.), $62 \mathrm{~m}$. alt. Bonda (Magd.), vecindad de Santa Marta; hacienda "La Aguada" (Sucre), golfo de Morrosquillo, al E. de Tolú; Caño Juí, Tierra Alta (Córdoba), Alto Sinú, agosto 2, 1965, Carlos A. Velásquez.

Comprende una especie selvícola y diurna; existe un marcado dimorfismo sexual; los machos tienen la parte dorsal de la cabeza negra, bordeada por una zona lateral amarillenta a cada lado. Son lagartos diminutos: los machos miden hasta unos 25 milímetros y las hembras hasta 32 milímetros aproximadamente. En cautividad, mantenidos fácilmente con Drosophila, ponen un solo huevo, blanco, de cáscara dura, en el suelo, debajo de hojarasca. Tres huevos puestos en marzo 16, marzo 23 y abril 11, 1966, midieron 4.5: $4.0 \mathrm{~mm}$.; 5.0: $4.5 \mathrm{~mm}$., y $5.0: 4.0 \mathrm{~mm}$., respectivamente. Un ejemplar nacido en marzo 23, 1966, desapareció el 25 del mes en curso, posiblemente devorado por uno de los adultos.

5. L. xantostigma (Noble), 1926. Terra typica: vecindad de Puerto Limón, Costa Rica. Sinónimo: L. microlepis (Noble), 1923, fide Burt \& Burt, (1931, p. 248; 1933, p. 6). Terra typica: "Río Quesada" o "Quesado", Atrato. Terra typica emendata: Ciénaga de Quesada (Ant.), unos 4 $\mathrm{kms}$. al sur de Murindó, Bajo Atrato; $7^{\circ} \mathrm{N} 76^{\circ} 45^{\prime}$ W, según Amer. Geogr. Soc., New York, Mapa, 1945, Bogotá - NB 18 (Medem, 1965, p. 343).

Género Lepidodactylus Fitzinger, 1843. Especie:

1. L. lugubris (Duméril \& Bibron), 1836. Terra typica: O'Taití, Polinesia, Océano Pacífico Occidental. Encontrado alrededor de Buenaventura (Valle), 1965, Kraig K. Adler (septiembre 3, 1967, in litt.). Evidentemente ha llegado en barcos desde las islas polinesias y se ha establecido en Colombia. Constituye un caso típico de la migración pasiva.

Género Phyllodactylus Gray, 1830.

Especies:

1. P. pulcher Gray, 1830. Al E. de Santa Marta; Guajira.

2. $P$. ventralis O'Shaughnessy, 1875 . En las zonas semiáridas y áridas de la costa del Caribe, Santa Marta, Bonda (Magd.).

Género Sphaerodactylus Wagler, 1830.

Especies:

1. S. argus andresensis Dunn \& Saxe, 1950. Terra typica: San Andrés, isla.

2. S. lineolatus Lichtenstein \& von Martens, 1856. Acandí (Chocó), golfo de Urabá; Tolú ; Cartagena, Barrio Bocagrande.

3. S. molei Boettger, 1894. Nordeste del litoral del Caribe (Dunn, 1944 j, p. 87).

4. S. scapularis Boulenger, 1902. Costa del Pacífico; Isla Gorgona.

Género Thecadactylus Oken, 1817. Monotípico. Especie:

1. T. rapicaudus (Houttuyn), 1782. En las costas del Atlántico y Pacífico; Isla Gorgona, norte, represa; valles del Magdalena y Sinú; Cúcuta; Catatumbo.

No observado en los Llanos Orientales y en el Vaupés. De hábitos nocturnos; comprende la es- 
pecie de tamaño mayor en el país, crece normalmente unos 150 milímetros de largo total, pero alcanza una longitud de unos 250 milímetros, en contraste con los géneros Lepidoblepharis y Sphaerodactylus que solamente crecen a unos 30 y 32 milímetros respectivamente.

$T$. rapicaudus es muy útil en las casas por razón de que se alimenta de insectos nocivos grandes, $v$. gr., cucarachas, grillos y aun alacranes; comen también arañas, cucarrones, pequeños caracoles (Mollusca), y, posiblemente, otros “Gecos", ya que hemos observado repetidas veces que persiguieron jóvenes de Hemidactylus brooki haitianus.

Actualmente está invadiendo paulatinamente las regiones a lo largo de las costas de Venezuela, las Guayanas y Brasil, y las hoyas del Orinoco y Amazonas; debido a su gran tamaño es un competidor eficiente y desplaza gradualmente varias especies nativas que ocupan el mismo habitat. (Roze, 1964, Mem. Soc. Ci. Nat. La Salle, Vol. 24, No 69, pp. 232-233, Caracas).

\section{Familia Iguanidae.}

Lagartos que comprenden la mayoría de las especies representativas suramericanas. Lengua carnosa, no protráctil; ovíparos. El género $A m$ blyrhynchus, confinado a las Islas de los Galápagos (Ecuador), es marino.

Género Anolis Daudin, 1802.

Lagartos arborícolas y terrestres; existe un dimorfismo sexual muy pronunciado: el saco gular de los machos es más desarrollado que el de las hembras, y, cuando lo inflan, tiene colores vivos (rojo, morado, azul, verde y blanco), según la especie. La costa del Pacífico y el Chocó constituyen una de las áreas principales para la evolución y dispersión del género Anolis.

Especies:

1. A. antonii Boulenger, 1908. Terra typica: Hacienda San Antonio (Valle), 1850 - 2200 metros alt., al occidente de Cali y a $17 \mathrm{kms}$. sobre la vertiente oriental de la Cordillera Occidental.

Mariquita (Tolima); Valle del Magdalena (ICN No 772$)$.

2. A. apollinaris Boulenger, 1919. Terra typica: alrededor de Bogotá. Terra typica emendata (Dunn, 1944 a, p. 25): Paime (Cund.), 1038 m. alt.

3. A. auratus Daudin, 1802. Sinónimos: Norops auratus (Wagler), 1830, fide Williams (1964, in litt.) ; Anolis rosenbergi Boulenger, 1896, Buenaventura. Es la especie más abundante al norte de la Cordillera Oriental; se desconocen los límites de su distribución hacia el sur-occidente; probablemente no existe en la región selvática.
4. A. biporcatus biporcatus (Wiegmann), 1834. Sinónimo: Anolis solifer Ruthven, 1916, La Concepción, Sierra Nevada de Santa Marta (Magd.), Sincelejo.

5. A. biporcatus parvauritus Williams, 1966. Holotypus: MCZ, $\mathrm{N}^{0}$ 78935. Terra typica: Isla Gorgona, norte, plantación de plátano y monte, febrero 1, 1961, F. Medem y Luis Salazar García; macho. Ríos Rosario y Mataje (Nariño), costa del Pacífico, marzo 1962, Gerardo Reichel-Dolmatoff.

6. A. breviceps Boulenger, 1913. Terra typica: Peña Lisa, Condoto (Chocó), 70-100 m. alt.

Nota: Peters $(1959$, p. 119) considera A. breviceps como sinónimo de Anolis granuliceps Boulenger, 1898, Parambá, Ecuador.

7. A. chloris Boulenger, 1898. Río Dubasa, afluente del Baudó (Chocó) ; Primavera (Chocó), Alto San Juan; río Calima (Valle), afluente del San Juan; Isla Gorgona; río Uré (Córdoba), afluente del Alto San Jorge, hoya del Magdalena.

8. A. concolor Cope, 1862. Sinónimo: Anolis pinchoti Cochran, 1931. Terra typica: Providencia, isla.

Nota: Dunn \& Saxe (1950, p. 152), comprobaron que existe una diferencia constante acerca de la longitud cabeza-cuerpo entre las populaciones de San Andrés, isla ( $75 \mathrm{~mm}$.) y de Providencia y Santa Catalina, islas $(50 \mathrm{~mm}$.). A pesar de que no se debe aplicar la longitud como carácter sistemático solo, sino en combinación con otros caracteres constantes, con cierto escepticismo, quizás, se pudiera considerar estas dos poblaciones tentativamente como subespecies válidas y denominarlas en la siguiente forma: Anolis concolor concolor Cope, 1862. Nicaragua, San Andrés, isla. Anolis concolor pinchoti Cochran, 1931. Islas Providencia y Santa Catalina.

9. A. eulaemus Boulenger, 1908. Terra typica: Pavas (Valle), $1600 \mathrm{~m}$. alt. aproximadamente, al NE de La Cumbre, Cordillera Occidental.

10. A. fasciatus Boulenger, 1885. Bajo Calima (Valle), campamento "Cartón de Colombia".

11. A. fraseri Günther, 1859. Costa del Pacífico, sin Jocalidad exacta; Buenaventura; Jamundí (Cauca) ; El Tambo (Cauca).

12. A. frenatus Cope, 1899. Terra typica: Bogotá (sic). Pueblorrico (Caldas), $1516 \mathrm{~m}$. alt.; El Centro (Sant.), 150 m. alt.; San Gil (Sant.), 1095 m. alt.; Muzo (Boyacá), 824 m. alt.

13. A. fusco-auratus D'Orbigny, 1837. Caño Guapayita (Meta), La Macarena, norte, $400 \mathrm{~m}$. alt., enero 1951, F. Medem; Finca "El Refugio" (actualmente el pueblo "La Macarena"), Alto Guayabero, $300 \mathrm{~m}$. alt., frente a La Macarena.

14. A. gorgonae Barbour, 1905. Terra typica: Isla Gorgona. 
15. A. granuliceps Boulenger, 1898. Costa del Pacífico.

16. A. incompertus Barbour, 1932. Terra typica: Villavicencio, territorio de San Martín (Meta), enero 1931, Nicéforo M.

17. A. jacare Boulenger, 1903. Terra typica: Mérida (Venezuela). Un solo ejemplar procedente de Tapatá (N. de Sant.), USNM, No 72745, fide Burt \& Burt (1930, p. 8).

18. A. latifrons Berthold, 1846. Terra typica: Provincia de Popayán, Nueva Granada. Ciénaga de Quesada, Bajo Atrato, fide Burt \& Burt, (1931, p. 259). Isla Gorgona; Buenaventura; Bajo Calima; Turbo (Ant.), golfo de Urabá.

19. A. lemniscatus Boulenger, 1898. Isla Gorgona.

20. A. lemurinus Cope, 1861. Sinónimo: A. vittigerus Cope, 1862 , río Truandó, afluente del Bajo Atrato. Bajo Calima.

21. A. leptocelis Boulenger, 1885. Campamento "Soratama" (Vaupés), Alto Apaporis, marzo 1952, F. Medem.

22. A. lionotus Cope, 1861 . Boca de Raspadura (Chocó), entre el río Quito y Alto San Juan.

23. A. macrolepis Boulenger, 1911. Terra typica: Nóvita, río Tamaná, afluente del Alto San Juan (Chocó), $70 \mathrm{~m}$. alt.

24. A. maculiventris Boulenger, 1898. Primavera (Chocó), Alto San Juan; desembocadura del río Dubasa (Chocó), afluente del Baudó.

25. A. mariarum Barbour, 1932. Terra typica: Sampedro (Ant.), a $45 \mathrm{kms}$. al N. de Medellín.

26. A. mirus Williams, 1963. Terra typica: Río San Juan (Chocó), sin localidad exacta, 1910, M. G. Palmer.

27. A. notopholis Boulenger, 1896. Terra typica: Buenaventura (Valle). Río Dubasa (Chocó).

28. A. palmeri Boulenger, 1908. Terra typica: Los Mangos (Valle), entre Buenaventura y El Pilón, a $12 \mathrm{kms}$. en la carretera hacia Cali.

29. A. pentaprion Cope, 1862. Terra typica: Río Truandó, afluente del Bajo Atrato.

30. A. poecilopus Cope, 1862. Terra typica: Colombia, sin localidad exacta.

31. A. princeps Boulenger, 1902. Terra typica: Colombia, sin localidad exacta. El Centro (Sant.), valle del Magdalena.

32. A. purpurescens Cope, 1899. Terra typica: Río Truandó; únicamente conocido de la localidad típica.

33. A. scypheus Cope, 1864. Villavicencio (Meta), 498 m. alt.; Puerto López, Alto Meta; "El Refugio" (= La Macarena), Alto Guayabero.
34. A. solitarius Ruthven, 1916. Terra typica: San Lorenzo (Magd.), Sierra Nevada de Santa Marta.

35. A. sulcifrons Cope, 1899. Terra typica: Bogotá (sic). Andagoya (Chocó), Alto San Juan; Mariquita (Tolima), fide Dunn, 1944 a, p. 91.

36. A. tolimensis Werner, 1916. Terra typica: Cañón del Tolima, arriba de Ibagué, $1700 \mathrm{~m}$. alt.

37. A. tropidogaster (Hallowell), 1856. Terra typica: Colombia, sin localidad exacta. Sinónimos: Anolis albi Barbour, 1932, Andagoya; A. incompertus nicefori Barbour, 1932, Humbo (= Muzo) ; $A$. radulinus Cope, 1862 , río Truandó; $A$. stigmosus Bocourt, 1869, río Magdalena (fide Williams, 1964, in. litt.).

38. A. ventrimaculatus Boulenger, 1911. Terra typica: Río San Juan (Chocó). Boca de Raspadura (Chocó), "Río Quesada" (= Ciénaga de Quesada), fide Burt \& Burt (1931, p. 263).

Nota: Ernest E. Williams está preparando una revisión total del género Anolis.

\section{Género Basiliscus Laurenti, 1768. \\ Especies:}

1. B. basiliscus basiliscus (L.), 1758. "Saltarroyo, Guataco". Hoyas del Magdalena y Sinú; hasta el Alto Uré (Córdoba), afluente del San Jorge, y río Manso (Córdoba), afluente del Alto Sinú. Pto. Berrío; Tocaima (Cund.) ; Honda; Melgar (Tolima); Valle del Atrato; Boca de Raspadura; Alto San Juan.

Nota: En las áreas de los ríos Uré y Manso, es simpátrico con $B$. galeritus; constituye, sin embargo, la especie dominante, debido a su abundancia mayor; en el Alto San Juan y Boca de Raspadura, ambas especies son, igualmente, coexistentes, pero, al parecer, $B$. galeritus es más abundante.

2. B. basiliscus barbouri Ruthven, 1914. Terra typica: Río Gaira (Magd.). Minca, San Lorenzo, 600 m. alt. ; Río Hacha (Guajira) ; Ciénaga Grande (Magd.) ; Tibú y Caño Seis, Catatumbo (N. de Sant.).

3. B. galeritus Duméril, 1851. Terra typica: Nueva Granada. Sinónimo: B. galeritus seemanni (Gray), 1852. Terra typica: Isla Coiba, Panamá. Terra typica emendata (Medem, 1965, p. 315): Quibdó (Chocó), Alto Atrato, Colombia.

"Cucurucho, Guachoró, Sandoró". Chocó, ríos Baudó y San Juan; costa del Pacífico hasta la región de Tumaco y río Curay (Nariño) ; Isla Gorgona; Valle del Magdalena (Melgar; El Centro; Muzo) ; Lebrija (Sant.), 1140 m. alt.; La Girona (Sant.), al E de Lebrija. 
Género Corythophanes Boie, 1826. Monotípico. Especie:

1. C. cristatus (Merrem), 1820. Especie arborícola y muy escasa. Manta (Cund.), $33 \mathrm{kms}$. arriba de Puerto Salgar, río Magdalena, abril 15, 1960, Horst Schimmer y Ernesto Osorno Mesa (ICN No 1044); Muzo, Andagoya.

Género Ctenosaura Wiegmann, 1828.

Especie:

1. C. similis (Gray), 1831. Sinónimo: C. similis multipunctata Barbour \& Shreve, 1934, Isla Providencia.

Islas San Andrés, Providencia y Santa Catalina; constituye un elemento faunístico de la América Central.

Género Enyalioides Boulenger, 1885. Especies:

1. E. heterolepis (Bocourt), 1874. Sinónimo: $E$. insulae Barbour, 1905. Costa del Pacífico; Alto San Juan; especialmente abunda en el norte de la Isla Gorgona. Su habitat consiste en la zona montañosa de 30 a 90 metros de altura; se encuentra hasta unos 150 metros pero escasamente; igualmente poco abundante en la parte sur-occidental de la Isla Gorgona, frente a la Gorgonilla, donde el monte es notablemente más húmedo ; principalmente terrestre y nunca ha sido observado en los arbustos o árboles de más de un metro de altura; viven en huecos de árboles podridos en el suelo o excavan huecos profundos en la tierra, preferiblemente cerca de las raíces de los árboles gruesos; se alimentan de insectos.

2. E. laticeps laticeps (Guichenot), 1855. Pto. Nariño (Am.); La Pedrera (Am.); Amanavén (Guainía), desembocadura del río Guaviare, agosto 1951, Leopold Richter (ICN, N9 839).

3. E. laticeps festae Peracca, 1897. Río Guamués, afluente del Alto Putumayo, frente a Puerto Asís; Villavicencio.

Género Iguana Laurenti, 1768.

Especie:

1. I. iguana iguana (L.), 1758. "Iguana". Común en las zonas tropicales del país, especialmente en el valle del Magdalena.

Género Leiocephalus Gray, 1827.

Especies:

1. L. erythrogaster (Hallowell), 1856. Terra typica: Nueva Granada. Especie rara y, evidentemente, confinada a la Sierra Nevada de Santa Marta. Río Toribio (Magd.), hacienda "Papare", carretera entre Ciénaga y Santa Marta, julio 21,
1964, F. Medem, en el monte húmedo cerca del río, en el suelo dentro de la hojarasca seca de guaduas; hembra. Debido a su color muy parecido a las hojas secas, estuvo virtualmente invisible, sobre todo, como no trató de escapar sino se quedó inmóvil. Otras localidades: Bolívar, hacienda al occidente de Santa Marta hacia Minca; Tucurinca; Valencia, situadas dentro del mismo habitat (Ruthven, 1922).

2. L. ornatus trachycephalus (Duméril), 1851. Terra typica: Santa Fe de Bogotá, Nueva Granada. El "Collarejo" es común en la Sabana de Bogotá; Gutiérrez (Cund.); Facatativá; Muzo.

\section{Género Mariguana Dunn, 1939 Monotípico.}

Especie:

1. $M$. agassizii (Stejneger), 1900. Confinada a la Isla Malpelo, Pacífico.

Género Phenacosaurus Barbour, 1920.

Especies:

1. P. heterodermus (Duméril), 1851. Terra typica: Nueva Granada. Sabana de Bogotá. Parecido a los Anolis; arborícola, se encuentra encima de arbustos y rastrojo, pero también en el suelo. Páramos de Chipaque y Cruz Verde; Soatá (Boyacá); región del Lago de Tota (Boyacá).

2. P. nicefori Dunn, 1944. Terra typica: Pamplona (N. de Sant.), 2340 m. alt., Nicéforo M. Conocido solamente de la localidad típica, lo que no quiere decir que no tenga una distribución más amplia.

3. $P$. richteri Dunn, 1944. Terra typica: Tabio (Cund.), Sabana de Bogotá, Leopold Richter. Simpátrico con heterodermus en la Sabana de Bogotá; Fusagasugá (Cund.); El Delirio (Ant.), $3100 \mathrm{~m}$. alt.; arriba de Medellín; Laguneta, Sonsón, San Pedro (Ant.).

Nota: Williams (1962, comunicación personal) pone en duda la validez de $P$. richteri debido a ciertas características específicas no constantes.

Género Plica Gray, 1831. Especie:

1. P. plica (L.), 1758. Río Apaporis (Vaupés), raudal de Jirijírimo, raudal "El Engaño"; Alto Inírida, Cerro de Las Pinturas o Lindosa; río Guayabero (Meta), Angostura No 1, Angostura No 2 (Cerro de las Pinturas); mesetas áridas de La Macarena, sur, Alto Guayabero; Puerto Carreño (Vichada), su habitat consiste en las vertientes de las mesetas áridas de la formación Roraima (Guiana Shield) del Cretáceo y en el monte seco alrededor de ellas. Ponen dos huevos grandes y alargados en enero y febrero; se alimentan de insectos. 
Género Polychrus Cuvier, 1817.

Especies:

1. P. gutturosus Berthold, 1946. Terra typica: Provincia de Popayán, Nueva Granada. Valle del Magdalena.

2. P. spurrelli Boulenger, 1914. Terra typica: Peña Lisa (Chocó), río Condoto. Costa del Pacífico; valle del Atrato.

Nota: Parker (1935, p. 516) considera spurelli como subespecie de gutturosus; Peters (1959, p. 120 ), igualmente, adapta este punto de vista, y escribe $P$. gutturosus spurrelli.

3. P. marmoratus marmoratus (L.), 1758. "Camaleón". Llanos Orientales del Meta; hoya del Amazonas; según Dunn (1944 j, p. 93), también en el litoral del Caribe; no confirmado hasta la fecha.

Género Tropidodactylus Boulenger, 1885. Monotípico.

Especie:

1. T. ónça (O'Shaughnessy), 1875. "Jacóiva" en el idioma Guajiro; Península de la Guajira.

Género Tropidurus Wied, 1824.

Especie:

1. T. torquatus hispidus (Spix), 1825. "Tuteque". No era conocido de Colombia, sino de Venezuela (Isla Margarita, etc.), según Roze (1964, p. 235). Durante la expedición de la Sección de Biología Tropical al Orinoco, de diciembre 1-9, 1967, se coleccionaron unos 32 ejemplares de ambos sexos en la región de Puerto Carreño (Vichada). Su habitat consiste en el área rocosa donde es abundante; también se observaron ejemplares adultos pero principalmente juveniles encima del rastrojo. Los machos crecen hasta unos 300 milímetros; ocupan un territorio definido que vigilan desde un punto elevado y defienden contra los invasores de la misma especie y otras. Es simpátrico con el "Cangasapo", Plica plica, pero el nicho ecológico de ambos es algo distinto; mientras Tropidurus se encuentra principalmente encima de las rocas mismas, Plica plica, que es menos abundante, ha sido coleccionado encima de arbustos y árboles de la misma región; a pesar de esto existe posiblemente una competencia inter-específica. También en Pto. Inírida (Guainía).

Género Uranoscodon Kaup, 1826. Monotípico. Especie:

1. U. superciliosum (L.), 1758. Gino-Gojé (Am.), campamento cauchero a dos horas arriba de la desembocadura del río Pirá - Paraná, afluente del Bajo Apaporis; construído en 1952 y lue- go abandonado; agosto 7, 1957, el sitio era cubierto por arbustos y escasamente discernible como lugar antes habitado; constituye la localidad típica para varias especies de plantas, coleccionadas en 1952 por Richard Evans Schultes, Hernando García Barriga e Isidoro Cabrera (ICN, No 828 , abril 10, 1952, I. Cabrera), Amanavén (Guainía), agosto 1951, L. Richter (ICN, No 839). Caño "Veinte" (= Caño Guapayita), La Macarena, norte, $400 \mathrm{~m}$. alt., febrero 23, 1962, Hugo Arévalo, en un bejuco unos tres metros de altura, subiendo; (ICN No 677).

Género Urocentron Kaup, 1827. Sinónimos: Uracentron Kaup, 1827.Urocentrum Wiegmann, 1835. Urocentron Fitzinger, 1843.

Especies:

1. U. castor Cope, 1870. Caucayá (= Puerto Leguízamo), río Putumayo, noviembre 1948, Roberto Jaramillo (ICN No 606). Río Guamués, Santa Rosa de los Kofanes (Putumayo), Hervé Le Nestour.

2. U. werneri Mertens, 1925. Amanavén (Guainía), agosto 1951, L. Richter; (ICN No 604). Cerro Yapobodá (Vaupés), región del Alto Cuduyarí, afluente del Vaupés, octubre 5, 1951, I. Cabrera; (ICN No 603). Sabana del Cubiyú (Vaupés), 300-400 m. alt., caño Cubiyú, afluente del Vaupés, 5 horas arriba de Mitú, junio 29, 1958. Pablo Bernal; (ICN No 605). Finca "El Refugio" (= La Macarena), Alto Guayabero, frente a la Sierra de La Macarena (Valdivieso \& Tamsitt, 1963 a).

Ambas especies son escasas; poseen una cola corta, plana y cubierta de numerosas pequeñas espinas, posiblemente una adaptación a la vida arborícola; el habitat de $U$. castor consiste en la selva tropical; en cambio, $U$. werneri se ha encontrado en el monte alrededor de las mesetas áridas de la formación Roraima, trepando encima de arbustos y en la corteza de árboles; el ejemplar registrado por Valdivieso \& Tamsitt es, indudablemente, procedente de la vertiente sur de La Macarena, según el habitat, donde también se encuentra Plica plica como ya mencionado. Posiblemente no existe una competencia entre ambas especies por razón de que U. werneri es arborícola, mientras el nicho ecológico de $P$. plica consiste en un terreno rocoso.

\section{Familia Scincidae.}

Comprende lagartos de cuerpo cilíndrico y de cola puntiaguda; cabeza cónica y corta; con cuatro, dos y aun sin extremidades; el escamado formado por escamas superpuestas, pequeñas y lisas que suelen tener un aspecto brillante; de tamaño hasta unos 250 milímetros; terrestres y subterráneos; se desconoce datos sobre su reproducción. 
Género Mabuya Fitzinger, 1826.

Fispecies:

1. M. mabouya mabouya (Lacepéde), 1788. "Lisa". Común en todas las zonas tropicales del país; vive generalmente en pares.

2. M. mabouya pergravis Barbour, 1921. Terra typica: Providencia, isla. Conocida solamente de la localidad típica.

\section{Familia Teiidae.}

Lagartos característicos del Nuevo Mundo, muy parecidos a los Lacertidae de Eurasia y Africa. Se distinguen por las siguientes características anatómicas de estos últimos: carecen de dientes con bases huecas, mientras los Lacértidos los tienen. Las escamas córneas de la piel que cubren la cabeza, están separadas de los huesos del cráneo, mientras en los Lacértidos están unidas (Schmidt \& Inger, 1959). Usualmente de cuerpo alargado con cuatro extremidades; en las formas subterráneas reducidas o ausentes; lengua bífida y retráctil; ovíparos; terrestres, subterráneos y semiacuáticos. Se alimentan principalmente de insectos, ranas, otros lagartos, pequeñas aves y roedores, pero también de frutas y hojas; un género, Dracaena, es semiacuático y especializado de alimentarse de moluscos de agua dulce y posee dientes grandes y planos, adaptados para aplastar las conchas duras de los caracoles.

Género Ameiva Meyer, 1795.

Especies:

1. A. ameiva ameiva (L.), 1758. "Lobito, Mato". Hoyas del Orinoco y Amazonas.

2. A. ameiva fuliginosa (Cope), 1892. Sinónimo: A. planchora Barbour, 1921, Isla Providencia.

3. A. ameiva praesignis (Baird \& Girard), 1852. Bajo Atrato; Acandí (Chocó) ; río Sinú; Alto Uré (Córdoba) ; Honda; Medellín; La Girona (Sant.) ; Caño Seis, $15-20$ kms. al N. de Tibú, Catatumbo (N. de Sant.) ; Navarro (Valle), $10 \mathrm{kms}$. SE. de Cali, 980 m. alt. (Kraig Adler, septiembre 3, 1967, in litt.).

4. A. bifrontata bifrontata Cope, 1862. Costa del Caribe, especialmente entre Ciénaga, Santa Marta y Riohacha. Los machos crecen hasta 921 $\mathrm{mm}$.; en la región de Santa Marta se encuentran híbridos entre $A$. bifrontata bifrontata y $A$. bifrontata divisa.

5. A. bifrontata divisa (Fischer), 1879. Terra typica: Barranquilla, Nueva Granada. Hoya del Magdalena; se desconocen los límites de su distribución geográfica. En la región del Canal del Di- que, Ciénaga de Amajahuevo (Bol.), Estación de Piscicultura de la C.V.M., frente a San Cristóbal, es simpátrico con $A$. ameiva praesignis.

6. A. bridgesii Cope, 1868. Islas Gorgona y Gorgonilla (Cauca); Tumaco (Nariño); río Curay (Nariño), al N. de Tumaco; río Raposo (Valle), al S. de Buenaventura. Esta especie ha sido confundida frecuentemente con $A$. septemlineata.

7. A. festiva festiva Lichtenstein \& von Martens, 1856. Hoyas del Orinoco y Amazonas. Es simpátrico con $A$. ameiva ameiva, pero su nicho ecológico es distinto: prefiere los lugares no expuestos al sol dentro de la selva tropical, $v . g r$., la vecindad de los caños, rastrojo tupido y árboles caídos. En el sur de La Macarena, 1959, se observó $A$. festiva festiva únicamente en el monte, en cambio, A. ameiva ameiva cazaba su presa en la orilla del río Guayabero, igual a Cnemidophorus lemniscatus.

8. A. festiva niceforoi Dunn, 1943. Terra typica: Sasaima (Cund.), 1200 m. alt., 75 noroeste de Bogotá. Se desconocen los límites de su distribución.

9. A. festiva occidentalis Taylor, 1956. Los ejemplares coleccionados en el Alto Uré, afluente del San Jorge, 1963, poseen las características de occidentalis (Medem, 1965, p. 337), originalmente descrita de Costa Rica.

10. A. petersi Cope, 1868. Leticia y Puerto Nariño (Am.).

11. A. septemlineata Duméril, 1851. Andagoya, río San Juan, donde es simpátrico con $A$. festiva (ioccidentalis?), según Dunn (1944 j, p. 101). Boca de Raspadura y río Puné, afluente del Atrato, fide Burt \& Burt (1931, p. 311). Se desconocen los límites de su distribución; posiblemente es simpátrico con $A$. bridgesii en la costa del $\mathrm{Pa}$ cífico; ambas especies se encuentran en la costa del Pacífico ecuatoriano (Peters, 1964. Bull. Southern Cal. Acad. Sci., Vol. 63, part. 3). Respecto a la taxonomía y nomenclatura, el género Ameiva está en un estado de alta confusión y necesita urgentemente una revisión total.

Género Anadia Gray, 1845.

Lagartos pequeños, pronunciadamente alargados en algunas formas, y con extremidades reducidas; principalmente subterráneos; ovíparos.

Especies:

1. A. angusticeps Parker, 1926. Terra typica: Isla Gorgona.

Nota: Un ejemplar (ICN No 649), isla Gorgona, norte, colonia penal, febrero 14, 1961, F. Medem. Capturado a las 11.00 a.m., en el suelo; color dorsalmente carmelita claro, ventralmente blanco; trepa con gran agilidad encima de ramas delgadas y pasto alto en búsqueda de pequeños grillos (Orthoptera), de los cuales se alimentó en 
cautividad; diurno y, evidentemente, no subterráneo; vivía en cautividad hasta marzo 11, 1961, y murió en Bogotá.

2. A. bogotensis (Peters), 1862. Terra typica: Santa Fe de Bogotá. Bastante frecuente en los cerros arriba de Bogotá; Gutiérrez; Muzo; Lago de Tota.

3. A. ocellata Gray, 1845. Unicamente conocido de Jericó (Ant.), 1760 m. alt., fide Burt \& Burt, (1932, p. 213).

4. A. pamplonensis Dunn, 1944. Terra typica: Pamplona (N. de Sant.).

5. A. pulchella Ruthven, 1926. Terra typica: La Cumbre, hacienda "Vista Nieve", 2100 m. alt., Sierra Nevada de Santa Marta, octubre 1925, M. A. Carriker, Jr., en una Bromeliácea.

6. A. vittata Boulenger, 1913. Terra typica: $\mathrm{Pe}-$ ña Lisa, Condoto. Región entre Buenaventura y el Bajo Calima, campamento "Cartón de Colombia", mayo 5, 1960, Isidoro Cabrera (ICN Nos. $663,664)$.

Género Argalia Gray, 1846. Monotípico. Especie:

1. A. marmorata Gray, 1846. Terra typica: “Columbia" (sic), sin localidad exacta. Se desconocen la distribución y el habitat, que yo sepa.

Género Arthrosaura Boulenger, 1885.

Especie:

1. A. reticulata (O'Shaughnessy), 1881. Puerto Asís (Putumayo), finca "La Cocha", octubre 21, 1958, F. Medem, en la selva húmeda debajo de un árbol caído (ICN No 618). Río Cananarí, afluente del Apaporis, arriba del raudal de Jirijírimo (Vaupés), enero 1952, I. Cabrera (ICN No 619). Alto Apaporis, agosto 1951, I. Cabrera (ICN No 646).

Género Bachia Gray, 1845.

Lagartos pequeños de cuerpo vermiforme; extremidades muy reducidas; subterráneos; considerados como venenosos en varias regiones del país, son, naturalmente, inofensivos; se desconocen datos sobre su reproducción.

Especies:

1. B. bicolor (Cope), 1896. Terra typica: Bogotá (sic). Alrededor de Mariquita, $535 \mathrm{~m}$. alt., agosto 5, 1961, Horst Schimmer y Hermann Duplat, debajo de piedras (ICN No 1043). Bonda (Magd.); Cartagena, Barrio Manga y Jardín Zoológico; Canal del Dique (Bol.), alrededor de la Estación de Piscicultura de la C. V. M., frente a San Cristóbal, 1965, 1966, F. Medem, Carlos A. Velásquez, Luis A. Cepeda. Lagos del Cacique, $1018 \mathrm{~m}$. alt., $4 \mathrm{kms}$ al S. de Bucaramanga.

2. B. parkeri Ruthven, 1925. Terra typica: Río Chenapowu, curso alto del río Potare, Guayana Británica. Un solo ejemplar del río Tiquié, afluente del Vaupés, Colombia.

3. B. talpa Ruthven, 1925. Terra typica: Valledupar (Cesar), agosto 4, 1920, A. G. Ruthven. Valencia (Magd.) ; Fonseca (Guajira), río Ranchería.

\section{Género Cnemidophorus Wagler, 1830.}

Especie:

1. C. lemniscatus lemniscatus (L.), 1758. "Lagartija, Lobito". Muy común en las zonas cálidas de todo el país, especialmente en la costa del Caribe, las Islas del Rosario y en el valle del Magdalena; en general, es simpátrico con varias especies del género Ameiva, pero su nicho ecológico es algo diferente: prefiere más bien los lugares expuestos al sol, v.gr., zonas áridas, las orillas de los ríos y, dentro de la selva tropical, se encuentra alrededor de los fundos de los colonos. Son terrestres, pero trepan con gran agilidad encima de los arbustos hasta unos tres metros de altura.

Existen marcadas diferencias acerca del color entre las poblaciones de $C$. lemniscatus procedentes de la costa del Caribe, la Guajira, del Catatumbo y de los Llanos Orientales; quizás se trata de poblaciones locales (Demes) bien distintas que tengan otras características constantes. Un ejemplar anidó en el criadero de la C.V.M. en Cartagena, noviembre 29, 1965; puso tres huevos en un hueco excavado de unos $15 \mathrm{cms}$. de profundidad. Las dimensiones y el peso son las siguientes:

1) $17.5 \mathrm{~mm} .: 12.0 \mathrm{~mm}$.; peso: $1 \mathrm{~g}$., $320 \mathrm{mg}$.

2) $17.0 \mathrm{~mm}$ : $12.0 \mathrm{~mm}$.; peso: $1 \mathrm{~g} ., 350 \mathrm{mg}$.

3) $18.0 \mathrm{~mm} .: 12.0 \mathrm{~mm}$.; peso: $1 \mathrm{~g} ., 350 \mathrm{mg}$.

Género Echinosaura Boulenger, 1890. Especies:

1. E. horrida horrida Boulenger, 1890. Isla Gorgona, norte, $40 \mathrm{~m}$. alt., febrero 2, 1961. F. Medem (ICN Nos. 648, 656), en el monte, de día, debajo de tablas.

2. E. horrida palmeri Boulenger, 1911. Terra typica: Noanamá (Chocó), Alto San Juan. Bajo Calima, 40-45 m. alt., campamento "Cartón de Colombia”, en el suelo debajo de un árbol, abril 30, 1960, I. Cabrera (ICN Nos. 725, 726). Dos ejemplares procedentes de la Isla Gorgona representan híbridos entre $E$. horrida horrida y $E$. horrida palmeri (Uzzell, 1965). Echinosaura centralis Dunn, 1944, de Muzo y Robledo (Ant.), es sinónimo con E. horrida palmeri (Uzzell, op. cit.). 
Género Gymnophthalmus, Merrem, 1820. Especie:

1. G. speciosus (Hallowell), 1860. Minca (Magdalena), 600-900 m. alt.; Sierra Nevada de Santa Marta, 1950, sin colector (ICN Nos. 624, 625). Caño Juí, Tierra Alta, Alto Sinú, 40 m. alt. aproximadamente, agosto 2,1965 , C. A. Velásquez. Agosto 12, 1965, puso un solo huevo blanco y de cáscara dura en el suelo sin enterrarlo.

Midió $5.5 \mathrm{~mm}$.: $4.0 \mathrm{~mm}$.

Género Iphisa Gray, 1851. Monotípico.

Especie:

1. I. elegans Gray, 1851. Terra typica: Pará, Bajo Amazonas (Brasil). Un solo ejemplar procedente de Puerto Boy (Caquetá), Alto Caquetá, (no Putumayo, como indicó Dunn, 1945 j, p. 105).

Género Kentropyx Spix, 1825.

Especies:

1. $K$. calcaratus Spix, 1825. Leticia (Am.); río Apaporis (Am.), 1952, Isidoro Cabrera; río Putumayo; Morelia (Caquetá), 1945, Kjell von Sneidern.

2. K. striatus (Daudin), 1802. Quenane (Meta), al E. de Villavicencio, carretera a Puerto López, 1947, E. R. Dunn. Finca "El Mico" (Meta), Sabana de San Juan de Arama, frente a La Macarena, noviembre 28, 1950, Robert C. Stebbins y John R. Hendrickson; tenía seis huevos blancos de cáscara blanda en ambos oviductos (Medem, 1965, p. 337).

Género Leposoma Spix, 1825.

Especies:

1. L. parietale (Cope), 1885. Río Cananarí (Vaupés), afluente del Alto Apaporis, enero 1952, I. Cabrera (ICN Nos. 620, 621). Villa María (Caquetá), $45 \mathrm{kms}$. al S. de Florencia, Alto Orteguaza, 1960, Nicéforo M.

2. L. percarinatum (L. Müller), 1923. Sinónimo: Hylosaurus muelleri Mertens, 1925, río Inírida. Gino-Gojé (Am.), Bajo Apaporis, marzo 8, 1952, I. Cabrera (ICN No 645).

3. L. rugiceps (Cope), 1868. Terra typica: Río Magdalena. Holotypus: ANSP Ne 9635, fide Ruibal, 1950, p. 489). Sinónimo: Leposoma dispar Peters, 1880, Cáceres (Ant.), río Cauca. El Paraíso (Atl.), región de Barranquilla, enero 31, 1946, sin colector (ICN No 614). Finca "Junquillo" (Córdoba), caño Betancí, afluente del Sinú, septiembre 20, 1956, F. Medem (ICN No 647). La Macarena, sur, Alto Guayabero (Meta), alrededor del campamento $\mathrm{N}^{0} 1$; en el monte entre raíces de árboles gruesos, enero a marzo 1959, F. Medem, C. A. Velásquez (ICN Nos. 634-643). Río Frío,
Las Pavas (Magd.), Sierra Nevada de Santa Marta, Fundación, Tucurinca, Valencia, hacienda "Bolívar", alrededor de Santa Marta (Ruibal, op. cit.), Caño Juí, Tierra Alta, Alto Sinú (Adler, septiembre 3, 1967, in litt.), El Centro (Sant.), 1943, E. R. Dunn.

Estos pequeños lagartos de color carmelita claro se encuentran esporádicamente en lugares húmedos tanto en el monte como cerca de la orilla de los ríos en pequeños grupos de dos a seis aproximadamente; forman, evidentemente, populaciones aisladas en ciertos lugares y tienen, quizás, un nicho ecológico definido; dentro del mismo habitat, $v . g r$. . la selva tropical, no se encuentra a veces por semanas enteras ni un solo ejemplar a pesar de que no se nota diferencias respecto a los nichos ecológicos.

Género Neusticurus Duméril \& Bibron, 1839. Especie:

1. N. ecpleopus Cope, 1875. Cerro Isibucurí, Sibucurí o Sibocure, Bajo Cananarí, afluente del Apaporis, enero 24, 1952, F. Medem, Isidoro Cabrera (ICN Nos. 615, 623). Araracuara (Am.), río Caquetá, sin fecha, A. Pocaterra (ICN No 631).

Los representantes del género Neusticurus crecen hasta unos 70 milímetros aproximadamente; son principalmente diurnos y de hábitos semiacuáticos; se encuentran en la selva tropical cerca de caños y pozos; perseguidos, se retiran a las aguas, nadando con la cabeza erguida; se alimentan de cucarrones acuáticos (Coleoptera), renacuajos y pequeñas sardinas; anidan en árboles podridos cerca de las aguas. Wake y Etheridge, julio 12, 1961, encontraron dos nidos con cuatro y cinco huevos respectivamente con la cría naciendo y saliendo; posiblemente los nidos contenían huevos puestos por varias hembras por razón de que en 12 ejemplares disecados se encontraron únicamente dos huevos en cada hembra (Uzzell, 1966, p. 313).

Género Pantodactylus Duméril \& Bibron, 1839. Especie:

1. P. copii (Boulenger), 1885. Terra typica: Pallatanga y Canelos, Oriente (Ecuador). Dunn (1944 j, p. 104) registró un ejemplar procedente del Chocó sin localidad exacta; posiblemente debido a un error, ya que todas las especies de este género conocidas han sido coleccionadas en el área del Alto Amazonas y sus afluentes en el Ecuador y Perú.

Nota: $P$. tyleri Burt \& Burt, 1931, representa una especie del género Arthrosaura (Ruibal, 1952, p. 512). El mismo autor usa el nombre genérico original Alopoglossus Boulenger, 1885 en vez de Pantodactylus (Ruibal, op. cit., p. 500). 
Género Prionodactylus O'Shaughnessy, 1881.

Especies:

1. P. argulus (Peters), 1862. Terra typica: Santa Fe de Bogotá (sic). Fusagasugá, sin fecha, E. R. Dunn.

Nota: Tiene algunas características de $P$. columbiensis (Uzzell, julio 9, 1962, in litt.) ; (ICN No 628). Muzo (Boyacá), 800-900 m. alt.

2. P. columbiensis Werner, 1916. Terra typica: Cañón del Tolima, arriba de Ibagué, $1700 \mathrm{~m}$. alt. Caño Guapaya (Meta), La Macarena, norte, 400 m. alt., enero 11, 1951, F. Medem, de día, entre raíces de un árbol; (ICN No 644). Tiene también características de $P$. argulus (Uzzell, cit.). Villavicencio; Garagoa (Boyacá), región de Miraflores, $1639 \mathrm{~m}$. alt., vertiente oriental de la Cordillera Oriental hacia el Casanare; Muzo.

3. P. oshaughnessy Boulenger, 1885. Alto Apaporis (Vaupés), enero 29, 1952, I. Cabrera (ICN No 630). Río Güéjar (Meta), La Macarena, norte, entre el aeropuerto y el campamento "La Macarena" del Instituto "Roberto Franco", mayo 29, 1951, F. Medem (ICN No 617).

Nota: Tiene también características de $P$. columbiensis (Uzzell, cit.).

4. P. palmeri Boulenger, 1908. Terra typica: Hacienda San Antonio (Valle).

5. P. stenolepis (Boulenger), 1908. Terra tripi$c a$ : San Antonio (Valle).

Nota: $P$. stenolepis y $P$. palmeri son, posiblemente, sinónimos.

6. P. vertebralis (O'Shaughnessy), 1879. Arracachal (Cund.), planta eléctrica del Salto del Tequendama, sin fecha, E. R. Dunn, (ICN Nos. 626, 627). Quindío; Jericó, Sonsón, Sampedro (Ant.). Pasto (Nariño) ; 2594 m. alt. (Valdivieso \& Tamsitt, 1963 a).

Nota: Varios autores, v.gr., Boulenger, separan los nombres genéricos Euspondylus Tschudi, 1845, y Prionodactylus, no obstante que otros los consideran como sinónimos. Debido a la falta de ejemplares en cantidades suficientes, la clasificación exacta de varios géneros de la familia Teiidae es muy difícil por razón de que son de tamaño menor (hasta unos 80 milímetros) y muy parecidos entre ellos.

Género Proctoporus Tschudi, 1845.

Especies:

1. P. laevis (Boulenger), 1908. Terra typica: San Antonio (Valle), hacienda a $17 \mathrm{kms}$. sobre la vertiente oriental de la Cordillera Occidental, 1850-2200 m. alt., al occidente de Cali. Cordilleras Central y Occidental (Dunn, 1944 j, p. 103).
2. P. striatus (Peters), 1962. Terra typica: Montañas altas en la vecindad de Bogotá. Pequeño lagarto de cuerpo muy alargado; extremidades muy reducidas; no es principalmente subterráneo. Relativamente común en la vertiente de la Cordillera Oriental, arriba de Bogotá. Se encuentra debajo de piedras; ponen un solo huevo; tres ejemplares pusieron en marzo 1960; los huevos midieron de $13.9 \mathrm{~mm}$.; $14.0 \mathrm{~mm}$.; y $14.1 \mathrm{~mm}$. respectivamente (Valdivieso \& Tamsitt, 1963).

También conocido de Muzo.

Género Ptychoglossus Boulenger, 1890. Sinónimo: Gonioptychus Werner, 1916.

Especies:

1. P. bicolor (Werner), 1916. Terra typica: Cañón de Tolima. Moscopán (Cauca), 1945, K. v. Sneidern (ANSP No 25512).

2. P. festae (Peracca), 1896. Medellín; Angelópolis (Ant.), fide Dunn (1944 g, p. 68).

3. P. nicefori (Loveridge), 1929. Terra typica: Río Garagoa, cerca de Macanal (Boyacá), Cordillera Oriental, región de Miraflores, 1928, Nicéforo $M$.

Depresión de Guaicáramo (Boyacá), entre El Engaño, al $\mathrm{N}$ de Medina y Barranca de Upía, al E del Meta; Buenavista (Meta), 1000-1230 m. alt., arriba de Villavicencio, 1943, E. R. Dunn (ICN No 633).

4. P. picticeps (Cope), 1885. Gino-Cojé, río Apaporis, 1952, I. Cabrera (MCZ No 53254).

Género Scolecosaurus Boulenger, 1885. Especie:

1. S. pallidiceps (Cope), 1862. Terra typica: Río Truandó (Chocó); río Quesada (= Ciénaga de Quesada), Bajo Atrato, R.D.O. Johnson (AMNH No 18230).

Género Tretioscincus Cope, 1862. Monotípico. Especie:

1. T. bifasciatus (Duméril), 1851. Terra typica: Valle del Magdalena, Nueva Granada.

La Mesa (Cund.), finca "La Milagrosa", febrero 1949 , sin colector (ICN No 616). Muzo (ICN No 629), sin fecha y colector. Bonda (Magd.), al E de Santa Marta, 1964, F. Medem y C. A. Velásquez. Victoria (Caldas), $850 \mathrm{~m}$. alt., aproximadamente, octubre 9, 1963, P. Ivo Schaible y Richard Schahl (comunicación personal); Honda; río Don Diego (Magd.); Valledupar; Fonseca, Arroyo de Arenas (Guajira); Medellín.

Estos pequeños lagartos se distinguen fácilmente por su coloración; las dos líneas dorso-laterales son verduscas-azulosas y la cola tiene un color azul intenso en muchos ejemplares; posiblemente 
se trata de un dimorfismo sexual. Se encuentran tanto en el monte húmedo como en regiones expuestas al sol, $v . g r$., en potreros y vertientes de cerros.

Género Tupinambis Daudin, 1802. Especies:

1. T. nigropunctatus Spix, 1825. "Lobo pollero, Caripiari, Mato". Desde la costa del Caribe hasta los Llanos Orientales y el Amazonas. Es bastante frecuente en la Isla Fuerte (Córdoba), el río Don Diego (Magd.), donde se encuentra en los manglares, y en la región de Ayapel (Córdoba), Alto San Jorge, que consiste principalmente en numerosas lagunas, arroyos y pantanos. En los Llanos Orientales del Meta son menos abundantes y su ambiente preferido consiste en áreas cubiertas por rastrojo y manchas de monte. Son raros en las selvas.

2. T. teguixin (L.), 1758. "Caripiari, Mato". Llanos Orientales del Orinoco hasta el Amazonas. Ambas especies crecen hasta unos 950 milímetros aproximadamente; por lo menos nunca hemos medido un ejemplar que tenía un metro o más. Se alimentan principalmente de otros animales, $v$. $g r$., insectos, otros lagartos, aves y pequeños mamíferos.

En la Isla Fuerte (Córdoba), hemos observado en mayo de 1955, que los T. nigropunctatus persiguieren ejemplares adultos de Ameiva ameiva praesignis y Cnomidophorus lemniscatus con frecuencia; en general los alcanzaron y, después de una lucha a veces prolongada, los devoraron. Son también muy inclinados a alimentarse de pollos y gallinas. Durante la época de anidación de las tortugas acuáticas, tanto de agua dulce como marinas, excavan los nidos y se alimentan de los huevos, succionando el interior y luego escupen la cáscara; v. gr., los del "Gogó" (Caretta caretta caretta) en la orilla del mar entre Don Diego, Buritaca y el río Piedras; de la "Tortuga" (Podocnemis lewyana) en el Magdalena y Sinú; de la "Terecay" ( $P$. unifilis). "Sabanera" ( $P$. vogli) y "Tortuga" $P$. expansa) en los Llanos Orientales. También se alimentan de frutas silvestres y de plátanos y papayas.

Anidan en el lugar más inverosímil para un lagarto terrestre, es decir, en los nidos de comejenes (termites) arborícolas.

En noviembre 11, 1956, hemos encontrado en el Caño Betancí, afluente del Sinú, cerca de la finca "Junquillo" de la orilla en el monte bajo un nido de comejenes, situado en un árbol más bien delgado en unos cinco metros de altura que tenía un hueco recientemente hecho; pensando en un nido de cierto lorito, denominado "Cara sucia", hemos investigado el lugar y encontrado ocho huevos blancos alargados y de cáscara blanda, lo que indicaba que fueron de un reptil, lagarto o serpiente.
Los habitantes nos informaron que han sido puestos por un "Lobo pollero" muy recientemente, ya que el hueco todavía no ha sido cerrado por los mismos comejenes. Schmidt \& Inger (1959, p. 140), se refieren también a esta costumbre y hábito de anidar.

En diciembre 10, 1965, un $T$. nigropunctatus, procedente de Santa Rosa (Bol.), anidó en el jardín zoológico de Mr. Dennie Sebolt en Cartagena; el nido consistía en una excavación al pie de una mata de plátano y contenía cinco huevos, las dimensiones y el peso de los cuales son las siguientes:

1) $50.0 \mathrm{~mm}: 27.0 \mathrm{~mm}$; peso: $19 \mathrm{~g}, 450 \mathrm{mg}$.

2) $50.0 \mathrm{~mm}: 27.0 \mathrm{~mm}$; peso: $20 \mathrm{~g}, 650 \mathrm{mg}$.

3) $50.0 \mathrm{~mm}: 27.0 \mathrm{~mm}$; peso: $20 \mathrm{~g}, 320 \mathrm{mg}$.

4) $51.0 \mathrm{~mm}$ : $26.0 \mathrm{~mm}$; peso: $21 \mathrm{~g}, 100 \mathrm{mg}$.

5) $50.0 \mathrm{~mm}: 27.0 \mathrm{~mm}$; peso: $20 \mathrm{~g}, 900 \mathrm{mg}$.

Son diurnos; durante la noche y los días lluviosos permanecen en cuevas excavadas por ellos mismos o por otros animales, $v . g r$., el "Cachicamo" (Dasypus novemcinctus). Los "Lobos polleros" de la costa del Caribe, de los valles del Magdalena y del Sinú están más inclinados hacia una vida semiacuática que aquellos procedentes de los Llanos Orientales. Nadan con frecuencia y caminan encima del junco y fango de los sectores pantanosos en la búsqueda de caracoles acuáticos; en cautividad se bañan con mucha frecuencia y permanecen por horas en los pozos; sin embargo, no buscan el agua en el caso de persecución, como suelen hacerlo las iguanas, sino el monte, para esconderse.

Existe una gran diferencia respecto al color entre los Tupinambis procedentes de la costa del Atlántico y de los Llanos Orientales respectivamente. Mientras todos los adultos de la costa del Caribe, etc., tienen un color negro brillante salpicado con numerosas manchas blancas o amarillentas, los de los Llanos Orientales y de la selva tropical del Vaupés y Amazonas son pardos claros con numerosas fajas delgadas transversales oscuras y manchas negruzcas.

Existen otras características morfológicas externas entre ambas poblaciones. Además, hay que advertir que las características específicas dadas por Boulenger (1885, pp. 336, 337), para distinguir las dos especies nigropunctatus y teguixin, no son constantes en muchos casos ; así, por ejemplo, nigropunctatus debe tener una sola escama Loreal, mientras teguixin dos grandes de ellas.

Evidentemente, se necesita un estudio a base de material suficiente para determinar exactamente los Tupinambis existentes en Colombia, hasta la fecha podemos solamente seguir el camino de la clasificación tradicional. 


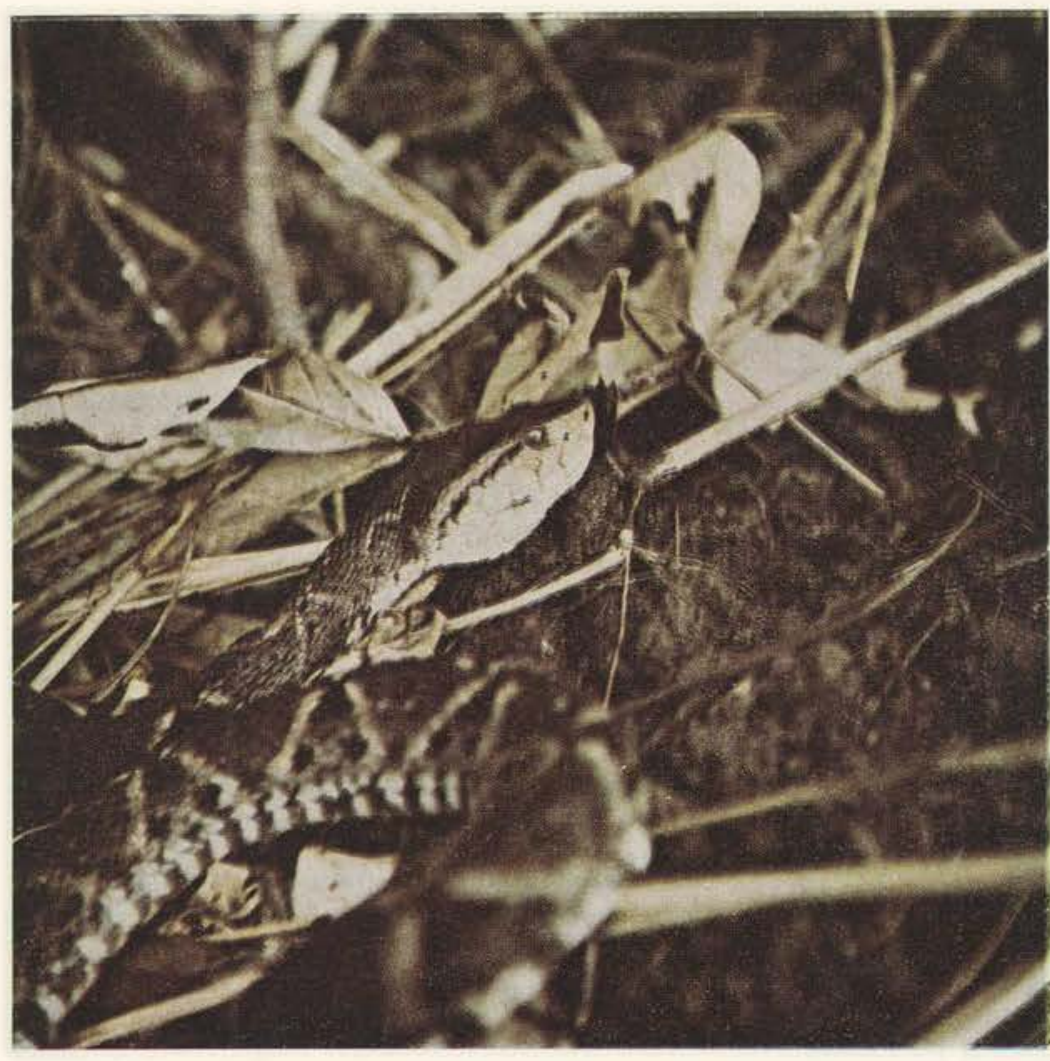

No. 3

Bothrops atrox atrox. "Mapaná". Alto Uré (Córdoba), febrero 7, 1963; nembra 1.61 metros. Obsérvase la fosa facial, situada entre el orificio nasal y los ojos. Vista lateral de la cabeza.

No. 4

Lachesis muta muta. "Rieca, Verru goso". Región de Leticia (Am.), julio 21, 1959; 2.0 metros. Obsérvase la fosa facial; la escama que cubre el ojo está opaca y no trans parente, lo que indica que el ejemplar pronto mudará la piel. Vista lateral de la cabeza.

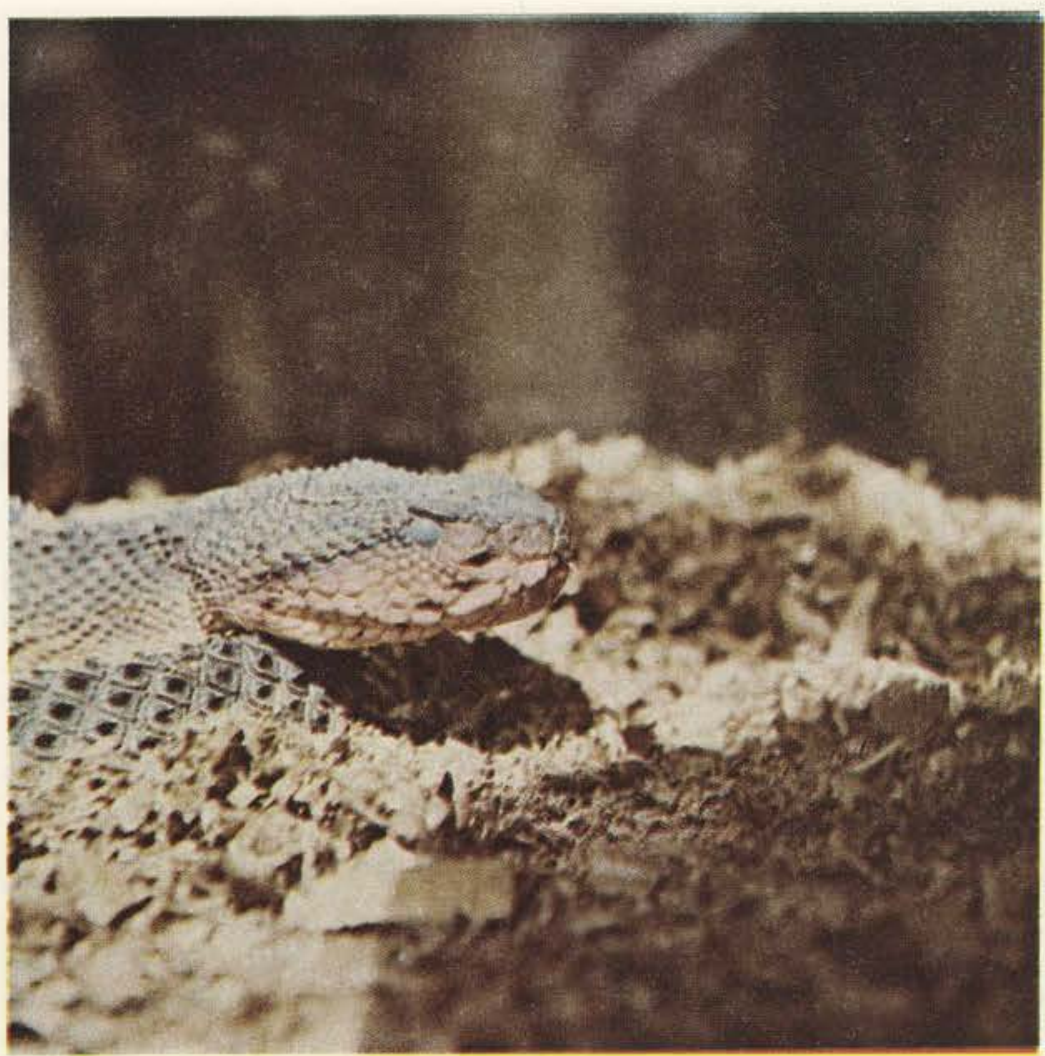


Familia Amphisbaenidae.

Lagartos de cuerpo vermiforme; extremidades y cinturas rudimentarias o ausentes; ojos diminutos, situados debajo de una escama transparente; en su mayoría ovíparos; subterráneos; maxilares y mandíbulas provistas de dientes puntiagudos; se alimentan de comejenes y lombrices; son totalmente inofensivos, no obstante que la superstición popular los tilda como extremadamente venenosos.

Género Amphisbaene Linnaeus, 1758.

Especies:

1. A. alba Linnaeus, 1758. "Tatacoa, Ciega, $\mathrm{Cu}$ lebra de dos cabezas". Leticia (Am.) ; caño Guapaya, Sierra de La Macarena; Villavicencio; La Girona (Sant.), al E de Lebrija.

Crece hasta unos 600 milímetros aproximadamente; color pardo claro uniforme dorsalmente; ventralmente blanco.

2. A. fuliginosa fuliginosa Linnaeus, 1758. "Tatacoa, etc.". Hoya del Amazonas; se desconocen los límites exactos de su distribución; coexistente con A. fuliginosa amazonica en la región de Leticia. Color blanco con numerosas manchas negras; crece hasta unos $400 \mathrm{~mm}$.

3. A. fuliginosa amazonica Vanzolini, 1951. Leticia; Villavicencio.

4. A. fuliginosa varia Laurenti, 1768. Chocó; Sampedro (Valle); La Girona; Honda; Paime (Cund.) ; Muzo; Barrancabermeja; Medellín; Villavicencio.

En Villavicencio existen híbridos entre $A$. fuliginosa amazonica y A. fuliginosa varia (Vanzolini, 1951).

5. A. spurrelli Boulenger, 1915. Terra typica: Andagoya, confluencia de los ríos Condoto y San Juan, $100 \mathrm{~m}$. alt.; conocida únicamente de la localidad típica y de Tucutí, río Tuira, costa del $\mathrm{Pa}$ cífico, Panamá.

Género Mesobaena Mertens, 1925. Monotípico.

Especie:

1. M. huebneri Mertens, 1925. Terra typica: emendata (Medem, 1965, p. 322) : Río Inírida, afluente del río Guaviare (Vaupés), Colombia, en vez de "Inírida, sur de Venezuela".

Actualmente el Inírida pertenece a la Comisaría del Guainía.

El Holotypus (SMF No 5450; 1885, Georg Hübner), mide 270 milímetros total, cola $18 \mathrm{~mm}$. y el diámetro $6 \mathrm{~mm}$. ; el color (en alcohol) es rosado, muy parecido al de una lombriz de tierra o de Ascaris (lombriz intestinal; Nematodo). Solamente conocida de la localidad típica y a base del tipo. Como el colector, Hübner, no ha indicado una localidad precisa, se desconoce el habitat defini- do, es decir, puede consistir o en la selva tropical húmeda o en las mesetas áridas que bordean extensas áreas a lo largo del río.

\section{Familia Anguidae.}

Lagartos de configuración muy variada, extremidades presentes, reducidas o ausentes. El género que representa esta familia en Colombia posee una cabeza achatada y triangular, un cuerpo relativamente grueso y aplanado, cubierto de escamas lisas no aquilladas, y una cola corta y redondeada; los maxilares y mandíbulas están provistos de dientes cortos pero fuertes.

Género Diploglossus Wiegmann, 1834. Especies:

1. D. millepunctatus O'Shaughnessy, 1874. Endémico en la Isla de Malpelo, Océano Pacífico; crece hasta 450 milímetros y se alimenta principalmente de cangrejos marinos (Crustacea).

2. D. monotropis (Kuhl), 1820. "Madre de culebra, Madre de Coral". Andagoya ; Cordillera del Baudó (Chocó) ; ríos Rosario y Mataje (Nariño) ; Muzo; posiblemente en La Girona (Sant.), al E de Lebrija, donde, en 1960, los habitantes nos informaron sobre la "Madre Coral", un lagarto grueso de cabeza plana y muy "bravo", es decir, venenoso, que se encuentra a veces en los bejuqueros densos. La deseripción de su configuración y coloración indica una especie del género Diploglossus.

D. monotropis crece hasta unos 300 milímetros aproximadamente; el color de los adultos es gris blancuzco con numerosas barras oscuras transversales y algo de rojo ventro-lateralmente; los ejemplares juveniles tienen una coloración más viva: dorsalmente negra, ventralmente roja y lateralmente con fajas rojas y negruzcas alternantes. Son muy escasos; posiblemente subterráneos, aunque se encuentran de día en lugares húmedos y cubiertos de pasto; perseguidos, se paran, se inflan y se defienden a mordiscos (Reichel-Dolmatoff, marzo 1961, comunicación personal) ; son inofensivos a pesar de las creencias de los nativos. Se desconocen, que yo sepa, datos exactos sobre su modo de reproducirse; en cambio, D. millepunctatus es vivíparo (H. Marx, 1963, comunicación personal).

\section{Paleontología.}

En Colombia se encontraron Sauria fósiles en los siguientes sitios:

Coyaima (Tolima), Oligoceno Superior.

Un maxilar con dientes de Tupinambis spec., posiblemente teguixin (Teiidae). 
La Venta (Huila), Villavieja; formación Honda del Mioceno Superior.

1. Una mandíbula con dientes de Tupinambis, teguixin.

2. Un maxilar, la mandíbula, el fémur y vértebras de una nueva especie de la familia Teiidae, Dracaena colombiana, spec. nov. Representa un género actualmente distribuido en las Guayanas, el Bajo Amazonas (Brasil), el río San Francisco (Brasil) y en Paraguay.

3. Iguanidae, gen. et spec. indeterminados, pero parecido al género Polychrus (Estes, 1961).

La presencia de una especie del género Dracaena Daudin, 1802, indica que la región de Villavieja-San Nicolás (Huila), que actualmente es árida y tiene una altitud de 400 a 500 metros, formaba parte del habitat selva pluvial tropical, y tenía, además, una elevación menor durante el Mioceno Superior, parecido a la selva del Bajo Amazonas, por razón de que estos lagartos son de hábitos semiacuáticos y especializados en alimentarse de caracoles acuáticos (Mollusca). Además, el habitat de Tupinambis consiste también en terrenos bajos, silvestres y relativamente húmedos.

Los representantes más antiguos de los Sauria se encontraron en el Jurásico Superior: evolucionaron, probablemente, de los Eosuchia, un grupo de reptiles pequeños y parecidos a los lagartos que floreció durante el Permiano y Triásico.

Durante el Cretáceo Superior ya aparecen los grupos modernos de las Iguanidae y Anguinidae.

Las Gekkonidae y Amphisbaenidae están representados en el Eoceno, los Teiidae en el Oligoceno, y los Scincidae en el Plioceno.

Se desconocen todavía fósiles de las demás familias; posiblemente por razón de que muchas de ellas representan lagartos de tamaño menor que poseen, por lo general, huesos delgados y dientes diminutos, los cuales son poco resistentes y, consecuentemente, han sido destruídos en la mayoría de los casos durante el proceso de la fosilización.

El número total de lagartos encontrados en Colombia es el siguiente:

\begin{tabular}{|c|c|c|}
\hline FAMILIA & Géneros & $\begin{array}{r}\text { Especies y } \\
\text { Subespecies }\end{array}$ \\
\hline Gekkonidae ........ & 8 & 22 \\
\hline Iguanidae......... & 16 & 62 \\
\hline Scincidae ........ & 1 & 2 \\
\hline Teïdae $\ldots \ldots \ldots \ldots$ & 19 & 50 \\
\hline Amphisbaenidae $\quad \ldots \ldots$ & 2 & 6 \\
\hline Anguidae $\quad \ldots \ldots \ldots$ & 1 & 2 \\
\hline
\end{tabular}

Hasta la fecha se conocen 47 géneros con 144 especies y subespecies de Sauria en Colombia.

\section{Superorden SQUAMATA}

Orden Serpentes.

La mayor parte de las características distintivas de las serpientes van asociadas al alargamiento de su cuerpo; éste parece ser consecuencia del tipo de locomoción 'lateral ondulatoria', adaptado por el grupo de lagartos de que las serpientes evolucionaron. En relación con la forma alargada del cuerpo está la pérdida de las extremidades, el alargamiento de los órganos internos y la pérdida de un pulmón funcional, generalmente el izquierdo. Mandíbulas articuladas anteriormente por un ligamento, lo que permite una mayor expansión de la boca durante el acto de ingerir la presa entera; ojos inmóviles, sin párpados y cubiertos por un par de escamas transparentes; lengua alargada, bífida y protráctil; contribuye en las percepciones olfativas a llevar estímulos químicos al "Organo de Jacobson", situado en la cavidad nasal; ovíparas, ovovivíparas y vivíparas; terrestres, subterráneas, arborícolas y acuáticas, es decir, de agua dulce, salobre y salada.

\section{Familia Typhlopidae.}

Serpientes pequeñas subterráneas; comúnmente denominadas como "Ciegas" por poseer un par de ojos vestigiales debajo de escamas opacas.

Género Anomalepis Jan, 1861.

Especie:

1. A. colombia Marx, 1953. Terra typica: La Selva, Pueblo Rico (Caldas), $1700 \mathrm{~m}$. alt. Constituye el primer registro de este género para Colombia.

Género Helmintophis Peters, 1860.

Especies:

1. H. praeocularis Amaral, 1924. Terra typica: Honda (Tolima), marzo 1924, Nicéforo M. Ibagué; San Gil; Cúcuta.

Género Liotyphlops Peters, 1881.

Especies:

1. L. albirostris (Peters), 1857. Mariquita; Barranquilla, Santa Marta, Cartagena, Estación de Piscicultura de la C.V.M., Canal del Dique, frente a San Cristóbal.

2. L. anops (Cope), 1899. San Vicente de Chucurí (Sant.), Paime (Cund.).

3. L. cucutae Dunn, 1944. Terra typica: Cúcuta (N. de Sant.), 215 m. alt. Puerto Berrío (Ant.), 112 m. alt., valle del Magdalena (Valdivieso \& Tamsitt, 1963). 
4. L. flavoterminatus (Peters), 1857. Región de Cúcuta (Roze, 1959).

5. L. metae Dunn, 1944. Terra typica: Villavicencio (Meta), $498 \mathrm{~m}$. alt.; solamente conocido de la localidad típica.

Un ejemplar, capturado en el centro de Villavicencio, agosto 14, 1967, Rafael Ruszinke (Taller Rodríguez), tenía las siguientes dimensiones: total: 325.0 milímetros; cola: 8.0 milímetros.

Género Typhlops Duméril \& Bibron, 1844. Especie:

1. T. reticulatus (L.), 1758. Hoyas del Orinoco y Amazonas.

\section{Familia Leptotyphlopidae.}

Se distinguen de los Typhlopidae únicamente por poseer vestigios del fémur y de la cintura pélvica.

Género Leptotyphlops Fitzinger, 1843. Especies.

1. L. albifrons magnamaculata Taylor, 1940. Islas San Andrés y Providencia (Dunn \& Saxe, 1950).

2. L. brevissima Shreve, 1964. Terra typica: Florencia (Caquetá), febrero 10, 1951, Nicéforo María. Sonsón (Ant.).

3. L. dugandi Dunn, 1944. Terra typica: Juanmina (Atl.) y Barranquilla, jardín del Colegio Biffi.

Nota: En junio de 1964, hemos buscado el tipo y paratipo en el Colegio Biffi; ambos están evidentemente perdidos; varios frascos contenían ejemplares en estado de descomposición y sin letreros; por esta razón una clasificación ha sido imposible.

4. L. goudoti (Duméril \& Bibron), 1844. Terra typica: Valle del Magdalena, Nueva Granada, Goudot. Río Negro, región de Bucaramanga (Sant.), 1018 m. alt.; Honda; Ambalema (Tolima); Apulo (Cund.); Ibagué.

5. L. joshuai Dunn, 1944. Terra typica: Jericó (Ant.), 1967 m. alt., Andes (Ant.) ; Villa María (Caldas), $2005 \mathrm{~m}$. alt.

6. L. macrolepis (Peters), 1857. Ocaña (N. de Sant.), 1200 m. alt.; Barichara y San Gil (Sant.) ; Chaparral; Guamo; Mariquita (Tolima).

7. L. nicefori Dunn, 1946. Terra typica: Mogotes (Sant.), $1646 \mathrm{~m}$. alt. Solamente conocido de la localidad típica.
Familia Aniliidae.

Género Anilius Oken, 1816.

Especie:

1. A. scytale (L.), 1758. "Coral". Inofensiva; subterránea; crece hasta 1.20 metros (Nicéforo M., 1930 a). Un ejemplar de Peralonso (Meta), carretera entre Villavicencio y Puerto López, junio 10, 1967, Sixto Rodríguez, capturado de día en la orilla de un caño, se alimentó en cautividad en el Instituto "Roberto Franco" de comejenes y lombrices; murió septiembre 15, 1967; sus dimensiones comprenden las siguientes: total 997 mm.; cola: 30 milímetros.

Desde los Llanos Orientales hasta la Amazonía.

\section{Familia Boidae.}

Ofidios de tamaño grande; los vestigios de las extremidades posteriores consisten en los tres huesos de la cintura pélvica, muy separados de los del lado opuesto, y en el fémur muy pequeño; externamente tienen un par de espolones o garras córneas pequeñas, bien discernibles en los machos, menos en las hembras. Eso quiere decir, que la familia Boidae, igual a la de las Leptotyphlopidae, representan formas muy antiguas que todavía no han perdido por total ciertos vestigios esqueletales durante el proceso de la evolución orgánica, y que sus antepasados constituyeron un grupo de reptiles poseedores de las cuatro extremidades bien desarrolladas y funcionales.

\section{Género Eunectes Wagler, 1830.}

- Especie:

1. E. murinus gigas (Latreille), 1802. "Güio negro, Anaconda”. Representa la serpiente más grande del mundo; el único ejemplar de tamaño mayor, procedente de los Llanos Orientales del Meta, ha sido debidamente medido por el geólogo petrolero Roberto Lamón, y midió 11.50 metros total (37.5 pies), fide Dunn, (1944 k, p. 183).

Se habla con frecuencia de ejemplares de 14 a 30 metros de longitud, pero todavía no existe ninguna comprobación respaldada por dimensiones exactas. El "Güio negro" es vivíparo, como todas las Boidae; su habitat consiste en lagunas, pantanos y caños; se alimenta de peces, babillas, (Caiman sclerops), aves y mamíferos hasta de un tamaño de un zaíno y ternero pequeño; principalmente acuático, se encuentra en las hoyas del Amazonas y Orinoco; de Colombia solamente la subespecie $E$. murinus gigas se ha registrado hasta la fecha.

Género Ungialophis Müller, 1882.

Especie:

1. U. danieli Prado, 1940. Terra typica: Andes (Ant.), 1350 m. alt., octubre 1938, Daniel, Hno. 
Solamente conocida de la localidad típica; pequeña $\mathrm{y}$ de hábitos desconocidos.

Género Trachyboa Peters, 1860.

Especie:

1. T. boulengeri Peracca, 1910. "Orito, Pudridora". Inofensiva; crece hasta unos 250-300 milimetros; ovovivípara (Barbour, 1937).

En zonas pantanosas del Bajo Calima; ríos Dagua y Sabaletas (Valle), al S de Buenaventura (Adler, septiembre 3, 1967, in litt.); (ICN No 431, Bajo Calima, febrero 11, 1960, Isidoro Cabrera) ; (ICN N? 415, campamento "Cartón de Colombia", entre Buenaventura y el Calima, 1960, I. Cabrera) ; Alto Sinú, arriba del río Verde (Córdoba), diciembre 23, 1959, George Dahl, en la orilla de un caño, de día; (ICN No 349), es el primer ejemplar encontrado al E del litoral Pacífico.

$T$. boulengeri comprende una especie muy rara y de hábitos desconocidos; don Isidoro Cabrera me informó que consiguió un ejemplar en un pozo dentro del agua poco profunda.

Género Constrictor Laurenti, 1768.

Especies:

1. C. constrictor constrictor (L.), 1758. "Güio perdicero, Galán, Boa". Crece hasta unos 4 metros aproximadamente; principalmente al oriente de la Cordillera Oriental.

2. C. constrictor imperator (Daudin), 1803. "Boa". Principalmente a lo largo de las costas del Atlántico y Pacífico; islas San Andrés y Providencia. El color es, por lo general, gris azuloso y las manchas y barras rojas y amarillas menos pronunciadas que en $C$. constrictor constrictor.

Género Epicrates Wagler, 1830.

Especies:

1. E. cenchria cenchria (L.), 1758. "Macabrel, Macaurel". Crece hasta unos tres metros; en las hoyas del Orinoco y Amazonas.

2. E. cenchria maurus Gray, 184.9. "Boá azul, Mapaná mariposa” (sic). Litoral del Caribe, Va. lle del Magdalena.

Género Boa Linnaeus, 1758.

Especies:

1. B. annulata (Cope), 1875. "Boa, Boba". Costa del Pacífico del Chocó, Valle, Cauca y Nariño. Aparentemente terrestre.

2. B. canina (L.), 1758. "Macaurel, Macabrel". Color verde brillante con zonas blancas transversales; crece hasta unos 3 metros; arborícola; hoyas del Orinoco y Amazonas. Caño Guapaya (Meta), La Macarena, norte, febrero 16, 1962, Hugo
Arévalo y Jesús M. Idrobo, encima de un árbol de cacao, en $10 \mathrm{~m}$. alt. (ICN No 1495).

3. B. hortulana hortulana (L.), 1758. "Macabrel, Macaurel". Crece hasta tres metros; arborícola; hoyas del Orinoco y Amazonas; abunda en el río Muco (Vichada).

4. B. hortulana cooki (Gray), 1842. "Matabogas, Mapaná Tigre, Oroya". Arborícola; se encuentra de noche en los arbustos cerca de la orilla de los arroyos; por su agresividad considerada como muy venenosa, en realidad inofensiva; se alimenta de aves y a veces de "Saltarroyos" ( $B a-$ siliscus, Iguanidae). Litoral del Caribe; Catatumbo; Cúcuta; Magdalena; Valle del Atrato; Acandí (Chocó).

\section{Familia Colubridae.}

Comprende la mayoría de las serpientes inofensivas; a base de ciertas características anatómicas del hemipenis (doble como en los Sauria), está dividida en varias subfamilias, entre ellas las Colubrinae y Xenodontinae. Esta división, sin embargo, no corresponde a la realidad biológica en muchos casos, sino es bastante artificial y existen discrepancias entre los especialistas. Por esta razón no me refiero a las subfamilias, sino únicamente a la familia Colubridae.

La mayoría de los géneros necesita, además, una revisión taxonómica urgente. Existen varias excelentes revisiones, $v . g r$., sobre el género Atractus del Ecuador (Savage, 1960); la subfamilia Dipsadinae (Peters, 1960 a), y los géneros Dryadophis (Stuart, 1941); Leptodeira (Duellman, 1958) y Leptophis (Oliver, 1958).

Se distinguen dos grupos grandes principales como siguen:

Grupo I. Aglypha. Ofidios aglifos. Dientes posteriores maxilares sin acanaladura.

Grupo II. Opistoglypha. Ofidios opistoglifos. Dientes posteriores maxilares acanalados; generalmente dos pares de ellos; poseen un veneno efectivo para paralizar su presa, pero no peligroso para el género humano.

\section{Grupo I. Aglypha.}

Género Atractus Wagler, 1828.

Serpientes pequeñas, subterráneas; por lo general pardo-oscuras o negruzcas; sin embargo, varias especies poseen colores vivos que consisten en anillos rojos, negros, blancos y amarillos, muy parecidos a los de las verdaderas "Corales" (género Micrurus), y se confunden fácilmente. Este género necesita una revisión total, y es muy probable que varias especies y subespecies descritas de Colombia no son válidas, sino representan sinónimos de otras o meramente diferencias indi- 
viduales, debido a la gran irregularidad del escamado de la cabeza, muy común en el género Atractus.

Especies:

1. A. andinus Prado, 1944. Terra typica: Andes (Ant.),

2. A. arangoi Prado, 1939. Terra typica: Colombia (sic.), sin localidad exacta.

3. A. biseriatus Prado, 1940. Terra typica: Manizales (Caldas).

4. A. colombianus Prado, 1939. Terra typica: Chocontá (Cund.).

5. A. crassicaudatus (Duméril \& Bibron), 1854. Terra typica: Bogotá. Choachí, Gutiérrez (Cundinamarca), Fusagasugá, Arracachal (Cund.), San Mateo (Boyacá), 2800 m. alt.

6. A. dubius (Jan), 1862. Terra typica: Bogotá.

7. A. elaps (Günther), 1858. Sinónimo: A. elaps tetrazonus Amaral, 1931, depresión de Guaicaramo (Boyacá), al E del río Meta. Gino-Gojé, río Apaporis; río Vaupés; Villavicencio, septiembre 11, 1967, Abraham Pérez.

9. A. fuhrmanni Peracca, 1914. Terra typica: Quebrada en la vecindad de Bogotá.

10. A. indistinctus Prado, 1939. Terra typica: Ocaña (N. de Sant.).

11. A. lasallei Amaral, 1931. Terra typica: Sampedro (Ant.).

12. A. latifrons (Günther), 1868. Río Apaporis, Putumayo, Caquetá.

13. A. (Leptocalamus) limitaneus Amaral, 1935. Terra typica: La Pedrera (Am.), Bajo Caquetá.

14. A. longimaculatus Prado, 1939. Terra typica: "Quindío", en realidad Pacho (Cund.), fide Dunn (1944 a).

15. A. loveridgei Amaral, 1930. Terra typica: Jericó (Ant.).

16. A. manizalensis Prado, 1939. Terra typica: No registrada para el tipo (sic). Villa María (Caldas) para el paratipo.

17. A. melanogaster Werner, 1916. Terra typica: Cañón del Tolima; arriba de Ibagué, 1700 metros aproximadamente.

18. A. melas Boulenger, 1908. Terra typica: Los Mangos (Valle); entre Buenaventura y El Pilón (Medem, 1965, p. 342).

19. A. multicinctus (Jan), 1865. Peña Lisa, Condoto.

20. A. nicefori Amaral, 1932. Terra typica: Jericó (Ant.).

21. A. nigriventris Amaral, 1932. Terra typica: Chita (Boyacá), 3005 m. alt.
22. A. obesus Marx, 1960. Terra typica: Santa Bárbara (Ant.), al pie del Cerro Frontino, Alto Urrao, afluente del río Penderisco, $2700 \mathrm{~m}$. alt., abril 1951, Philip Hershkovitz; El Roblal (Valle). río Pichindé, afluente del río Cali, Los Farallones, 2640 m. alt.; abril 25, 1946, José Cuatrecasas.

23. A. obtusirostris Werner, 1916. Terra typica: Cañón del Tolima.

24. A. oculotemporalis Amaral, 1932. Terra typica: Jericó (Ant.).

25. A. pamplonensis Amaral, 1937. Terra typica: Pamplona.

26. A. punctiventris Amarai, 1932. Terra typica: Villavicencio (Meta).

27. A. sanctae-martae Dunn, 1946. Terra typica: San Sebastián (Magd.), 2000 m. alt., Sierra Nevada de Santa Marta.

28. A. sanguineus Prado, 1944. Terra typica: Yarumal (Ant.).

29. A. trivittatus Amaral, 1932. Terra typica: Chita (Boyacá).

30. A. variegatus Prado, 1941. Terra typica: La Uvita (Boyacá), 2.408 m. alt.

31. A. vertebralineatus Prado, 1940. Terra typica: Ocaña (N. de Sant.).

32. A. vagleri Prado, 1945. Terra typica: Humbo (= Muzo).

33. A. werneri Peracca, 1914. Terra typica: Cafetal "Argelia", Mun. de Viotá (Cund.), 1830 m. alt. Santandercito (Cund.); Sabana de Bogotá.

Nota: Amaral (1932 b), registró A. guentheri (Wucherer), 1861, localidad típica: al sur de Bahía y Río de Janeiro, Brasil, de Jericó (Ant.), 1967 m. alt.; Werner (1899) señaló A. reticulatus Boulenger, 1885, localidad típica: São Lorenço, Rio Grande do Sul, sur de Brasil, como nuevo para Colombia, coleccionado en Fusagasugá, 1740 m. alt. La presencia de ambas especies nos parece muy poco probable en las localidades colombianas indicadas por razón del habitat completamente distinto.

Dunn (1944 a) consideró $A$. fuhrmanni como sinónimo con $A$. crassicaudatus, y A. longimaculatus y A. colombianus como sinónimos de A.werneri. Atractus elaps tretrazonus Amaral, 1931, es sinónimo con $A$. elaps (Günther), 1858, (Savage, 1960, p. 39).

Atractus dubius (Jan), 1862, de Bogotá, nunca ha sido encontrado más y, posiblemente, es uno de los sinónimos de $A$. crassicaudatus (Duméril \& Bibron), 1854.

La mayoría de los tipos y paratipos descritos por Amaral y Prado ha sido enviada por los Hermanos Apolinar y Nicéforo María.

Es evidente, que la nomenclatura del género Atractus se encuentra en un estado de alta con- 
fusión, debido parcialmente a la descripción de nuevas especies en forma acelerada y no hecha a base de ejemplares suficientes, sin tomar en cuenta las diferencias morfológicas individuales, y, además, no respaldada por estudios taxonómicos comparativos.

Género Chironius Fitzinger, 1826.

Especies:

1. C. carinatus (L.), 1758. "Cazadora, Lomo de machete, Matacaballos". Crece hasta unos tres metros; gruesa, agresiva y muy rápida; principalmente terrestre; es la especie más común y se encuentra en todo el país; es útil en las casas para la exterminación de roedores.

2. C. flavopictus (Werner), 1909. Río San Juan (Chocó).

3. C. fuscus (L.), 1758. Hoya del Amazonas.

4. C. grandisquamis (Peters), 1868. Isla Gorgona; litoral del Pacífico.

5. C. multiventris Schmidt \& Walker, 1943. Leticia (Am.), fide Shreve (1947 b).

6. C. sexcarinatus (Wagler), 1824. Entre Bucaramanga y Florida Blanca (Sant.), 895 - 1000 m. alt., marzo 10, 1961, Gilberto Toro García (ICN No 389 ), tentativamente det.: J. A. Peters; nuevo para Colombia.

7. C. schlueteri (Werner), 1899. Vertiente sur de La Macarena (Meta), hacia el Alto Guayabero, enero 19, 1959, F. Medem, Carlos A. Velásquez, Jorge Hernández Camacho (ICN Nos. 340, 344, 358, 379), det.: James A. Peters (1962). Por primera vez registrada en Colombia.

Género Dendrophidion Fitzinger, 1843.

Especies:

1. D. bi-vittatum (Duméril \& Bibron), 1854. Terra typica: Nueva Granada. Chocó, Antioquia, Tolima, Cundinamarca, Boyacá, Santander.

2. D. boshelli Dunn, 1944. Terra typica: Volcanes, 250 m. alt., Mun. Caparrapí (Cund.) ; solamente conocida de la localidad típica.

3. D. percarinatum (Cope), 1893. Río Napipí, afluente del Bajo Atrato (Chocó); El Centro; Paime; Muzo.

Género Diaphorolepis Jan, 1863.

Especies:

1. D. laevis Werner, 1923. Terra typica: Colombia, 1910, col: Fassl, sin localidad exacta; nunca ha vuelto a hallarse (Dunn, 1944 k, p. 213).

2. D. wagneri Jan, 1863. Distribución: Panamá y Ecuador (Bogert, 1964). Todavía no regis- trada de Colombia, pero muy posiblemente presente en el litoral del Pacífico. Los representantes de este género son muy escasos y, evidentemente, restrictos a ciertas áreas de Colombia, $\mathrm{Pa}$ namá y Ecuador, de 100 a 2200 metros de altura ; sus hábitos son desconocidos.

Género Dipsas Laurenti, 1768.

Serpientes pequeñas, delgadas, de hábitos nocturnos; arborícolas; se alimentan exclusivamente de moluscos terrestres y arborícolas.

Especies:

1. D. catesbyi (Sentzen), 1786. Morelia (Caquetá), al occidente de Florencia; Leticia; Villavicencio.

2. D. indica indica Laurenti, 1768. Leticia; Mitú (Vaupés).

3. D. pratti (Boulenger), 1897. Terra typica: Medellín (Ant.). Líbano (Tolima) ; Quindío; Cúcuta.

4. D. sancti-joannis (Boulenger), 1911. Terra typica: Pueblo Rico (Chocó), vertiente hacia el río San Juan, 5200 pies. Medellín; Jericó; El Tambo (Cauca).

5. D. temporalis (Werner), 1909. Peña Lisa, Condoto; Agua Clara (Chocó), río Tamaná, afluente del Alto San Juan, región de Primavera; sin fecha, col: Rahm (Peters, 1964).

Género Drepanoides Dunn, 1928.

Especie:

1. D. anomalus (Jan), 1863. Puerto Asís ( $\mathrm{Pu}$ tumayo), fide Dunn (1944 k); es muy rara y de costumbres desconocidas.

Género Dryadophis Stuart, 1939.

Especies:

1. D. bifossatus striatus Amaral, 1931. Terra typica: Villavicencio, Nicéforo M.

2. D. boddaerti boddaerti (Sentzen), 1796. "Lobera, Guardacamino, Yaruma”. Común en todo el país, inclusive la Isla Gorgona.

3. D. boddaerti mithveni (Stuart), 1933. Terra typica: San Lorenzo (Magd.), Sierra Nevada de Santa Marta. Principalmente en la Sierra Nevada, desde unos $900 \mathrm{~m}$. hasta $2000 \mathrm{~m}$. aproximadamente; existen, sin embargo, híbridos entre boddaerti boddaerti y boddaerti ruthveni procedentes de Bucaramanga.

4. D. pleei (Duméril \& Bibron), 1854. "Guardacamino". Común a lo largo del litoral del Caribe; Honda; La Mesa (Cund.); Jericó. 
Género Drymarchon Fitzinger, 1843. Especies:

1. D. corais corais (Boie), 1827. "Cazadora". Hoyas del Orinoco y Amazonas.

2. D. corais melanurus (Duméril \& Bibron), 1854. "Cazadora", "Sapa". Al norte y occidente de la Cordillera Oriental, desde la costa del $\mathrm{Pa}$ cífico hasta Santander aproximadamente. Un ejemplar (ICN No 267), procedente de San Antonio de Tena (Cund.), 1384 m. alt., río Bogotá, julio 7, 1962, Roberto Moros; comprende una localidad nueva.

Ambas especies son gruesas y de tamaño mayor; $D$. corais melanurus crece hasta 2.95 metros (Duellman, 1960, Copeia, $N^{\circ} 4$, pp. 367-368). Terrestres, pero se encuentran con frecuencia en los caños; en noviembre 3,1959 , hemos coleccionado un ejemplar de dos metros en el caño Becordó, afluente del San Juan, cerca de Noanamá (Chocó), el cual tenía una tortuga joven $(71 \mathrm{~mm}$. longitud del caparazón, (Geoemyda melanosterna nasuta), recién devorada, en el estómago (Medem, 1962 , p. 290). Los Drymarchon se alimentan principalmente de ranas y sapos (Bufo marinus), pero también de lagartos y aves (Nicéforo M., 1933).

Género Drymobius Fitzinger, 1843.

Especies:

1. D. margaritiferus (Schlegel), 1837. "Azotadora”. Litoral del Caribe; Valle del Magdalena.

2. D. rhombifer (Günter), 1860. Virtualmente en todo el país.

Género Drymoluber Amaral, 1929. Monotípico. Especie:

1. D. dichrous (Peters), 1863. Crece hasta un metro aproximadamente; desde la vertiente oriental de la Cordillera Oriental hasta la hoya del Amazonas.

Género Dugandia Dunn, 1944. Monotípico. Especie:

1. D. bicincta (Hermann), 1804. Terra typica: Raudal de Yuruparí (Vaupés), río Vaupés, noviembre 10, 1943, Paul H. Allen.

Nota: Hoge (1958) consideró que el nombre Hydrodynastes Fitzinger, 1843, tiene prioridad sobre Dugandia; por esta razón se debe aplicar la denominación Hydrodynastes bicinctus (Hermann), 1804; Medem (1965, p. 316).

Esta serpiente es bastante rara y de hábitos poco conocidos; es principalmente acuática; la hemos observado en 1958 en el Caño Carurú, afluente del Aito Vaupés. Por su color rosado con barras pardo-oscuras o negras en pares la confunden con las verdaderas "Corales" (género Micrurus).
Pertenece a la fauna del Amazonas, pero su distribución se extiende hasta los llanos del Meta; hemos encontrado tres ejemplares de este nuevo habitat, un poco sorprendente para una serpiente considerada como confinada a las selvas amazónicas: dos ejemplares adultos (ICN Nos. 238, 1281), enero 7, 1959, caño "Ema", hacienda "El Viento", frente a Matazul, Alto Meta, entre Puerto López y Remolino, Carlos A. Velásquez; murieron en el Instituto de Ciencias Naturales en abril 4 y mayo 13, 1959, respectivamente.

Otro ejemplar, procedente de Puerto Lleras (Meta), Mun. San Martín, Alto Ariari, mayo 11, 1967, F. Medem; comprado en Villavicencio; murió en julio 21, 1967; midió 1720 milímetros total, cola: $430 \mathrm{~mm}$., sexo: hembra; depositada en la colección de la Sección de Biología Tropical en Villavicencio.

Durante todo el tiempo permaneció tanto en el agua como en tierra; mudó la piel entre junio 29 y julio 18, 1967; se alimentó una sola vez de una rana arborícola (Hyla crepitans), pero no de pequeñas "Terecayes" (Podocnemis unifilis), "Babillas" (Caiman sclerops) y otras serpientes (Erythrolamprus aesculapii), tampoco de diferentes peces pequeños; por consecuencia, su alimento natural es desconocido, ya que es poco probable que una serpiente tan grande y fuerte se alimente de pequeñas ranas. Era poco agresiva, pero a veces trató a morder, inflando el cuello lateralmente como lo hace la "Sapa" (Xenodon severus). Los ejemplares del caño Carurú han sido observados de día en el agua, nadando y sacando la mitad de la cabeza afuera, igual al ejemplar mantenido en cautividad arriba mencionado, el cual era más bien diurno y de noche permaneció inmóvil en el fondo del acuario.

Género Enulius Cope, 1871.

Especies:

1. E. flavitorques (Cope), 1869. Terra typica: Río Magdalena, Colombia.

2. E. sclateri (Boulenger), 1894. Un ejemplar (ICN No 82) de El Centro, región de Barrancabermeja entre el río Oponcito y la quebrada de Nutria, 150-170 m. alt.; sin más datos; posiblemente coleccionado por Dunn el cual la señaló de Barrancabermeja (1944 k). Por su cabeza amarilla en contraste con el pardo oscuro o claro del cuerpo, confundida con la "Coral" (Micrurus). Ambas especies son raras, de hábitos desconocidos.

Género Geophis Wagler, 1830.

Serpientes pequeñas, subterráneas y muy escasas en Suramérica; constituyen elementos faunísticos de México y la América Central.

Especies:

1. G. nigroalbus (Boulenger), 1908. Terra typica: Pavas (Valle), $1600 \mathrm{~m}$. alt. 
2. G. brachycephalus (Cope), 1871. Landázuri (Sant.) ; por primera vez registrada en Colombia, (Downs, 1967, impreso).

Género Helicops Wagler, 1830.

Serpientes acuáticas ; crecen hasta unos $600 \mathrm{mi}-$ límetros aproximadamente; por su color confundidas con la "Mapaná" (Bothrops atrox); inofensivas.

Especies:

1. H. angulatus (L.), 1758. "Cuatronarices de agua”. Llanos del Meta; Alto Guayabero, La Macarena; se alimenta de peces, especialmente de "Anguillas" (Synbranchus marmoratus).

2. H. danieli Amaral, 1937. Terra typica: Carare (Sant.), afluente del Magdalena, Daniel, Hno.

Nota: La descripción específica ha sido hecha a base de un solo ejemplar juvenil; posiblemente la especie no es válida (Hoge, 1966, comunicación personal); es muy parecida a $H$. scalaris.

3. H. polylepis Günther, 1861. Hoya del Amazonas y, posiblemente, en los llanos del Meta (Adler, septiembre 3,1967 , in litt.).

4. H. scalaris (Jan), 1865. "Mapaná de agua". Costa del Caribe; hoya del Magdalena; río Uré; río Atrato hasta Quibdó; Cúcuta.

Género Hydrops Wagler, 1830.

Ofidios pequeños, acuáticas, muy parecidas a las "Corales" por su color.

Especies:

1. H. martii (Wagler), 1824. "Coral". Hoya del Amazonas.

2. H. triangularis triangularis (Wagler), 1824. La Pedrera (Am.), Bajo Caquetá.

3. H. triangularis venezuelanus Roze, 1956. Río Vaupés; Amazonas.

Género Lampropeltis Fitzinger, 1843.

Especie:

1. L. doliata micropholis Cope, 1861. "Coral".

Presentamos las siguientes localidades nuevas: Entre San Agustín (Huila) y el Estrecho del Magdalena, $1600 \mathrm{~m}$. alt. aproximadamente, julio 18 , 1960, Ernst Ullrich (ICN No 39). Montañita (Caquetá), a $40 \mathrm{kms}$. al oriente de Florencia, río Orteguaza, $500 \mathrm{~m}$. alt., aproximadamente, abril 1957, Col. (Pol. Nal.) Luis A. Hernández, (ICN No 165). Bello (Ant.), cerro de la represa "Fabricato", arriba del pueblo, $2500 \mathrm{~m}$. alt. aproximadamente, julio 18, 1966, Humberto Alvarez. Valle de Socorpá, Sierra de Perijá (Cesar), $1400 \mathrm{~m}$. alt., en una platanera de día, junio 9, 1966, Lars Persson. Arcabuco (Boyacá), cerca de Tunja,
2500 m. alt., aproximadamente, octubre 9, 1963, P. Ivo Schaible y Richard Schahl (comunicación personal, película en colores). Subía (Cund.), Salto del Tequendama, $2200 \mathrm{~m}$. alt., enero 1948, Alvaro Tocres Barreto.

Dunn, (1944 k, p. 207), registró un ejemplar procedente de Florencia (Caquetá), Alto Ortegua$\mathrm{za}, 450 \mathrm{~m}$. alt., aproximadamente.

L. doliata micropholis pertenece a un género que abunda en los Estados Unidos y México; constituye el único representante en Suramérica, muy posiblemente ha inmigrado durante épocas recientes al norte de Colombia hasta la Cordillera Oriental la cual penetró hasta su vertiente sur-oeste en la región de Florencia.

$\mathrm{Su}$ habitat consiste en las regiones montañosas de las tierras calientes hasta frías; nunca ha sido registrado del habitat tropical pluvial; crece hasta un metro aproximadamente y se alimenta de roedores; por su coloración que consiste en anillos rojos, negros y amarillos la confunden con las verdaderas "corales" del género Micrurus.

Género Leimadophis Fitzinger, 1843.

Especies:

1. L. bimaculatus bimaculatus (Cope), 1899. Terra typica: Vecindad de Bogotá. El tipo y los paratipos han sido enviados junto con otros reptiles, desde Bogotá para ser exhibidos, en el año de 1893, en la Exposición Mundial de Chicago (Medem, 1965, p. 307). "Sabanera". Sabana de Bogotá; La Uvita: Chita (Boyacá) ; Sasaima; Fusagasugá.

2. L. bimaculatus lamonae Dunn, 1944. Terra typica: Sonsón (Ant.), 2410 m. alt. Andes (Ant.), San Pedro (Ant.), Manizales (Caldas).

3. L. epinephalus epinephalus (Cope), 1862. Terra typica: Río Truandó, afluente del Bajo Atrato. Río San Juan, Jericó, Mariquita, Pacho (Cundinamarca), Sasaima, Pamplona.

4. L. melanotus (Shaw), 1802. "Esterilla". Costa del Atlántico, entre Barranquilla y Tolú (Sucre), Valle del Magdalena, Cúcuta, Arauca (Dunn, $1944 \mathrm{k})$.

5. L. pseudocobella (Peracca), 1914. Terra typica: Angelópolis y Pueblorrico (Ant.), 1955 y 1942 m. alt., respectivamente.

6. L. pygmaeus (Cope), 1868. Mocoa (Putumayo); en general en la hoya del Amazonas cerca de la vertiente de la Cordillera Oriental.

7. L. reginae (L.), 1758. La Pedrera, Bajo Caquetá; La Salina (Boyacá), 1439 m. alt., Santa Librada (N. de Sant.).

8. L. typhlus (L.), 1758. Puerto Asís, Alto $\mathrm{Pu}$ tumayo; La Tagua, Alto Caquetá; Medina (Cundinamarca), al $\mathrm{E}$ de Villavicencio, vertiente de la Cordillera Oriental; 576 m. alt., Suaita (Sant.), $1610 \mathrm{~m}$. alt. 


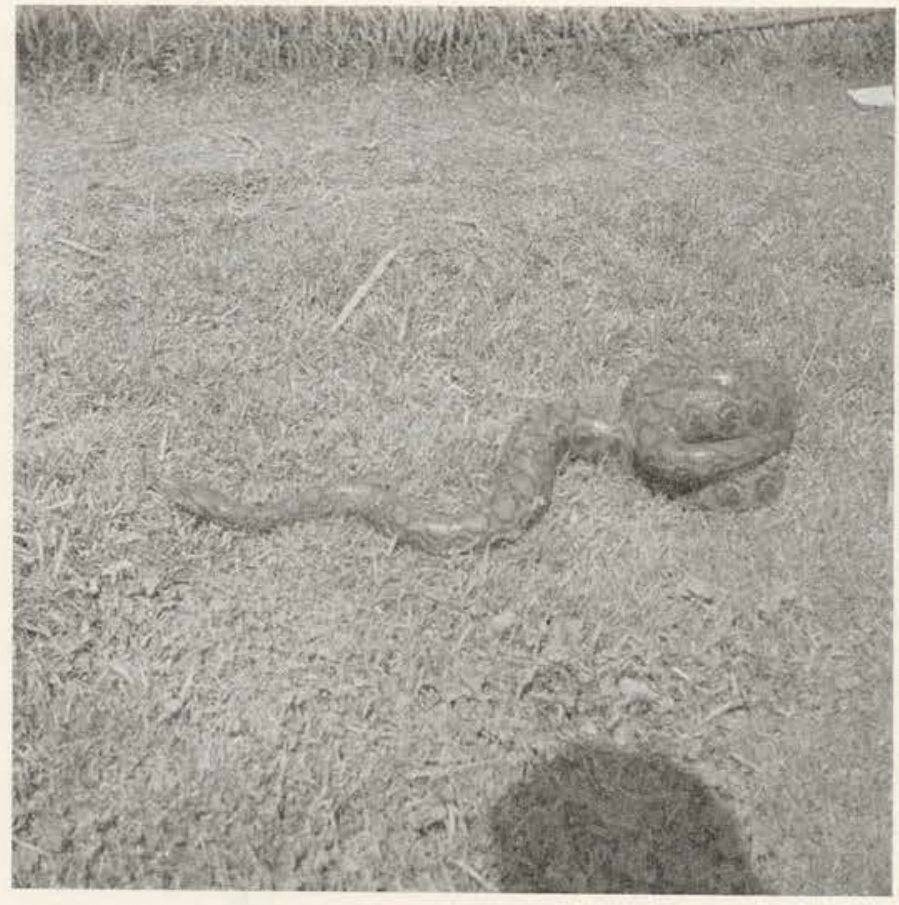

5. Epicrates cenchria cenchria. "Macabrel". Región de Puerto López (Meta); diciembre 3,$1958 ; 1.62$ metros.

6. Constrictor constrictor constrictor. "Boa, Güio perdicero". Río Guayabero (Meta), Angostura No 2, enero 3, 1957; 3.12 metros.

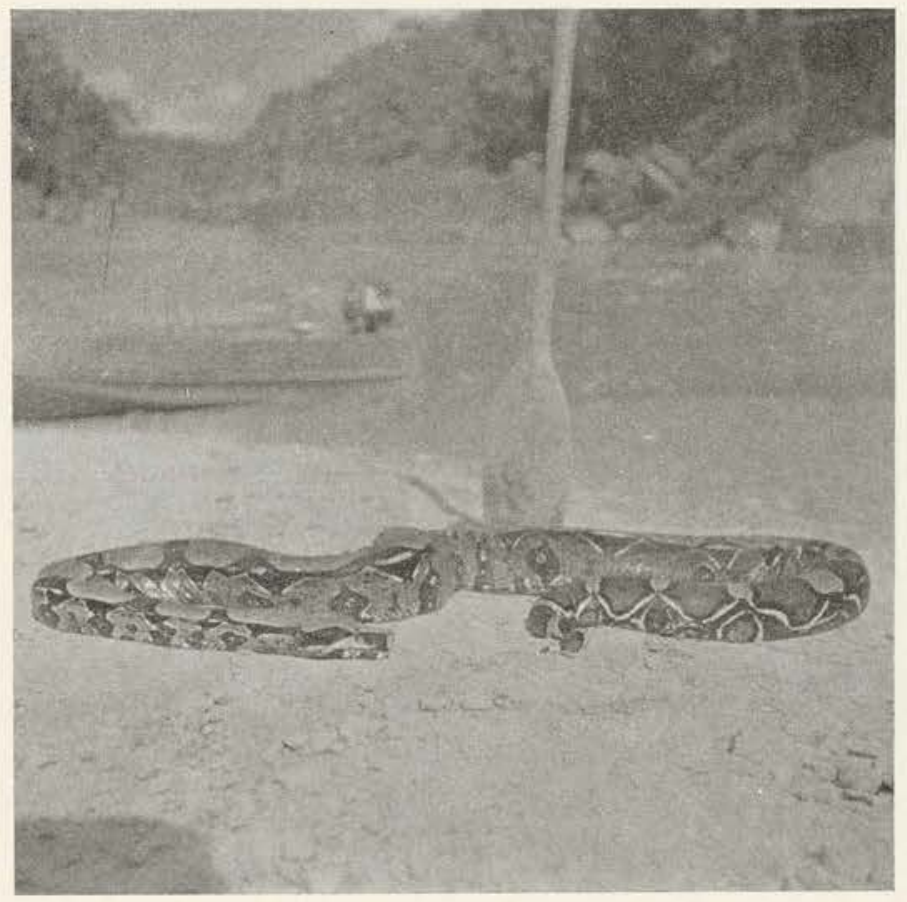




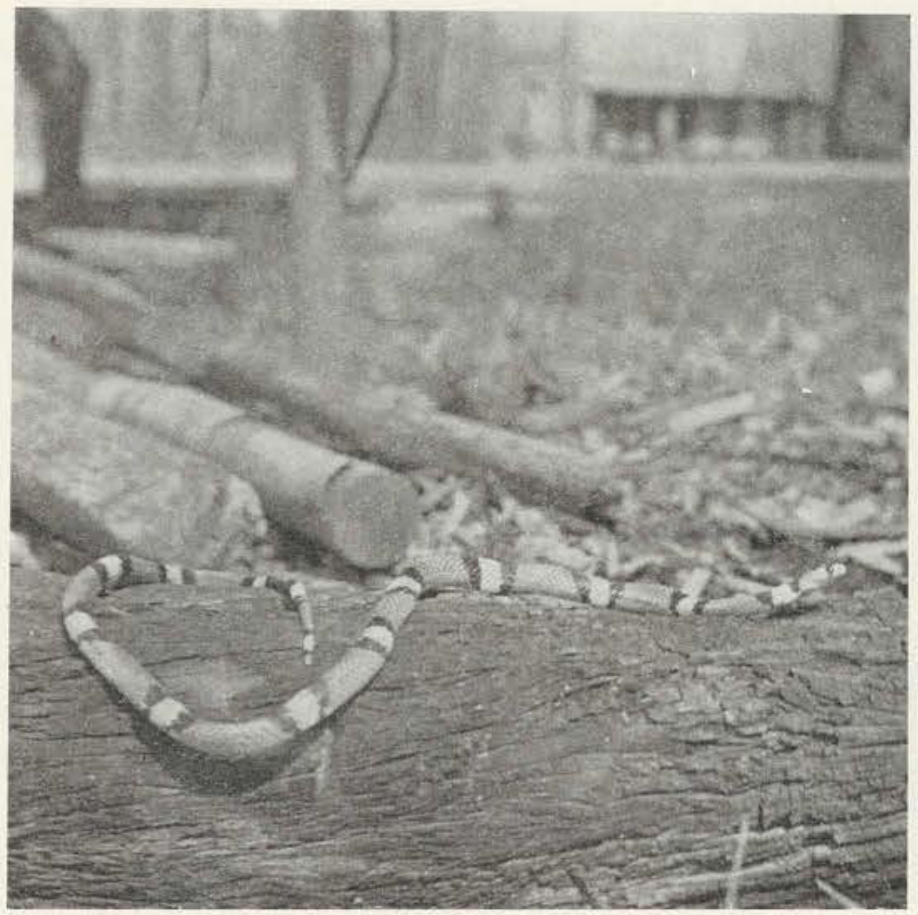

7. Erythrolamprus aesculapii ssp. "Falsa $\mathrm{Co}$ ral". Lago "El Dorado" (Vaupés), marzo 20,$1958 ; 83.6$ centímetros.

8. Xenodon severus. "Sapa". Sierra de La Macarena (Meta), Alto Guayabero, marzo 13, 1959. Ejemplar juvenil; 42.0 centímetros. Infla en cuello lateralmente, así se observan las líneas y la mancha central blancas sobre un fondo pardo oscuro.

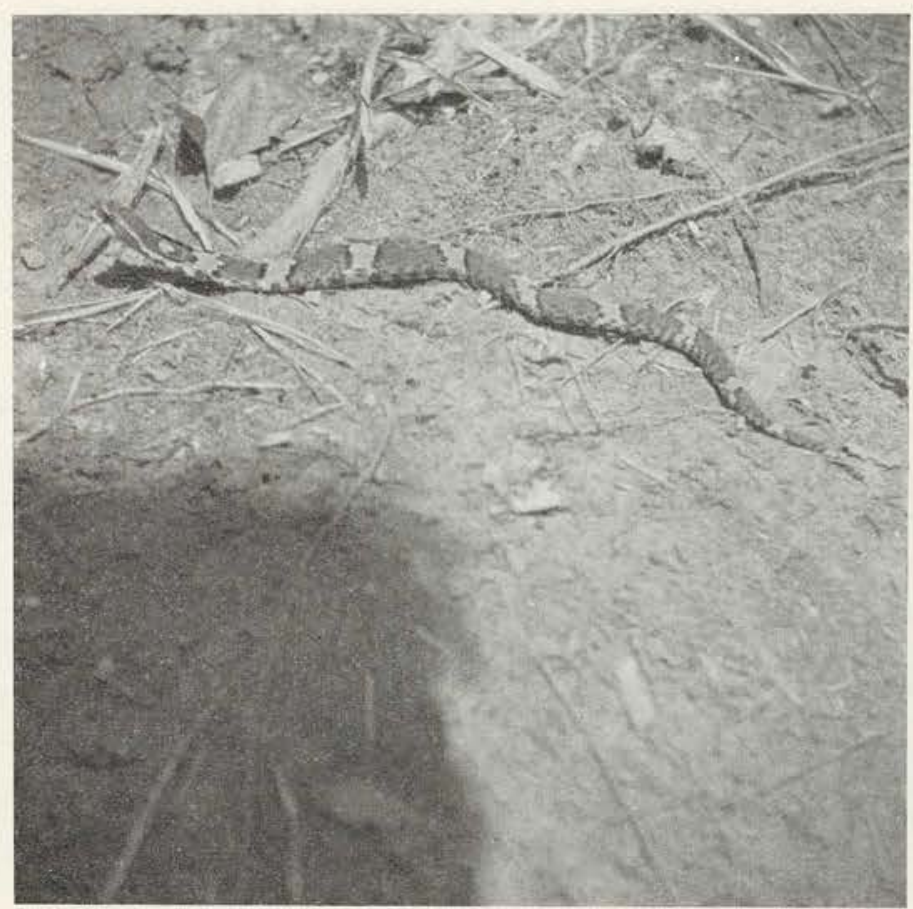




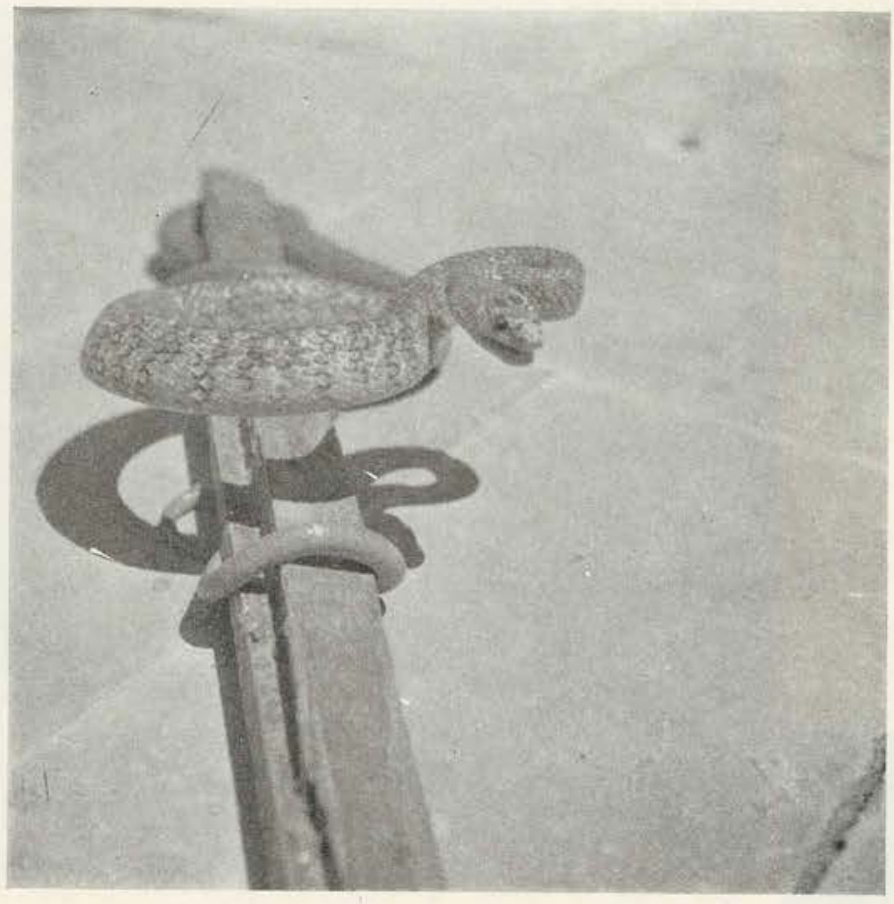

9. Philodryas viridissima. "Lora". Río Acacías (Meta), agosto 7, 1961. Serpiente semiacuática; 1.05 metros.

10. Leptophis ahaetulla occidentalis. Junqui1lo (Córdoba), caño Betancí, afluente del Sinú, octubre 19, 1956. "Cazadora verde"; un metro; vista lateral de la cabeza.

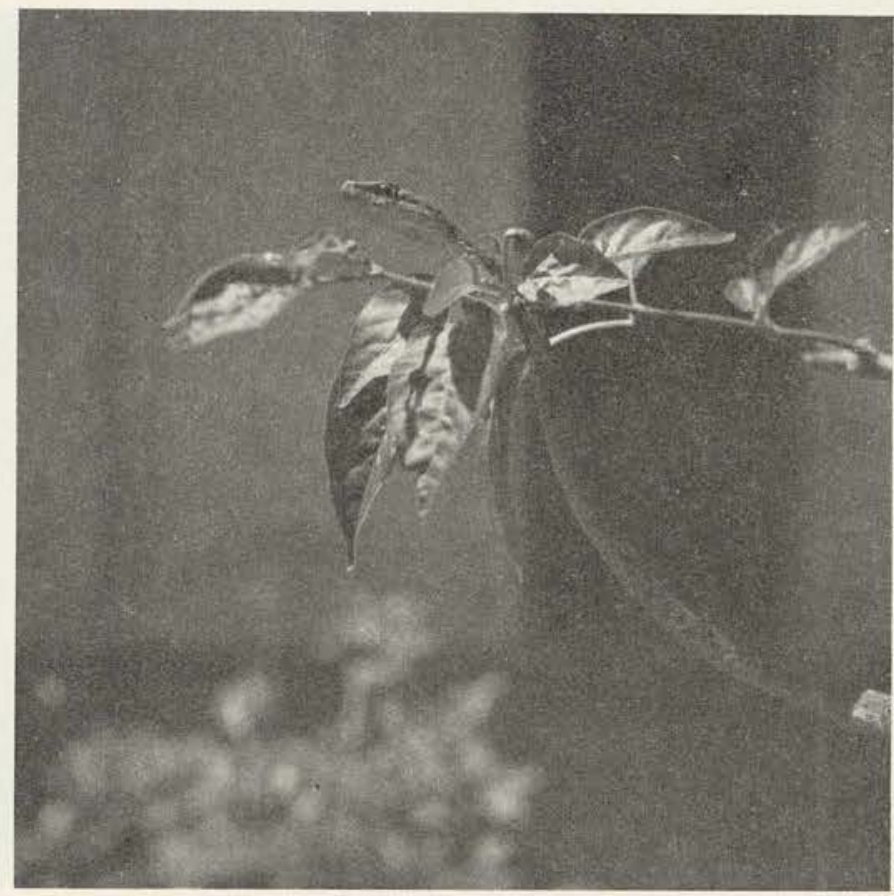




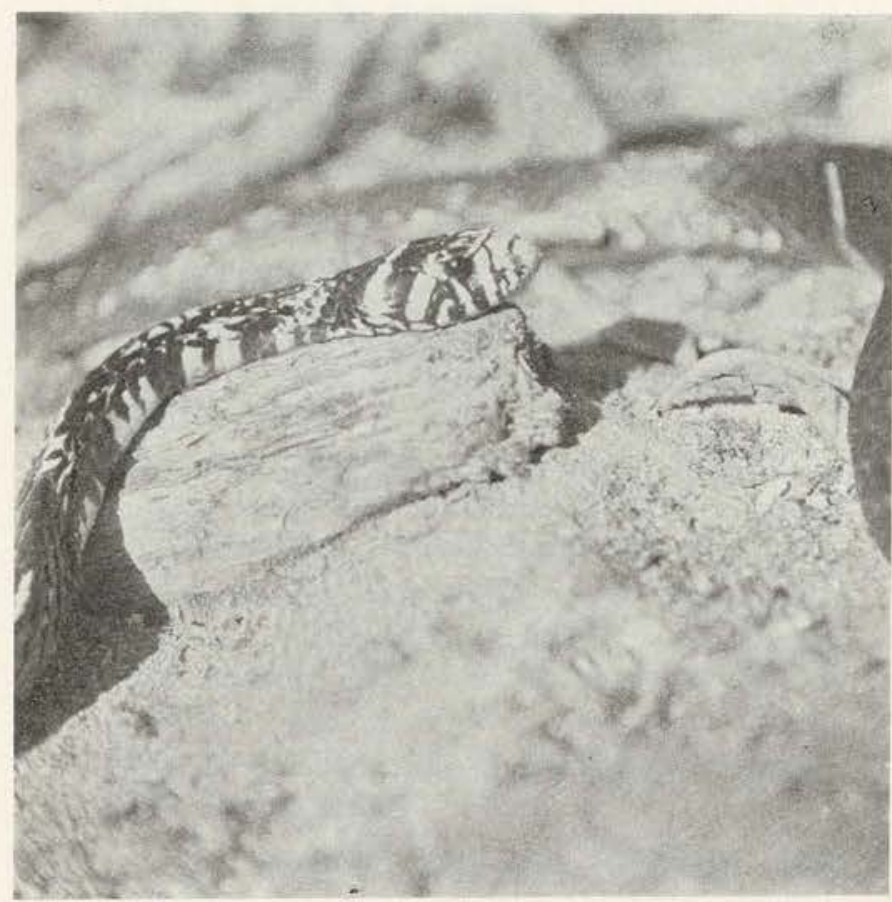

12. Pelamis platurus. "Serpiente marina". Isla Gorgona (Cauca), febrero 23, 1961; 50.2 centímetros. La cola está comprimida lateralmente; ofidio venenoso, abundante en el Pacífico.
11. Spilotes pullatus pullatus. "Tigra, Toche". Río Uré (Córdoba), afluente del San Jorge, febrero 11, 1963; 2.70 metros. Vista de la cabeza.
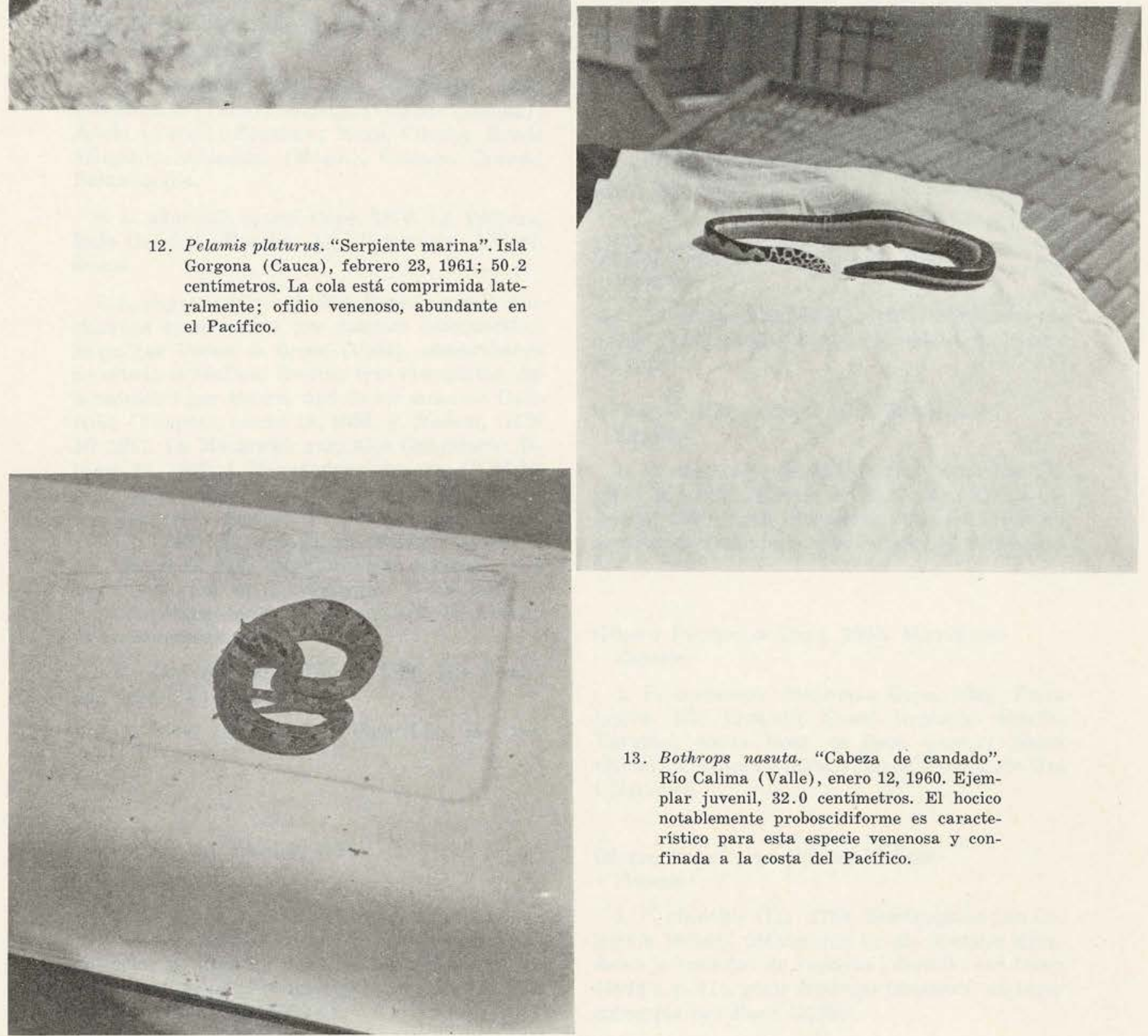

13. Bothrops nasuta. "Cabeza de candado" Río Calima (Valle), enero 12, 1960. Ejemplar juvenil, 32.0 centímetros. El hocico notablemente proboscidiforme es característico para esta especie venenosa y confinada a la costa del Pacífico. 
Género Leptophis Bell, 1825.

Serpientes "Cazadoras" o "Bejuquillas" de color verde brillante o azuloso; terrestres y arborícolas; crecen hasta 1.20 metros aproximadamente y se alimentan principalmente de lagartos y ranas.

Especies:

1. L. ahaetulla bocourti Boulenger, 1898. En Colombia encontrada solamente en la Isla Gorgona, sur, monte frente a la Isla Gorgonilla, $30 \mathrm{~m}$. alt., febrero 1, 1961, F. Medem y Alejandro Góngora (ICN No 392).

2. L. ahaetulla chocoensis Oliver, 1942. Terra typica: Peña Lisa, río Condoto. Río San Juan y Puerto Pizarro, desembocadura del río Baudó.

3. L. ahaetulla copei Oliver, 1942. Terra typica: Paratipos de Cararú, desembocadura del caño Carurú, afluente del Vaupés arriba del raudal Yuruparí.

4. L. ahaetulla nigromarginatus (Günther), 1886. Leticia (Am.).

5. L. ahaetulla occidentalis (Günther), 1859. Los Mangos (Valle); Medellín; Guamo (Tolima); Apulo (Cund.); Sasaima; Muzo, Cúcuta, Bonda (Magd.), Aracataca (Magd.), Ciénaga Grande, Barranquilla.

6. L. ahaetulla ortoni Cope, 1876. La Pedrera, Bajo Caquetá; Morelia, Alto Orteguaza; Villavicencio.

7. L. cupreus (Cope), 1868. Especie nunca considerada como válida por razones desconocidas, hasta que Peters \& Orcés (1960), comprobaron su estado específico. Existen tres ejemplares, determinadas por Peters, uno de los autores: Caño Itilla (Vaupés), marzo 13, 1958, F. Medem, (ICN No 191). La Macarena, sur, Alto Guayabero; febrero 13, 1959, J. Hernández Camacho, (ICN No 347). Alto Guayabero, Angostura No 1, frente a La Macarena, febrero 13, 1959, Pablo Bernal, (ICN No 390). Se trata de un elemento faunístico del Amazonas, cuya distribución se extiende hasta la vertiente sur de La Macarena, lo que también pasa con otros elementos de la fauna del Amazonas propiamente dicho.

8. L. depressirostris (Cope), 1860. Isla Gorgona; litoral del Pacífico.

9. L. riveti Despax, 1911. Peña Lisa, río Condoto.

Género Liophis Wagler, 1930.

Especies:

1. L. cobella (L.), 1758. Arboledas (N. de Sant.), 1070 m. alt.; Santa Librada (N. de Sant.) ; Villavicencio; La Pedrera. Localidades nuevas: Pasto; Obando (Cauca) ; Fusagasugá (Cund.) ; fide Valdivieso \& Tamsitt (1963 a).
2. L. purpurans (Duméril \& Bibron), 1854. Pto. Asís (Putumayo).

Género Lygophis Fitzinger, 1843.

Especies:

1. L. boursieri (Jan), 1867. Ricaurte (Nariño), a $78 \mathrm{kms}$. al occidente de Pasto, $1300 \mathrm{~m}$. alt., K. v. Sneidern. Comprende el primer hallazgo de esta especie en Colombia; era únicamente conocida del Ecuador. (Meyers, 1966).

2. L. lineatus (L.), 1758. "Guardacamino". Común en la costa del Atlántico; Barrancabermeja; Villavicencio; San Martín (Meta); San José del Guaviare (Vaupés).

Género Masticophis Baird \& Girard, 1853.

Especie:

1. M. mentovarius centralis Roze, 1953. Terra typica: Maicao (Guajira), Colombia, abril 16, 1941; Wetmore, Carriker, Jr. y F. Carlos Lehmann, encontrada en el buche de una ave rapaz (Buteo albicaudus colonus, fide Lehmann, 1964, comunicación personal); (Medem, 1965, p. 331). Confinada a la Guajira; constituye el único representante de este género norte y centroamericano en la América del Sur.

Género Ninia Baird \& Girard, 1853.

Especie:

1. N. atrata (Hallowell), 1845. Serpiente pequeña, subterránea; en todo el país en la Tierra caliente

Género Nothopsis Cope, 1871. Monotípico. Especie:

1. N. rugosus Cope, 1871. Agua Clara, Río Tamaná (Chocó), afluente del San Juan; Sierra del Baudó, 1000 m. alt. Serpiente pequeña y por su aspecto confundida con la "Mapaná" (Bothrops atrox), muy escasa.

Género Pliocercus Cope, 1860. Monotípico. Especie:

1. P. euryzonus euryzonus Cope, 1862. Terra typica: Río Truandó, Nueva Granada. Sonsón, Yarumal, Santa Rosa de Osos (Ant.); Neiva (Huila), Cimitarra (Sant.), Muzo, Paime, río Uré (Córdoba).

Género Pseudoeryx Fitzinger, 1826.

Especie:

1. $P$. plicatilis (L.), 1758. Semiacuática; en Colombia hallada únicamente en un pantano situado en la vecindad de Popayán; descrito por Dunn (1944 i, p. 71), como Hydrops lehmanni, un error corregido por Roze (1956). 
Género Pseustes Fitzinger, 1843.

Especies:

1. P. poecilonotus polylepis (Peters), 1867. "Cazadora". Hoyas del Amazonas y Orinoco.

2. P. poecilonotus shropshirei Barbour \& Amaral, 1924. Costas del Pacífico y Atlántico; Valle del Magdalena; Isla Gorgona.

3. P. sulphureus sulphureus (Wagler), 1824. Hoya del Amazonas; un solo ejemplar de La Macarena, sur, Alto Guayabero, cerca del campamento $\mathrm{N}^{\circ} 1$, febrero 22, 1959, C. A. Velásquez, (ICN Ne 393).

Rossman \& Williams (1966), obtuvieron una hembra de $P$. sulphureus sulphureus, enviada desde Leticia (Am.) y posiblemente capturada en la vecindad, aunque sin localidad exacta; midió 2939 $\mathrm{mm}$. total, cabeza - cuerpo: $2131 \mathrm{~mm}$., cola: 807 milímetros. Los mismos autores indicaron que esta especie no ha sido nunca registrada en Colombia.

Los representantes del género Pseustes comprenden ofidios gruesos de una longitud considerable. Hemos coleccionado (enero 15, 1951), entre los caños Guapaya y Guapayita, La Macarena, norte, una hembra de $P$. poecilonotus polylepis, que tenía las siguientes dimensiones: total: $2762 \mathrm{~mm}$.; cabeza-cuerpo: $2129 \mathrm{~mm}$; cola: 633 $\mathrm{mm}$.; y grosor: 131 milímetros. Su contenido estomacal consistía en las cáscaras blancas de un huevo, evidentemente de un ave, y plumas negras de un ave pequeña indeterminada. El género Pseustes es aparentemente más escaso al este de la Cordillera Oriental que los géneros Chironius y Spilotes.

Género Rhadinea Cope, 1863.

Serpientes pequeñas, subterráneas y poco abundantes en Colombia. La nomenclatura está todavía en un estado de confusión. Mientras Dunn (1944 d), aplica el nombre de Rhadinea, Roze (1958, 1964), está en favor de Urotheca Bibron, 1843. El primer autor indica que el género Urotheca ha sido usado para ambos géneros de Rhadinea y Pliocercus, y que el tipo de Urotheca no está bien establecido.

En cambio, Roze examinó el tipo de Urotheca en el Museo de Historia Natural de París, y le pareció ser congenérico con Rhadinea vermiculaticeps Cope, 1863, el género-tipo de Rhadinea; por esta razón prefiere el uso tentativo del nombre genérico Urotheca; según el mismo autor, una. revisión está en preparación.

Especies:

1. $R$. antioquiensis Dunn, 1943. Terra typica: San Pedro (Ant.), $2560 \mathrm{~m}$. alt., solamente conocida de la localidad típica.

2. R. brevirostris (Peters), 1863. La Pedrera (Am.).
3. R. lateristriga lateristriga (Berthold), 1859. Terra typica: Provincia de Popayán, Nueva Granada. Purnio (Ant.), antigua mina de oro al oeste de La Dorada, valle del Magdalena; Bucaramanga.

4. R. pachyura fulviceps Cope, 1886. Purnio; San Joaquín (Caldas); San Vicente de Chucurí (Sant.) ; Muzo.

Nota: Rhadinea decorata (Günther), 1858, descrita de México, ha sido registrada de Purnio por Werner (1899); es evidentemente un error y decorata no ha sido nunca hallada en Colombia; se trató de Rhadinea pachyura fulviceps incorrectamente identificada (Dunn, 1944 d, p. 492).

Género Scaphiodontophis Taylor \& Smith, 1943. Especie:

1. S. venustissimus (Günther), 1894. Muzo (Amaral, 1932 b). Un ejemplar (ICN No 23), procedente de la hacienda "El Trianón", Mun. de S. V. de Chucurí (Sant.), 300-400 m. alt., agosto 12, 1957, Jorge Hernández Camacho.

Es por su coloración, desde la cabeza hasta la tercera parte del cuerpo muy parecida a una "coral" (Micrurus), y de este sector hasta el extremo posterior de la cola de color carmelita-claro con líneas paralelas longitudinales, formadas por pequeñas manchas negras. Esta coloración y otras características morfológicas corresponden más bien a $S$. annulatus annulatus (Duméril \& Bibron, 1854); por falta de material comparativo no es posible de identificarla correctamente.

El género Scaphiodontophis es centroamericano y conocido desde México hasta la zona del Canal de Panamá, y, evidentemente, muy escaso en Colombia.

Género Sibon Fitzinger, 1826.

Especies:

1. S. nebulata nebulata (L.), 1758. Sierra Nevada de Santa Marta, La Concepción; San Lorenzo; Río Frío; Santa Rosa (Bol.), al S. de Cartagena hacia el Canal del Dique; Muzo, Villavicencio.

2. S. nebulata hartwegi Peters, 1960. Terra typica: Barrancabermeja (Sant.). Río Porce (Ant.), fluente del Nechí; Medellín; Paime; Sasaima.

3. S. nebulata leucomelas (Boulenger), 1896. Terra typica: Buenaventura, W. F. Rosenberg. Litoral del Pacífico; Andagoya.

4. S. nebulata popayanensis Peters, 1960. Terra typica: Popayán, enero 1947, K. v. Sneidern. Moscopán; Tierradentro (Cauca).

Género Spilotes Wagler, 1830.

Especie:

1. S. pullatus pullatus (L.), 1758. "Tigra, Toche". Color amarillo y negro brillante por lo general; la población procedente del Bajo Magda- 
lena es amarilla clara con pocas zonas negras ; arborícola y terrestre; se alimenta de ranas, lagartos, aves y pequeños mamíferos; es agresiva y se mueve con gran velocidad; de tamaño mayor. Un macho, procedente del río Uré (Córdoba), afluente del San Jorge, febrero 11, 1963, C. A. Velásquez, midió en total 2700 milímetros; cabeza-cuerpo: $1990 \mathrm{~mm}$; cola: $710 \mathrm{~mm}$. Relativamente común en todo el país.

\section{Género Synophis Peracca, 1896. \\ Especie:}

1. S. lasallei (Nicéforo María), 1950. Terra typica: Al norte de Albán (Cund.), 2200 m. alt., aproximadamente, a $60 \mathrm{kms}$. al noroeste de Bogotá, Cordillera Oriental, vertiente occidental. En Colombia conocida solamente de la localidad típica; comprende una especie muy rara y registrada de las zonas montañosas de Colombia y Ecuador.

Género Tretanorhinus Duméril \& Bibron, 1854. Especie:

1. T. taeniatus Boulenger, 1903. Conocida solamente por dos ejemplares, el tipo procedente de la costa del Pacífico del Ecuador, y otro hallado en la zona de manglares airededor de Buenaventura; se desconocen su distribución geográfica y costumbres; evidentemente, es una serpiente acuática o semiacuática y su habitat consiste en zonas inundadas por el agua salobre.

Género Xenodon Schlegel, 1837.

Especies:

1. X. rhabdocephalus (Wied), 1825. "Sapa". En todo el país, desde el Chocó hasta el Amazonas.

2. X. severus (L.), 1758. "Sapa". Hoyas del Amazonas y Orinoco. Su habitat consiste en regiones húmedas, $v . g r$., monte, pasto cerca de las lagunas, pantanos y rastrojo denso. Se alimenta de ranas y sapos (Bufo marinus). Un macho, procedente de Villavicencio, septiembre 12, 1967, Carlos A. Velásquez, midió en total $1330 \mathrm{~mm}$.: cola: 170 milímetros. El color de los adultos es pardo claro uniforme, mientras los juveniles en diferentes estados de desarrollo tienen colores muy distintos: los más pequeños son oscuros, con zonas transversales claras y, cuando aplanan la nuca lateralmente, aparece un diseño blanco sobre el pardo oscuro que consiste en una mancha en el centro y un par de zonas laterales; los juveniles de tamaño mayor son amarillentos con barras transversales oscuras y no tienen el mencionado diseño nucal.

\section{Grupo II. Opisthoglypha.}

Los ofidios opistoglifos poseen un par de dientes maxilares posteriores acanalados y su veneno es efectivo para paralizar su presa, en cambio, no forma un peligro para el género humano.

Género Apostolepis Cope, 1861. Especie:

1. A. nicefori Amaral, 1935. Terra typica: La Pedrera (Am.), Bajo Caquetá.

\section{Género Clelia Fitzinger, 1826.}

Especies:

1. C. clelia clelia (Daudin), 1803. "Cazadora negra, Chonta". Crece hasta unos tres metros y se alimenta exclusivamente de otras serpientes, entre ellas también de la "Mapaná" (Bothrops); por esta razón está protegida por la ley en el Brasil, en cambio, en Colombia no existe ninguna protección para ésta y otras serpientes útiles. Los juveniles se distinguen de los adultos por su color rojo de la parte dorsal del cuerpo y cola, negro de la cabeza y blanco amarillento de la nuca, muy parecido a la coloración de los adultos de Pseudoboa neuwiedi; en cambio, los adultos son de color negro brillante uniforme. Se encuentra en todo el país, inclusive en la Isla Gorgona.

2. C. clelia scytalina (Cope), 1866. En las tres Cordilleras desde 1500 hasta 2000 metros aproximadamente.

Género Coniophanes Cope, 1860.

Especies:

1. C. fissidens fissidens (Günther), 1858. Medellín, Jericó, Segovia (Ant.), y Barichara (Santander).

2. C. fissidens andresensis Bailey, 1937. Terra typica: San Andrés, isla, conocida solamente de la localidad típica.

Género Erythrolamprus Wagler, 1830.

Los representantes son muy parecidos a las "Corales" del género Micrurus; su color consiste en anillos negros en pares, rojos y amarillos blancuzcos.

Especies:

1. E. aesculapii aesculapii (L.), 1758. "Coral". Se alimenta de ranas, lagartos y de otras serpientes. Existe en todo el país.

2. E. aesculapii bizonus Jan, 1863. Se encuentra en todo el país.

3. E. mimus mimus (Cope), 1868. Alto Putumayo y Caquetá.

4. E. mimus micrurus Dunn \& Bailey, 1939. Andagoya; río San Juan; Bajo Calima, enero 1959, 
I. Cabrera (ICN No 310) ; Malta, 33 kms. de Pto. Salgar (Cund.), río Magdalena, abril 15, 1960, Horst Schimmer y Ernesto Osorno Mesa (ICN No 84).

Género Imantodes Duméril \& Bibron, 1853.

Serpientes delgadas y arborícolas; se alimentan principalmente de lagartos.

Especies:

1. I. cenchoa cenchoa (L.), 1758. "Bejuquilla". Se encuentra en todo el país.

2. I. inornatus (Boulenger), 1896. Bajo Calima, campamento "Cartón de Colombia", a $7 \mathrm{kms}$. de distancia del río en dirección a Buenaventura, 1960 , I. Cabrera (ICN No 398) ; no existe ninguna otra localidad exacta en Colombia, que yo sepa.

3. I. lentiferus (Cope), 1894. Dos ejemplares (ICN Nos. 172, 194) procedentes del Caucayá, afluente del Putumayo en la vecindad de Puerto Leguízamo, coleccionados por Santiago Rengifo y Roberto Jaramillo, sin fecha, y noviembre 16 , 1948, respectivamente. Son los únicos hallados en el país, que yo sepa.

Género Leptodeira Fitzinger, 1843.

Ofidios confundidos con la "Mapaná" (Bothrops atrox), debido a su diseño dorsal, que consiste en manchas y barras transversales pardooscuras sobre un fondo carmalita claro; se alimentan de ranas, igual a los Bothrops juveniles y por esta razón se encuentran a veces juntos en la orilla de los caños y pozos; como ambas son nocturnas, se confunden fácilmente; lo hemos observado varias veces en el río Piedras y otros ríos al E de Santa Marta en 1965.

Especies:

1. L. annulata annulata (L.), 1758. Principalmente al oriente de la Cordillera Oriental.

2. L. annulata ashmeadi (Hallowell), 1845. "Mapaná de rabo seco" (Sic). Sierra Nevada de Santa Marta; río Ranchería; Catatumbo.

3. L. annulata rhombifera (Günther), 1872. Posiblemente en el norte del Chocó, registrada de Panamá.

Nota: Hasta la fecha se encontraron solamente híbridos entre rhombifera y ashmeadi en Colombia, v.gr. entre Sautatá (Chocó), Bajo Atrato; Turbo (Ant.) ; Isla Fuerte (Córdoba) ; Santa Marta y Honda (Duellman, 1958).

4. L. septentrionalis ornata (Bocourt), 1844. Litoral del Pacífico, valle del Atrato, Cali, Villa Arteaga (Ant.), plantación de caucho en la región de Mutatá, carretera al mar de Medellín a Turbo; río Nechí (Ant.), afluente del Cauca; valle del Magdalena hasta Honda, Cúcuta.

Nota: Un ejemplar (ICN No 1497), La Unión (Nariño), 1745 m. alt., al occidente de Pasto, sep- tiembre 15, 1962, Luis Eduardo Mora, en matorrales secos, constituye un híbrido entre $L$. septentrionalis ornata y $L$. septentrionalis lacrorum Schmidt \& Walker, 1943, una subespecie no conocida de Colombia, sino del Ecuador.

Género Oxybelis Wagler, 1830.

Serpientes arborícolas muy delgadas y de hocico puntiagudo; se alimentan de lagartos (Anolis).

Especies:

1. O. aeneus aeneus (Wagler), 1824. "Bejuca, Bejuquilla”. Existe en todo el país. Sinónimo: 0 . acuminatus (Wied), 1825.

2. O. argenteus (Daudin), 1803. Hoyas del Orinoco y Amazonas.

3. O. brevirostris (Cope), 1861. Litoral del $\mathrm{Pa}$ cífico; Chocó ; cuatro ejemplares (ICN Nos. 395, 399, 403, 407), procedentes del Bajo Calima, 1960, I. Cabrera.

4. O. fulgidus (Daudin), 1803. Hoyas del Orinoco y Amazonas. Lago "El Dorado", Alto Vaupés; un ejemplar procedente de los alrededores de Villavicencio, septiembre 1967. Héctor Escobar, colección del Colegio Francisco José de Caldas, midió $1760 \mathrm{~mm}$. total: cola: 595 milímetros.

Género Oxyrhopus Wagler, 1830.

Especies:

1. O. formosus (Wied), 1820. "Coral". Hoya del Amazonas.

2. O. melanogenys (Tschudi), 1845. Generalmente del Alto Amazonas y sus afluentes; un solo ejemplar (ICN No 81) de Cimitarra (Sant.), río Guaytavita, afluente del Carare, 750 m. alt., 1948, Leopold Richter. Hemos comprobado que se trata de éste con los melanogenys depositados en el Field Museum of Natural History en Chicago (CNHM Nos. 40228-29; 40641-43).

3. O. petola petola (L.), 1758, p. 225, No 299. Sinónimos: O. petolarius (L.), 1758, p. $225, N^{0}$ 314. Oxyrhopus sebae Duméril \& Bibron, 1854. Costa del Atlántico; valle del Magdalena.

4. O. petola semifasciatus (Tschudi), 1845. Hoyas del Amazonas y Orinoco, v. gr. Villavicencio.

Género Philodryas Wagler, 1830.

Especie:

1. P. viridissima (L.), 1758. "Lora". Hoyas del Amazonas y Orinoco. Un ejemplar (ICN No 1222) procedente del río Acacías (Meta), 502 m. alt., marzo 1958, Carlos A. Velásquez, dentro de plantas acuáticas flotantes de un caño; vivía en cautividad hasta diciembre 1,1961 ; era virtualmente acuática y se alimentó exclusivamente de ra- 
nas (Hyla labialis) en Bogotá. Recién capturada midió entre 300 y 400 milímetros; en 1961 tenía las siguientes dimensiones: total: $1.052 \mathrm{~mm}$.; cabeza-cuerpo: $759 \mathrm{~mm}$.; cola: $293 \mathrm{~mm}$.; sexo: hembra. Durante todo el tiempo nunca se amansó sino que permaneció muy agresiva.

Género Pseudoboa Schneider, 1801.

Especies:

1. P. coronata Schneider, 1801. "Coral". Hoyas del Amazonas y Orinoco. Se alimenta de lagartos (Ameiva, etc.).

2. P. neuwiedii (Duméril \& Bibron), 1854. "Coral macho". Litoral del Caribe; valle del Magdalena; posiblemente en los Llanos Orientales.

Género Rhinostoma Duméril \& Bibron, 1854.

Sinónimo: Phimophis Cope, 1860. Monotípico. Especie:

1. R. guianense (Troschel), 1848. "Víbora”. Subterránea. Común en la costa del Caribe; se encuentra desde las zonas arenosas de la orilla del mar, especialmente en los cocales, hasta unos 500 metros de altura; se alimentan de lagartos (Gonatodes albogularis fuscus, etc.) y ranas; son nocturnos. También están presentes en los Llanos Orientales; un ejemplar (ICN No 97), procedente de Villavicencio, junio 21, 1960, C. A. Velásquez.

Género Rhinobothryum Wagler, 1830.

Especies:

1. R. bovallii Andersson, 1916. "Coral". Especie muy rara. Chocó; litoral del Caribe; un ejemplar (ICN No 112), procedente de Landázuri (Sant.), 800-900 m. alt., L. Richter, sin fecha.

2. R. lentiginosum (Scopoli), 1785. Hoyas del Amazonas y Orinoco. Muy rara y de hábitos desconocidos ; aparentemente arborícola, fide Amaral (1935, p. 130, Lista remisiva..., Vol. 10).

Género Siphlophis Fitzinger, 1843.

Especies:

1. S. cervinus cervinus (Laurenti), 1768. Serpiente arborícola, muy rara; se alimenta de pequeños moluscos, fide Amaral (1929, p. 97). Un ejemplar (ICN No 96), procedente de Soratama, campamento cauchero, Alto Apaporis, unas 5 horas arriba de la desembocadura del río Cananarí, abril 19, 1952, F. Medem; a las 5:30 p. m., encima de una palizada en la orilla del río.

2. S. cervinus geminatus (Duméril \& Bibron), 1854. Chocó; Panamá; Bajo Amazonas, fide Amaral (1929, p. 76).
Género Stenorhina Duméril \& Bibron, 1853. Monotípico.

Especie:

1. S. degenhardti degenhardti (Berthold), 1846. Terra typica: Provincia de Popayán, Nueva Granada, col: Degenhardt. Desde el Chocó hasta el Catatumbo; subterránea y bastante escasa.

Género Tantilla Baird \& Girard, 1853.

Serpientes pequeñas, subterráneas; varias especies parecidas a las "corales".

Especies:

1. T. alticola (Boulenger), 1903. Terra typica: Santa Rita (Ant.), al N de Medellín, 1487 m. alt.

2. T. longifrontalis (Boulenger), 1896. Terra typica: Cali.

3. T. melanocephala (L.), 1758. Existe en todo el país.

4. T. nigra (Boulenger), 1914. Terra typica: Peña Lisa, Condoto.

5. T. semicincta (Duméril \& Bibron), 1854. "Coral", "Coral macho". Litoral del Caribe; valle del Magdalena; Cúcuta.

Género Thamnodynastes Wagler, 1830.

Especie:

1. T. pallidus (L.), 1758. "Guardacamino". Litoral del Caribe; frecuentemente confundida con el "Patoco" (Bothrops lansbergi): Valle del Magdalena; Llanos Orientales.

Género Tripanurgos Fitzinger, 1843. Monotípico.

Sinónimo: Trypanurgos Tschudi (1845, p. 55;

Fauna Peruana...).

Boulenger (1896, p. 58; Catal. Vol. III), igualmente escribió Trypanurgos.

Especie:

1. T. compressus (Daudin), 1803. De cuerpo comprimido; arborícola (Amaral, 1935, p. 129, Lista remisiva..., Vol. 10); crece hasta un metro aproximadamente. Hoyas del Amazonas y Orinoco; Landázuri (Sant.), sin fecha, L. Richter, (ICN No 105) ; río Saija (Valle), costa del Pacífico, 1958, K. v. Sneidern (ICN No 1524) ; Andagoya, Alto San Juan (Chocó), fide Dunn (1944 k). El contenido estomacal de un ejemplar procedente de Villavicencio consistía en un lagarto arborícola juvenil (Enyalioides laticeps festae. Iguanidae), fide Nicéforo M. (1933).

2. T. leucomelas (Werner), 1916. Moscopán (Cauca), fide Downs (1961). 


\section{SERPIENTES VENENOSAS}

\section{Proteroglypha.}

Ofidios venenosos que poseen un par de colmillos rígidos, erectos, surcados o acanalados en la parte anterior del maxilar, que funcionan como conductores del veneno. El veneno está almacenado en un par de glándulas, una a cada lado del maxilar, conectadas por un conducto con cada colmillo. Estas glándulas son, en realidad, transformadas de glándulas salivales y el veneno no solamente funciona para paralizar o matar la presa, sino también para la predigestión por contener Encimas, etc.

\section{Familia Hydrophiidae.}

Serpientes marinas de cuerpo comprimido y de cola lateralmente aplanada. El centro de su evolución y dispersión constituye el Océano Indico. Una sola especie ha migrado hacia el Continente Americano y se ha establecido a lo largo de la costa del Pacífico centro-y suramericano, entre Baja California (México) y el golfo de Guayaquil.

Género Pelamis Daudin, 1803.

Sinónimo: Pelamydrus Stejneger, 1910.

Monotípico.

Especie:

1. P. platurus (L.), 1766.

(Mapa 1).

"Culebra del mar". Dorsal negro, ventral amarillo brillante, un diseño irregular amarrillo $\mathrm{y}$ negro en la parte lateral de la cola. Crece hasta unos 800 milímetros; se alimenta de peces, especialmente de anguillas; es vivípara.

Sobre la reproducción existen las siguientes observaciones: hemos encontrado en enero 30,1961 , en la Isla Gorgona, una hembra de 737 milímetros de largo, la cual tenía dos pequeños embriones de color blanco; febrero 23,1961 , otra procedente de la misma localidad con cinco embriones de color negro y amarillo, es decir, ya en un estado de desarrollo avanzado $\mathrm{y}$, aparentemente, listos para nacer. Gerardo Reichel-Dolmatoff coleccionó, en febrero de 1961, en Cabo Marzo (Chocó), un ejemplar de 712 milímetros de longitud total, con seis embriones blancos en diferentes estados de desarrollo.

Evidentemente existe una migración anual o, quizás, las serpientes marinas se amontonan en ciertas regiones durante una temporada definida con fines de procreación. Durante nuestra estadía en la Gorgona-Gorgonilla, de enero 26 a febrero 28,1961 , hemos observado la cantidad de ejemplares botados por la marea a la costa; se aumentó notablemente desde mediados de febrero.
Reichel-Dolmatoff (mayo 13, 1961, in litt.) suministró las siguientes observaciones: "Muy frecuentes de enero a abril de 1961. en Cabo Corrientes, Cabo Marzo y los Morros de Jurubidá (Chocó); poco frecuentes o ausentes en las áreas intermediarias; se observan principalmente cuando el mar está tranquilo, en cantidades enormes, es decir, flotando en extensas regiones, de 10 a 20 $\mathrm{kms} .^{2}$ aproximadamente; el agua está prácticamente cubierta por estas serpientes, a veces un ejemplar por cada metro ${ }^{2}$.

Los ejemplares adultos y jóvenes se encuentran raras veces en la misma área; más bien existen zonas donde predominan los adultos y otras vecinas donde se hallan los ejemplares juveniles. Hay tres fases de colores, una negra y amarilla, otra verdusca y la tercera parda o parda grisácea".

Pelamis platurus es altamente venenosa, aunque no agresiva y raras veces muerde. Enrique L. Díaz nos ha suministrado los siguientes datos (informe de W. L. Klawe, La Jolla, California, junio 5,1966 , in litt.): "Durante una exploración en relación con el petróleo en la bocana del río Guapi (Cauca), en 1962, una serpiente marina se enredó en el cable submarino y mordió a un hombre, de apellido Orozeo, en la mano; éste vomitó y no pudo comer más, y a pesar de inyecciones de suero antiofídico (contra "corales", género Micrurus, ya que el veneno es químicamente parecido), murió dentro de doce horas".

Este informe constituye, que yo sepa, el único sobre el efecto letal del mordisco de $P$. platurus en Colombia. Por lo general, los pescadores regionales no se dan cuenta del peligro, mientras consideran otras serpientes inofensivas como altamente venenosas.

Familia Elapidae. Verdaderas corales.

Poseen un par de colmillos en el maxilar; por lo general de colores muy vivos, que consisten en anillos negros, rojos y amarillos brillantes, dispuestos en "ternos", es decir, de tres en tres, $v . g r$. el anillo negro central está separado de los externos por medio de anillos amarillos, de manera que los anillos rojos separan los "ternos"; otras, sin embargo, tienen anillos negros y rojos alternantes, v. gr. el "Rabo de aji" (Micrurus mipartitus).

Mientras la mayoría de las "corales" miden menos de un metro, $M$. surinamensis alcanza una longitud de 1.50 metros y comprende la especie más grande conocida; M. lemniscatus; $M$. mipartitus y $M$. spixi obscurus crecen también hasta más de un metro. En cambio, M. dissoleucus nigrirostris mide solamente hasta 355 milímetros. Que se sepa, todas son ovíparas.

Virtualmente subterráneas, se alimentan de otras serpientes subterráneas, pequeñas (familias Typhlopidae y Leptotyphlopidae); por lo general, 
M A P A 1

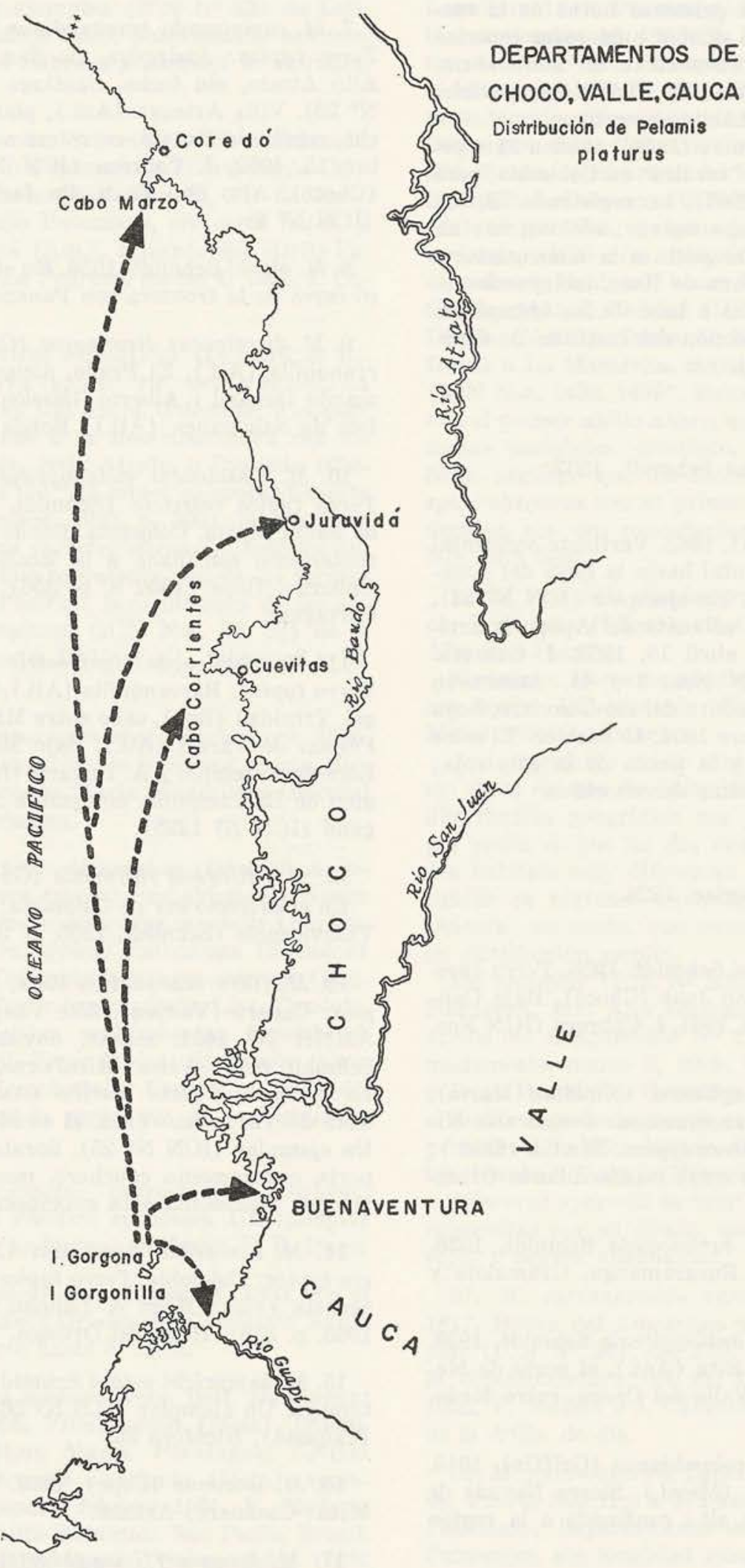


prefieren un ambiente húmedo $\mathrm{y}$ aun se encuentran en las aguas poco profundas de los caños.

Son principalmente nocturnas, pero se asolean con frecuencia en las primeras horas de la mañana. A pesar de que existen numerosas especies de "corales", no se encuentran en abundancia, sino son más bien raras en colecciones, posiblemente debido a sus hábitos secretivos.

Según Karl P. Schmidt (1955), existen 21 especies y subespecies de "corales" en Colombia, pero últimamente Roze (1967), ha registrado 28 , entre ellas dos subespecies nuevas; además, hay un cambio considerable respecto a la nomenclatura. Nos referimos a la obra de Roze, incluyendo varias localidades nuevas a base de los ejemplares depositados en la colección del Instituto de Ciencias Naturales (ICN).

Género Leptomicrurus Schmidt, 1937.

Especie:

1. L. narducci (Jan), 1863. Vertiente occidental de la Cordillera Oriental hacia la hoya del Amazonas, por lo general. Un ejemplar (ICN $N^{\circ} 24$ ), río Popeyacá (Am.), afluente del Apaporis arriba del Pirá-Paraná, abril 15, 1952, I. Cabrera. Dos ejemplares (ICN Nos. 3 y 4), Amanavén (Guainía), desembocadura del río Guaviare, hoya del Orinoco, septiembre 1951, L. Richter. El color es amarillo y negro y la punta de la cola roja; muy escasa y de hábitos desconocidos.

Género Micrurus Wagler, 1824.

Especies:

1. M. ancoralis jani Schmidt, 1936. Terra typica: Andagoya, río San Juan (Chocó). Bajo Calima, junio 11 y julio 8, 1961. I. Cabrera (ICN Nos. $309,402,413,424)$.

2. M. bocourti sangilensis (Nicéforo María), 1942. Sinónimo: $M$. ecuatorianus sangilensis Nicéforo María, 1942. Terra typica: San Gil (Sant.) ; 1095 m. alt. Regiones entre las Cordilleras Oriental y Central.

3. M. carinicauda carinicauda Schmidt, 1936. Catatumbo, Cúcuta, Bucaramanga, Gramalote y Chimacote (Sant.).

4. M. carinicauda antioquiensis Schmidt, 1936. Terra typica: Santa Rita (Ant.), al norte de Medellín, 1487 m. alt., Valle del Cauca, entre Medellín y Segovia.

5. $M$. carinicauda colombianus (Griffin), 1916. Terra typica: Minca (Magd.), Sierra Nevada de Santa Marta, $600 \mathrm{~m}$. alt.; confinada a la región de Santa Marta.

6. M. carinicauda dumerilii (Jan), 1858. Terra typica: Cartagena (Bol.). Santa Rosa (Bol.), al
$\mathrm{S}$ de Cartagena hacia el Canal del Dique; Río Frío; Bonda (Magd.), Sierra Nevada de Santa Marta; Catatumbo.

7. M. carinicauda transandinus Schmidt, 1936. Terra typica: Andagoya, río San Juan. Quibdó, Alto Atrato, sin fecha, Santiago Rengifo (ICN No 26). Villa Arteaga (Ant.), plantación de caucho, región de Mutatá, carretera a Turbo, diciembre 15, 1952, I. Cabrera (ICN No 9). Istmina (Chocó), Alto San Juan, sin fecha, S. Rengifo (ICN No 2).

8. $M$. clarki Schmidt, 1936. En el norte del Chocó cerca de la frontera con Panamá.

9. M. dissoleucus dissoleucus (Cope), 1859. Barranquilla (Atl.), El Prado, diciembre 1954, Armando Dugand y Alberto Gieseken (ICN No 18). Isla de Salamanca (Atl.); Bonda; Cúcuta.

10. M. dissoleucus melanogenys (Cope), 1860. Terra typica restricta (Schmidt, 1955) : Región de Santa Marta, Colombia. Bonda (Magd.) ; aparentemente confinada a la localidad típica, sin embargo, Cope (1862 b, p. 356), la registró de Cartagena.

11. M. dissoleucus nigrirostris Schmidt, 1955. Terra typica: Barranquilla (Atl.), 1897, Fritz Regel. Trinidad (Bol.), caño entre Magangué y Yatí. Palmar de Varela (Atl.), Bajo Magdalena, 1941, Roberto Jaramillo y A. Dugand (ICN NQ 37). Región de Barranquilla, noviembre 5, 1960. A. Dugand (ICN No 1225).

12. $M$. filiformis filiformis (Günther), 1859.

En el extremo sur de Colombia; río Putumayo; Villavicencio (Schmidt, 1955, p. 350).

13. M. filiformis subtilis Roze, 1967. Terra typica: Carurú (Vaupés), Alto Vaupés. Holotypus: AMNH No 4461, macho, noviembre 1906, H. Schmidt \& S. Weiss. Miraflores, Alto Vaupés; La Pedrera; Puerto Nariño (Am.), desembocadura del río Loreto-Yacu, al occidente de Leticia. Un ejemplar (ICN No 25), Soratama, Alto Apaporis, campamento cauchero, marzo 2, 1952, F. Medem, representa esta subespecie nueva.

14. M. hemprichi hemprichi (Jan), 1858. Terra typica: Colombia. Terra typica emendata: Venezuela (vide: Hoge \& Lancini, 1962; Medem, 1965, p. 316). Hoya del Orinoco.

15. M. hemprichi ortoni Schmidt, 1953. Río Putumayo. Un ejemplar (ILS No 568) de Florencia (Caquetá), Nicéforo M.

16. $M$. isozonus (Cope), 1860. Intendencia del Meta; Casanare; Arauca.

17. M. langsdorffi langsdorffi Wagler, 1824. Terra typica: Río Yapurá (Brasil), nombre del Caquetá en el Brasil. 
Sinónimos: Micrurus mimosus Amaral, 1935, río Putumayo. $M$. ornatissimus (nec Jan), Schmidt, 1955, (p. 345), Pto. Asís, Alto Putumayo; La Pedrera. Un ejemplar (ICN No 85) de Leticia (Am.), sin otros datos, posiblemente coleccionado por Isidoro Cabrera y Richard E. Schultes, 1952.

18. M. lemniscatus helleri Schmidt \& Schmidt, 1925. Entre el río Putumayo y Villavicencio (Meta). Dos ejemplares (ICN Nos. 31, 34) de Tarapacá (Am.), Bajo Putumayo, sin otros datos, y del caño Guacayá (Am.), afluente del Mirití-Paraná, arriba de La Pedrera, marzo 4, 1952, I. Cabrera.

19. M. mipartitus mipartitus (Duméril \& Bibron), 1854. Terra typica: "río sucio o senio". La localidad típica es Río Sucio, Colombia, o el pueblo situado frente a la desembocadura del río Truandó (Chocó), Bajo Atrato, o Riosucio (Caldas), $1813 \mathrm{~m}$. alt.; el "río senio" es probablemente el río Sinú (Medem, 1965, p. 300). Según Roze (1967, p. 37), las características del holótipo indican más bien que representa una de las formas de la costa del Pacífico, pero ninguna de las andinas. Dos ejemplares (ICN Nos. 29, 30) de la Isla Gorgona, norte, $10-15 \mathrm{~m}$. alt., febrero 7 y 15 , 1961, F. Medem.

20. M. mipartitus anomalus (Boulenger), 1896. Terra typica: Colombia, sin localidad exacta. Sierra Nevada de Santa Marta; Cordillera Oriental al Este del Magdalena.

21. M. mipartitus decussatus (Duméril \& Bibron), 1854. Terra typica: Probablemente Nueva Granada. Sinónimos: Micrurus mentalis (Boulenger), 1896. Terra typica: Pallatanga (Ecuador) y Cali (Valle), Colombia. Micrurus microps (Boulenger), 1913. Terra typica: Peña Lisa, Condoto. Micrurus mipartitus multiscutatus Rendahl \& Vestergren, 1940. Terra typica: El Tambo (Cau ca). Cordillera Occidental y Central, al oeste del Magdalena, y en la parte sur de la Cordillera Oriental.

22. M. nigrocinctus nigrocinctus (Girard), 1854. Costa del Pacífico chocoano. Un ejemplar (ICN No 13) de Andagoya, sin fecha, E. R. Dunn.

23. $M$. psyches psyches (Daudin), 1803. En el oriente de los Llanos Orientales; Comisaría Arauca; probablemente hasta el Meta.

24. M. psyches medemi Roze, 1967. Holotypus: AMNH No 96998, Villavicencio (Meta), Colombia, 1950, Nicéforo María. Paratypus: CNHM No 74371, macho, río Guatiquía (Meta), vecindad de Villavicencio, febrero 1951, F. Medem; otros en el Instituto Butantan, São Paulo, Brasil, e Instituto La Salle, Bogotá. Un ejemplar (ICN $\left.N^{\circ} 14\right)$, de Villavicencio, sin otros datos, posiblemente coleccionado por E. R. Dunn.
25. M. spixi obscurus (Jan), 1872. Los siguientes ejemplares indican una amplia distribución al E de la Cordilllera Oriental: Caucayá (=Puerto Leguízamo), río Putumayo, $4 \mathrm{kms}$. al $\mathrm{N}$ del pueblo, noviembre 16, 1948, R. Jaramillo y L. Richter, (ICN No 21). "Corregimiento Morelia", sin otros datos, (ICN No 110). Evidentemente se trata de Morelia (Caquetá), río Pescado, afluente del Orteguaza. Caño Guacayá (Am.), afluente del Mirití - Paraná (tributario del Bajo Caquetá), mayo 28, 1952, I. Cabrera, (ICN No 133). Mitú (Vaupés), marzo 1958, enviadas por los misioneros Javerianos, (ICN Nos. 248, 250, 261). Amanavén (Comisaría Guainía), bocas del río Guaviare, septiembre 1951, L. Richter, (ICN No 12). Laguna del Diablo (Meta), sabana de San Juan de Arama, frente a La Macarena, marzo 1, 1951, F. Medem (ICN Nos. 1438, 1439). Estos dos ejemplares tienen el primer anillo negro, que corre sobre las escamas parietales, completo. Schmidt, (1955, p. 351 ), registró que los únicos ejemplares de $M$. spixi obscurus con el primer anillo completo conocidos, son dos procedentes de Florencia (ILS Nos. 580, 589).

26. M. spurrelli (Boulenger), 1914. Terra typica: Peña Lisa (Chocó), río Condoto, afluente del Alto San Juan.

Sinónimo: Micrurus nicefori Schmidt, 1955. Terra typica: Villavicencio (Cund.) ; ex errore, (= Meta), Nicéforo María.

Aparentemente existe tanto en el occidente como en el oriente de Colombia, a pesar de que la distribución geográfica nos parece algo extraña por razón de que las dos localidades comprenden dos habitats muy diferentes y, además, están situadas en regiones separadas por la Cordillera Oriental, un hecho, que naturalmente no excluye su distribución amplia.

Un ejemplar (ICN No 335) de la Sierra de La Macarena, sur, Alto Guayabero, mesetas áridas arriba del campamento $\mathrm{N}^{0}$ 1, $500 \mathrm{~m}$. alt., aproximadamente, marzo 3, 1959, Carlos A. Velásquez y Jorge Hernández Camacho, cerca de un caño en el monte seco de la región rocosa. Otro ejemplar, procedente de Villavicencio, septiembre 1967, Héctor Escobar, Colegio Francisco José de Caldas.

Micrurus spurrelli es muy parecido a Micrurus mipartitus por su diseño, que consiste en anillos rojos y negros alternantes.

27. $M$. surinamensis surinamensis (Cuvier), 1817. Hoyas del Amazonas y Orinoco. Un ejemplar (ICN No 36), del Alto Apaporis, arriba de la desembocadura del río Cananarí, enero 28, 1952, F. Medem e I. Cabrera, en el monte cerca de la orilla, de día.

28. M. putumayensis Lancini. 1962. Terra typica: Puerto Socorro, a $270 \mathrm{kms}$. al NE de Iquitos, Putumayo, Departamento de Loreto, Perú. Río Putumayo, sin localidad exacta.

Nota: Existe una especie todavía no registrada en Colombia, cuya distribución en el territorio na- 
cional es, sin embargo, muy probable: Micrurus steindachneri steindachneri (Werner), 1901. Terra typica: Ecuador, sin localidad exacta.

Sinónimo: Micrurus fasslii (Werner), 1926. Terra typica: Colombia, sin localidad exacta. Peters (1960 b, p. 531), manifestó que el tipo de steindachneri también sirvió como tipo de fasslii, lo que es muy probable, ya que Werner confundió frecuentemente tanto ejemplares como localidades.

Micrurus steindachneri steindachneri se encuentra en la vertiente oriental de Los Andes, en la región Macas - Méndez, Oriente (Ecuador), en la hoya del Amazonas.

Resulta de la obra de Roze (1967, pp. 50-54), que actualmente dos géneros con 28 especies y subespecies de "corales" están registradas de Colombia; eso significa que entre todos los países del Continente Americano es sobrepasado solamente por México, donde se encuentran 31 representantes del género Micrurus; en cambio, toda la América Central, desde Guatemala hasta Panamá, tiene 26; Venezuela 13; Brasil 20; Ecuador 17, y el Perú 17, para nombrar solamente el número de las "corales" procedentes de los países vecinos.

\section{Solenoglypha.}

Serpientes venenosas que poseen un par de colmillos eréctiles en la parte anterior del maxilar, los cuales son perforados y actúan como una jeringa para inyectar el veneno; son plegables hacia atrás cuando no se emplean; existen, además, uno o varios pares de colmillos plegados, que sirven como reemplazo en el caso de desgaste; los huesos faciales son móviles.

\section{Familia Crotalidae.}

Ofidios solenoglifos que poseen una fosa facial, situada entre los orificios nasales y el sector ocular, la cual consiste en un par de depresiones, una a cada lado, provistas de una membrana conectada a numerosos terminales nerviosos; estas fosas "loreales" actúan como termodetectores y ayudan a localizar la presa de sangre caliente (aves y mamíferos) en la oscuridad, igual a las fosetas labiales de ciertas Boas arborícolas y terrestres (los géneros Boa, Epicrates), ya que tanto las Crotalidae como las Boas buscan su alimento de noche (Schmidt \& Inger, 1959).

Género Bothrops Wagler, 1824.

Especies:

1. B. atrox atrox (L.), 1758. "Cuatronarices, Mapaná, Taya equis, Barba amarilla, Boquidorá, etc.". Comprende la especie más común en todo el país.
$\mathrm{Su}$ habitat consiste principalmente en las zonas húmedas dentro del monte, aunque se encuentra en áreas rocosas, a larga distancia de las aguas. Los juveniles pequeños hasta unos 600 milímetros, se alimentan de ranas, mientras los más grandes y los adultos, de roedores (Sexton, 1958). Crecen hasta unos 1.50 metros, y en casos excepcionales hasta unos 2.50 metros.

2. B. atrox asper (Garman), 1883. En el norte del Chocó. Ambas subespecies poseen una "uña" córnea en la punta de la cola, la cual es, en realidad, una escama alargada y puntiaguda; de ninguna manera la "Mapaná" la utiliza para "inyectar el veneno", una superstición popular que todavía prevalece.

3. B. bilineatus (Wied), 1825. "Lora". Arborícola, de cola prensil; color dorsalmente verde; se encuentra en el rastrojo en una altura de $\mathbf{1 . 5 0}$ a $2.0 \mathrm{~m}$., completamente mimetizada dentro de las hojas verdes; conocida del campamento Soratama, Alto Apaporis, abril 1, 1952, F. Medem, (ICN Nos. 1001, 1002) ; también de la región de Miraflores, Alto Vaupés.

4. B. castelnaudi (Duméril \& Bibron), 1854. Especie muy rara; conocida de La Pedrera, de $\mathrm{Me}$ dina y Garagoa, vertiente oriental de la Cordillera Oriental, al este del río Meta.

5. B. hyoprora Amaral, 1935. Terra typica: La Pedrera (Am.), Bajo Caquetá. "Equis sapa". Un ejemplar (ICN No 452), de Salado (Caquetá), vecindad de Puerto Boy, situado en la orilla occidental del río abajo de la hacienda "Curiplaya", noviembre 17, 1958, F. Medem, en un yucal, de día; midió: total $490 \mathrm{~mm}$; cuerpo-cabeza: 420 mm.; cola: 70 milímetros.

Es corta y gruesa y de hocico proboscidiforme; color amarillento de arena, con pocas barras transversales carmelitas; debido a su coloración es virtualmente invisible dentro de la hojarasca seca. Conocida del río Tiquié (Vaupés) y río Guamués, afluente del Alto Putumayo; muy rara y de hábitos desconocidos.

6. B. lansbergi lansbergi (Schlegel), 1841. Terra typica: Turbaco (Bol.), $200 \mathrm{~m}$. alt., a $12 \mathrm{kms}$. de Cartagena hacia el occidente. "Patoco, Patoquilla", corta, gruesa y de hocico proboscidiforme. Existen varias fases de color: negro, gris oscuro con barras negras transversales y laterales, amarillento arena y color de herrumbre; crece hasta unos 700 milímetros y se alimenta principalmente de ranas y lagartos; la cría, entre 9 y 12 ejemplares de unos $100 \mathrm{~mm}$. de largo, nace entre abril y junio. Conocida del litoral del Caribe; río Uré, río Sinú, valle del Magdalena, hasta Santander aproximadamente; los límites exactos de su distribución son desconocidos.

7. B. lansbergi venezuelensis Roze, 1959. Península Guajira.

8. B. nasuta Bocourt, 1868. "Cabeza de candado, Patoquilla real, Hilván”. Crece hasta unos 600 
milímetros; gruesa ; proboscis del hocico muy pronunciado; color gris claro con barras transversales negras o pardo-oscuras; los juveniles poseen una serie de manchas oscuras laterales, bordeadas por una zona blanca a cada lado y por eso se confunden fácilmente con los ejemplares jóvenes de $B$. lansbergi. Viven en las selvas húmedas de la costa del Pacífico, en el suelo; suben a veces a arbustos hasta un metro de altura aproximadamente, pero no tienen la cola prensil y de ninguna manera son arborícolas, como afirmó Posada Arango (1889, 1909).

9. B. neglecta Amaral, 1923. "Rabo de ratón". La Pedrera (Am.). Especie muy rara, selvática y de hábitos desconocidos.

10. B. punctata (García), 1896. "Rabo de Chucha". Terra typica: "habitat en las montañas del Dagua". De color gris-amarillento o verdusco, con numerosas manchas pardas pequeñas; crece hasta 1.20 metros aproximadamente; semiarborícola; bastante escasa. Conocida del Valle, Quibdó (Chocó), Alto Atrato, Andagoya y Andes (Ant.).

11. B. schlegeli (Berthold), 1846. Terra typica: Provincia de Popayán, Nueva Granada. "Birrí, Colgadora, Patoco de pestaña". Posee una serie de pequeñas escamas levantadas encima de los ojos, parecidas a pestañas; de cola prensil; arborícola y terrestre; color verdusco o amarillento, salpicado con numerosas manchas oscuras; también existen ejemplares de color amarillo claro. En el litoral del Pacífico, Valle, Cauca, Chocó, Alto Sinú, Territorio Vásquez (Sant.), Muzo, hasta la región del Táchira (Venezuela), al E de Cúcuta. Evidentemente confinada a regiones montañosas.

Género Crotalus Linnaeus, 1758.

Especie:

1. C. durissus terrificus (Laurenti), 1768. "Cascabel”. Es probablemente la serpiente más venenosa en relación con su tamaño; crece hasta 1.50 metros aproximadamente; es vivípara. La "cascabel" en el extremo posterior está formada por una serie de segmentos córneos en forma de anillos embutidos unos dentro de otros, pero flojamente ajustados, cada uno de los cuales comprende el vestigio de una muda de la piel; mudan de cuatro a cinco veces por año. Por esta razón la creencia popular de que cada anillo corresponde a un año es absolutamente errónea. Se alimenta principalmente de roedores, pero también de aves pequeñas. Su habitat consiste en las zonas semiáridas o áridas del litoral del Caribe, Tolima, Huila, Cundinamarca y de los Llanos Orientales.
Género Lachesis Daudin, 1803. Monotípico.

Especie:

1. L. muta muta (L.), 1766. "Rieca, Verrugosa, Surucucú". Posee las escamas dorsales sobresalientes y fuertemente aquilladas en forma de verrugas; color rosado, con zonas oscuras en forma de una " $X$ "; el extremo posterior de la cola está cubierto por numerosas espinitas y termina en una "uña" córnea y puntiaguda, mucho más pronunciada que en Bothrops atrox. Cuando la "Rieca" está excitada, golpea el suelo con la cola, lo que produce un sonido vibrante, aunque diferente a los sonidos típicos producidos por la "cascabel". Según una creencia popular no comprobada, emite también otro sonido muy parecido al cacareo de una gallina. Hemos oído repetidas veces estos "cacareos" fuertes y en intervalos cortos, que duran unos segundos y nunca fueron contestados por otros iguales, de noche en las selvas del Chocó y del Amazonas, donde normalmente existe Lachesis muta, pero nunca hemos hallado el origen del sonido. Los únicos ofidios conocidos que producen sonidos vibrantes son varios representantes del género norteamericano Pituophis que poseen una membrana adherida a la epiglotis, la cual vibra cuando se expulsa el aire del pulmón espirando (Goin \& Goin, 1962, p. 116). Crece hasta unos cuatro metros en casos extremos y representa la segunda de las serpientes venenosas más grandes del mundo; únicamente la sobrepasa la "cobra real" asiática (Ophiophagus hanna), que alcanza una longitud de 5.40 metros.

$\mathrm{Su}$ habitat consiste en lugares húmedos dentro de la selva o las vertientes de las Cordilleras; se encuentra con frecuencia en los huecos de los roedores silvestres, v.gr. "Guatinaja" "Ñeque, etc." (Género Dasyprocta); es nocturna y se alimenta de roedores. Es más bien escasa y de hábitos desconocidos debido a la falta de observaciones hechas con ejemplares en su ambiente natural; a menudo se encuentran en pares, por lo general macho y hembra, pero nunca se han hallado ejemplares juveniles pequeños, que yo sepa.

Comprende el único representante de la familia Crotalidae, que es ovíparo; pone hasta unos 11 huevos en los troncos podridos de los árboles, cerca de los caños, y la hembra proteje el nido, según informes de los nativos, aún no comprobados.

Amaral (1936), registró la postura de huevos por un ejemplar de 1.94 metros, procedente de Marahú, Bahía, Brasil, en diciembre 6, 1921; puso 11 huevos subelípticos, blancos o ligeramente amarillentos; midieron de $80.0 \mathrm{~mm}$. a 40.0 milímetros de longitud. Schweizer (1956), informó sobre el único caso de que Lachesis muta aceptó alimentación en cautividad, que yo sepa: un ejemplar, procedente del Brasil y comprado en septiembre 20, 1955, midió 1.60 metros; en enero 9, 1956, ya tenía 1.95 metros de longitud. En octubre 1, 1955, se alimentó de ratones (género Microtus) a las 10:00 p. m.; noviembre 3,1955 , otra vez de 
día pero en un lugar oscuro; por última vez se alimentó de dos Microtus en enero 17, 1956, pero más tarde murió, sin haber aceptado alimento.

\section{Paleontología.}

Nuestro conocimiento sobre las serpientes fósiles está todavía bastante limitado, debido a las circunstancias de que los huesos craneales son delgados y flojamente conectados entre sí; después de la muerte del ejemplar se dispersan y se pierden, lo que dificulta la fosilización de un organismo entero; usualmente se encuentran las vértebras sólidas preservadas en un estado identificable. En Colombia, las vértebras de ofidios han sido encontradas en el sitio La Venta (Huila), formación Honda del Mioceno Superior (Stirton, 1953); faltan todos los demás datos.

Los ofidios evolucionaron indudablemente de ciertos grupos de lagartos y, muy probablemente, de los Dolichosauridae, una familia de saurios relativamente pequeños conocidos del Cretáceo Inferior, de forma alargada y con las extremidades y cinturas ya reducidas. El primer hallazgo de serpientes propiamente dichas comprende representantes parecidos a las Boidae del Cretáceo Superior de Patagonia (familia Dinilysiidae). Entre las familias actualmente existentes, las Boidae se conocen desde el Eoceno y las Colubridae, Elapidae y Viperidae desde el Mioceno.

El número total de ofidios encontrados en Colombia hasta la fecha, es el siguiente:

\begin{tabular}{|c|c|c|}
\hline FAMILIA & Géneros & $\begin{array}{l}\text { Especies y } \\
\text { Subespecies }\end{array}$ \\
\hline Typhlopidae . . . . . . & 4 & 8 \\
\hline Leptotyphlopidae. . . . . & 1 & 7 \\
\hline Aniliidae $\ldots \ldots \ldots$ & 1 & 1 \\
\hline $\begin{array}{llllll}\text { Boidae } & \ldots & \ldots & \ldots & \ldots\end{array}$ & 6 & 11 \\
\hline $\begin{array}{lllll}\text { Colubridae } & \ldots & \ldots & \ldots\end{array}$ & 50 & 158 \\
\hline Hydrophïdae . . . . . . & 1 & 1 \\
\hline Elapidae $\ldots \ldots \ldots$ & 2 & 29 \\
\hline $\begin{array}{lllll}\text { Crotalidae } & \ldots & \ldots & \ldots & \ldots\end{array}$ & 3 & 13 \\
\hline
\end{tabular}

Se conocen 68 géneros con 228 especies y subespecies de serpientes colombianas, entre ellas 6 géneros con 43 especies y subespecies de ofidios venenosos, que se dividen en los siguientes grupos:

1. Hydrophiidae (serpiente marina) ..... 1

2. Elapidae (verdaderas corales). ... ... 29
3. Crotalidae:

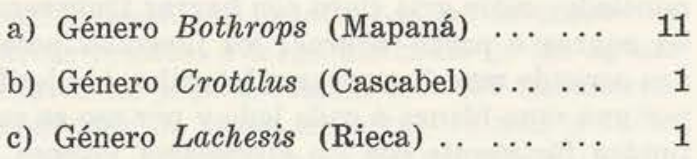

CONCLUSION:

Según nuestro conocimiento actual, todavía incompleto, se han registrado los siguientes órdenes, géneros y especies hasta la fecha:

A mphibia.

\begin{tabular}{lcc}
\hline O R D E N & Géneros & $\begin{array}{c}\text { Especies y } \\
\text { Subespecies }\end{array}$ \\
\hline Apoda (Tatacoas).... & 5 & 18 \\
\hline Caudata (Salamandras) & 2 & 12 \\
\hline Anura (Ranas y Sapos) & $35-36$ & 225 aprox. \\
\hline
\end{tabular}

Reptilia.

\begin{tabular}{lcc}
\hline O R D E N & Géneros & $\begin{array}{r}\text { Especies y } \\
\text { Subespecies }\end{array}$ \\
\hline Testudinata (Tortugas) . . . & 14 & 36 \\
\hline Crocodylia (Caimanes, etc.) & 4 & 8 \\
\hline Sauria (Lagartos) . . . . . . & 47 & 144 \\
\hline Serpentes (Ofidios). . . . . & 68 & 228 \\
\hline
\end{tabular}

Eso comprende un número total de 43 géneros con 255 especies y subespecies de anfibios y de 133 géneros con 416 especies y subespecies de reptiles.

Por consecuencia, la herpeto-fauna de Colombia está representada por 176 géneros con 671 especies y subespecies.

\section{AGRADECIMIENTOS}

Me es grato expresar mi sincera gratitud a los siguientes colegas y otras personas que me brindaron su amplia colaboración: Prof. Dr. Juan Herkrath, Decano Facultad de Ciencias, Universidad Nacional; Prof. Dr. Luis Eduardo MoraOsejo, Director del Instituto de Ciencias Naturales, Universidad Nacional; Prof. Gerardo ReichelDolmatoff, Director del Instituto de Antropología, Universidad de Los Andes, Bogotá, D. E.; Dr. Enrique L. Díaz, Jefe Departamento de Investigaciones Ictiológicas y Faunísticas, C.V.M., Cartagena; Dr. James A. Peters, Curator of Reptiles 
and Amphibians, USNM; Dr. Ernest E. Williams, Curator, Department of Herpetology, MCZ; Mr. Benjamin Shreve, Research Associate, Department of Herpetology, MCZ; Dr. Coleman J. Goin, Prof., Department of Biology, University of Florida, Gainesville; Dr. Thomas M. Uzzell, Jr., Department of Biology, University of Chicago; Dr. Charles M. Bogert, Curator, Department of Herpetology, AMNH; Dr. Jánis A. Roze, Research Associate, Department of Herpetology, AMNH; Dr. Hymen Marx, Associate Curator, Department of Herpetology, FMNH; Dr. Philip Hershkovitz, Research Curator, Department of Mammalogy, FMNH; Mr. Kraig K. Adler, Department of Herpetology, UMMZ.

Igualmente me place expresar mis agradecimientos a los señores don Carlos Alberto Velásquez Moreno, Técnico-Preparador de la Sección de Biología Tropical en Villavicencio, por su incansable labor, y a don Fernando Eraso Pabón, Almacenista de la misma instıtución, quien elaboró las tablas y el mapa.

Finalmente, deseo expresar mi sincera gratitud a la John Simon Guggenheim Memorial Foundation, la cual me brindó en dos ocasiones la oportunidad para complementar estudios bibliográfi$\cos$ en los Estados Unidos.

\section{ABREVIATURAS \\ de Museos e Instituciones Científicas.}

$\begin{array}{ll}\text { AMNH: } & \begin{array}{l}\text { American Museum of Natural History, New } \\ \text { York. }\end{array} \\ \text { ANSP: } & \begin{array}{l}\text { Academy of Natural Sciences, Philadelphia. } \\ \text { Chicago Natural History Museum; actual- } \\ \text { mente denominado }\end{array} \\ \text { FMNH: } & \text { Field Museum of Natural History, Chicago. } \\ \text { C.V.M.: } & \begin{array}{l}\text { Corporación Autónoma Regional de los Va- } \\ \text { lles del Magdalena y del Sinú. }\end{array} \\ \text { ICN: } & \begin{array}{l}\text { Instituto de Ciencias Naturales, Universi- } \\ \text { dad Nacional de Colombia, Bogotá, D. E. }\end{array} \\ \text { ILS (MLS) : Instituto (Museo) La Salle, Bogotá, D. E. } \\ \text { MCZ: } & \begin{array}{l}\text { Museum of Comparative Zoology, Harvard } \\ \text { University, Cambridge, Massachusetts. }\end{array} \\ \text { SMF: } & \begin{array}{l}\text { Natur - Museum Senckenberg, Frankfurt / } \\ \text { Main; Alemania. }\end{array} \\ \text { UMMZ: } & \begin{array}{l}\text { University of Michigan, Museum of Zoology, } \\ \text { Ann Arbor. }\end{array} \\ \text { USNM: } & \begin{array}{l}\text { United States National Museum, Smith- } \\ \text { sonian Institution, Washington, D. C. }\end{array}\end{array}$

\section{BIBLIOGRAFIA SELECCIONADA}

Nota: La bibliografía presentada está subdividida en varios sectores. Hemos incluído referencias sobre la paleogeografía, geografía, geología y aun varios datos suministrados por los historiadores, con el fin de facilitar el entendimiento acerca de las migraciones y la distribución geográfica de la fauna herpetológica. Nos referimos más ampliamente a los datos sobre los anfibios recientes y sobre la paleontología de anfibios y reptiles colombianos; en cambio, la recopilación bibliográfica está presentada en Medem (1965), respecto a los reptiles recientes, y por esta razón citamos meramente las publicaciones recién salidas y varias de las obras generales con fines de orientación básica sobre este grupo.

Geología, paleogeografia, geografía.

Anónimo. 1959. Atlas de Economía Colombiana. Primera entrega. Aspectos físico y geográfico. Banco de la República, Departamento de Investigaciones Económicas. Bogotá, D. E.

BürGL, Hans, 1961. Historia geológica de Colombia. Rev. Acad. Colomb. Cs. Exact., Fís., Nat., Vol. 11, No 43, pp. 137-191, figs. 1-41.

DUQUe Gómez, Luis. 1954. Los problemas antropogeográficos de Colombia y la Escuela Rural. Ciencias Soc., Vol. 5, No 29, pp. 194-206.

FielDS, Robert W., 1959. Geology of the La Venta Badlands, Colombia. Univ. Cal. Publ. Geol. Ser., Vol. 32, No 6 , pp. $405-444$; pls. $37-40$, figs. $1-2$; tabs. $1-3$; mapas 1-2.

Hammen, Thomas van der, 1961. The Quaternary Climate Changes of Northern South America. Ann. New York Acad. Sci., Vol. 95, № 1, pp. 676-683, figs. 1-3.

- 1962. Palinología de la región de "Laguna de los Bobos". Historia de su clima, vegetación y agricultura durante los últimos 5.000 años. Rev. Acad. Colomb. Cs. Exact., Fís., Nat., Vol. 11, No 44, pp. 359-361; figs. 1-5.

HERSh kovitz, Philip, 1966. Mice, Landbridges and Latin American Faunal Interchange. En: Ectoparasites of Panamá, pp. 721-751; figs. 151-154. Field Museum of Natural History, Chicago.

Hettrer, Alfred, 1892. La Cordillesa de Bogotá. Resultados de viajes $y$ estudios. Cuaderno Suplementario. No 104 de "Petermann's Mitteilungen". Gotha: Justus Perthes. Primera versión castellana por Ernesto Guhl, pp. 7-351; lám. 1-2; figs. en el texto 1-4, 1966, Ediciones del Banco de la República.

Krogzemis, James R., 1967. A Historical Geography of the Santa Marta area, Colombia. University of California, pp. 1-176, figs. 1-53, mapas 1-10.

NYGREN, W. E., 1950. Bolívar Geosyncline of Northwestern South America. Bull. Amer. Assos. Petro-Geol., Vol. 34, No 10 , pp. 1998-2006, figs. 1-3.

RAmírez, Jesús Emilio, S. J., 1957. Bibliografía de la Biblioteca del Instituto Geofísico de Los Andes Colombianos sobre Geología y Geofísica de Colombia. Segunda edición corregida y aumentada. Inst. Geofís. Andes Colomb., Serie C-Geología, Bol. No 6, pp. 7-521, Imp. Banco de la República.

Reichel - Dolmatoff, Gerardo, 1965. Colombia. Ancient Peoples and Places. Thames \& Hudson, London, pp. 5-231, pls. 1-65, figs. 1-66, tabs. 1-2, mapas 1-2.

Simpson, George Gaylord, 1950. History of the Fauna of Latin America. Amer. Scientist, Vol, 38, № 3, pp. 361-389, figs. $1-10$.

$$
\text { Historia. }
$$

Calasanz Vela, José de, Fr., 1890. Desde Villavicencio hasta San Fernando de Atabapo (en 1889). Editorial "Semanario Popular", Cartagena, 1936, pp. 1-112. 
Don Antonio Julí̂́n, P., 1787. La Perla de la América, Provincia de Santa Marta, reconocida, observada y expuesta en discursos históricos. 1854. Reimpresión, pp. v-xxvi, 1-339. Imp. E. Thunot \& CA. París.

Gummla, Joseph, S. J., 1741. El Orinoco Ilustrado, Historia Natural, Civil y Geográfica de este gran Río y de sus caudalosos vertientes. Tomos I-II, pp. 1-580; figs. 1-3, mapa 1. Madrid: por Manuel Fernández. 1944. Reimpresión. Tomo I, pp. ix-xx, 7-360. Tomo II, pp. 7-334. Biblioteca Popular de Cultura Colombiana. Ed. ABC. Bogotá, D. E.

$$
\text { Paleontología. }
$$

Anónimo, 1936. Cerca del caserío de El Rodeo, en la región de Cúcuta, se hizo un importante descubrimiento paleontológico: un Caimán fósil. Bol. Inst. La Salle, № 147 , pp. 110-113, figs. 1-4. Bogotá, D. E.

Botero Arango, Gerardo, 1936. Bosquejo de Paleontología Colombiana. An. Esc. Nac. Minas, Medellín, No 35 , pp. 1-86, figs. 1-70, mapas 1-4. Publicado también en Rev. Indias, 1937, № 3. Bogotá.

Estes, Richard, 1961. Miocene Lizards from Colombia, South America. Breviora, Mus. Comp. Zool., No 143, pp. 1-11, figs. 1-5.

Estes, Richard \& R. WASSERSUG, 1963. A Miocene Toad from Colombia, South America. Breviora, No 193, pp. $1-13$, figs. $1-5$.

Langston, Wann, Jr., 1965. Fossil Crocodilians from Colombia and the Cenozoic History of the Crocodilia in South America. Univ. Cal. Publ. Geol. Sci., Vol. 52, pp. v-vii, 1-157, pls. $1-5$, figs. $1-48$, tabs. $1-4$, A-1.

- 1966. Mourasuchus Price, Nettosuchus Langston, and the Family Nettosuchidae (Reptilia: Crocodilia). Copeia, No 4, pp. 882-885, fig. 1.

Porta, Jaime de, 1961. Algunos problemas estratigráficofaunísticos de los vertebrados en Colombia (con una bibliografía comentada). Bol. Geol. Univ. Indust. Sant., No 7, pp. 83-104, figs. 1-2, Bucaramanga.

Royo y G6́mez, José, 1942. Un nuevo Crocodilido fósil del Huila. Min. Minas Petrol., Serv. Geol. Nal., Comp. Estud. Geol. Ofic. Colomb., Vol. 5, pp. 325-326, Bogotá, D. E.

- 1945. Los Vertebrados del Terciario Continental Colombiano. Rev. Acad. Colomb. Cs. Exact., Fís., Nat., Vol. 4, No 24, pp. 496-511, pls. 1-5, figs. 1-7.

SaVAGe, Donald E., 1951. Report on fossil Vertebrates from Upper Magdalena Valley, Colombia. Science, Vol. 114 , No 2955 , pp. 186-187.

Stirton, Rubén A., 1946. The first Lower Oligocene fauna from Northern South America. Min. Minas Petrol., Serv. Geol. Nal., Vol. 7, pp. 325-340, pls. 1-3.

- 1953. Vertebrate Paleontology and Continental Stratigraphy in Colombia. Bull. Geol. Soc. Amer., Vol. 64, pp. 603-622, figs. 1-13.

\section{Herpetología. General.}

Duellmann, William E., 1966. The Central American Herpetofauna: An Ecological Perspective. Copeia, No 4 , pp. 700-719, figs. $1-8$, tabs. $1-5$.

Gorn, Colemann, J. \& Olive B. GoIn, 1962. Introduction to Herpetology. W. H. Freeman \& Comp., San Francisco \& London, pp. v-vii, 1-341, figs. 1-1 - 17-2.

NeIL, Wilfred T., 1958. The occurrence of Amphibians and Reptiles in saltwater areas. Bull. Marine Sci. Gulf Caribbean, Vol. 8, № 1, pp. 1-97.
Peters, James A., 1964. Dictionary of Herpetology. Hafner Publ. Comp. pp. v-vii, 1-392; figs. 1-30.

Schмidт, Karl, Patterson \& Robert F. INGER, 1959. Los Reptiles. Editorial Seix Barral. S. A. Barcelona, pp. 5-294, pls. 1-145, figs. sin números. Traducción por Eduardo De Salas.

Amphibia. Caeciliidae.

DunN, Emmett Reid, 1942. The American Caecilians. Bull. Mus. Comp. Zool., Vol. 92, No 6, pp. 439-540.

- 1944. A new Caecilian of the genus Gymnophis. Caldasia, Vol. 2, No 10, pp. 473-474.

Fuhrmann, Otto, 1914, Le Genre Typhlonectes. En: Fuhrmann, Otto \& Eugén Mayor. Voyage d'Exploration Scientifique en Colombie. Mém. Soc. Neuchatel Sci. Nat., Vol. 5, pp. 112-138, figs. 1-21.

$C a u d a t a$.

Brame, Arden H., Jr., \& David B. WAKE, 1963. The Salamanders of South America. Los Angeles County Mus. Contrib. Sci., No 69 , pp. 5-72, figs., 1-26.

Nicéforo María, Hno., 1958. Sección Herpetológica. Amphibia Caudata. Familia Plethodontidae. Hallazgo de los huevos de Bolitoglossa adspersa (Peters). Bol. Inst. La Salle, No 198, pp. 10-12, fig. 7. Publicado también en "Caldasia", 1960, Vol. 8, pp. 337-339, fig. 1.

Posada Arango, Andrés, 1909. Nueva especie de Salamandrido. En: Estudios científicos..., p. 125. Medellín.

WaKe, David B. \& Arden H. Brame, 1962. A new Species of Salamander from Colombia and the status of $\mathrm{Geo}$ triton andicola, Posada Arango. Los Angeles County Mus. Contrib. Sci., № 49 , pp. 1-8, fig. 1.

$$
\text { Anura (Salientia). }
$$

DunN, Emmett Reid, 1944. Los géneros de anfibios y reptiles de Colombia. Parte I: Anfibios. "Caldasia", Vol. 2, No 10, pp. 497-529, figs., 1-9.

GoIN, Coleman J., 1957. Status of the frog genus Sphoenohyla, with a Synopsis of the species. "Caldasia", Vol. 8, No 36, pp. 11-31, figs. 1-2.

- 1965. Studies on the frogs of Colombia. Proc. Second Latin American Congress, Vol. 2, pp. 247-248. São Paulo.

Hunter, Alice S. \& Beatriz Murcia de Valdivieso, 1962. La reproducción de la Rana, Hyla labialis. "Caldasia", Vol. 8, No 40, pp. 573-583, tabs. 1-3.

MYers, George S. \& John W. Funkhouser, 1951. A new Giant Toad from Southwestern Colombia. Zoologica, Sci. Contrib. N. Y. Zool. Soc., Vol. 36 , No 4, pp. 279282 ; pl. 1, figs. $1-2$.

StebBins, Robert C. \& John R. Hendrickson, 1959. Field Studies of Amphibians in Colombia, South America. Univ. Cal. Publ. Zool., Vol. 56, No 5, pp. 497-540, fig. 1 , tabs. 1-6.

Uribe Piedrahíta, César, 1947. Contribuciones al estudio de la Parasitología en Colombia. 1. Un Myxobolidae parásito de la vesícula biliar de una Rana de los Llanos Orientales. "Caldasia", Vol. 4, No 20, pp. 649-653, figs. $1-2$. 


\section{Reptilia. General.}

MeDEM, Federico, 1965. Bibliografía comentada de reptiles colombianos. Rev. Acad. Colomb. Cs. Exact., Fís., Nat., Vol. 12 , No 47 , pp. 299-346.

$$
\text { Testudinata. }
$$

Kaufmann, Reinhard, 1966. Das Vorkommen von Meeresschildkröten in Kolumbien und ihre Nutzung als Nahrungsquelle. Natur und Museum, Vol. 96, No 2, pp. 44-49, figs. 1-3. Frankfurt/Main.

Medem, Federico, 1966. Contribuciones al conocimiento sobre la ecología y distribución geográfica de Phrynops (Batrachemys) dahli; (Testudinata, Pleurodira, Chelidae). "Caldasia", Vol. 9, No 45, pp. 467-489, figs. 1-7, mapa 1 .

$$
\text { Sa } u \text { r } i a \text {. }
$$

Uzzell, Thomas M., Jr., 1966. Teiid Lizards of the genus Neusticurus (Reptilia. Sauria). Bull. Am. Mus. Nat. Hist., Vol. 132, No 5, pp. 279-327, figs. 1-6, tabs. 1-12.

Wrlliams, Ernest E., 1966. South American Anoles: Anolis biporcatus and Anolis fraseri (Sauria. Iguanidae) compared. Breviora Mus. Comp. Zool., No 239, pp. 1-14, figs. 1-5.

$$
\text { Serpentes. }
$$

Amaral, Afranio do, 1926. Collectánea ophiológica. Sobre a Lachesis muta Daudin, 1803, especie ovípara. Rev. Mus. Paulista, Vol. 15, pp. 43-45, figs. 1-3.
Higgins, S. H., 1870. Culebras $i$ reptiles venenosas, sus hábitos, características $i$ particularidades. Imprenta de Gaitán, 1870, Bogotá. (Cuentos populares).

MYers, Charles W., 1966. Lygophis boursieri (Jan), a new Snake to the fauna of Colombia. Copeia, No 4, pp. 886-888.

Peters, James A., 1964. Supplemental notes on snakes of the subfamily Dipsadinae (Reptilia: Colubridae). Beitr. Neotrop. Fauna, Vol. 4, No 1, pp. 45-50.

- 1964. The Lizard genus Ameiva in Ecuador. Bull. South. Cal. Acad. Sci., Vol. 63, No 3, pp. 113-127, figs. 1-A, 1-B, 2-A, 2-B.

Rossman, Douglas A. \& Kenneth L., Williams, 1966. Defensive Behavior of the South American Colubrid Snakes Pseustes sulphureus (Wagler) and Spilotes pullatus (Linnaeus). Proc. Louisiana Acad. Sci., Vol. 29 , pp. 152-156, figs. 1-2.

Roze, Jánis A., 1967. A Check List of the New World venomous Coral Snakes (Elapidae); with descriptions of new forms. Amer. Mus. Novitates, No 2287, pp. 1-60, figs. $1-17$.

Shreve, Benjamin, 1964. A new Species of the Snake Leptotyphlops from Colombia. Breviora Mus. Comp. Zool., Nọ 211, pp. 1-4.

Schweizer, Hans, 1953. Die Anaconda als SchlangenFresserin. DATZ, Vol. 6, 우 9, pp. 236-238, fig. 1.

- 1956. Der Buschmeister-Lachesis muta (L.) - im Terrarium. DATZ, Vol. 9, No 5, pp. 132-133, fig. 1. 